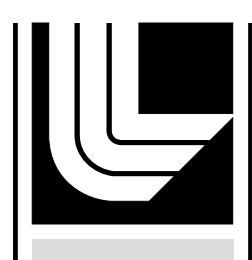

LAW RENCE LIVERMORE N A T IO N A L LABORATORY

\title{
UCRL-TR-224850
}

Atomic, Crystal, Elastic, Thermal, Nuclear, and Other Properties of Beryllium

A. Goldberg

September 29, 2006 
This document was prepared as an account of work sponsored by an agency of the United States Government. Neither the United States Government nor the University of California nor any of their employees, makes any warranty, express or implied, or assumes any legal liability or responsibility for the accuracy, completeness, or usefulness of any information, apparatus, product, or process disclosed, or represents that its use would not infringe privately owned rights. Reference herein to any specific commercial product, process, or service by trade name, trademark, manufacturer, or otherwise, does not necessarily constitute or imply its endorsement, recommendation, or favoring by the United States Government or the University of California. The views and opinions of authors expressed herein do not necessarily state or reflect those of the United States Government or the University of California, and shall not be used for advertising or product endorsement purposes.

This work was performed under the auspices of the U.S. Department of Energy by University of California, Lawrence Livermore National Laboratory under Contract W-7405-Eng-48. 
DTED Report No: CODTU-2004-1514

ATOMIC, CRYSTAL, ELASTIC, THERMAL, NUCLEAR, AND OTHER PROPERTIES OF BERYLLIUM

\author{
Alfred Goldberg
}

One of a Series of Reports on Beryllium

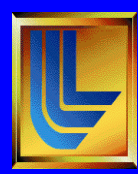

May 15, 2004

Lawrence Livermore National Laboratory, Livermore, CA 94551

This effort is funded by the Weapons System Engineering

Certification Campaign (C6) 


\section{ATOMIC, CRYSTAL, ELASTIC, THERMAL, NUCLEAR, AND OTHER PROPERTIES OF BERYLLIUM}

\section{Table of Contents}

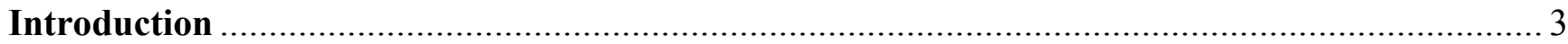

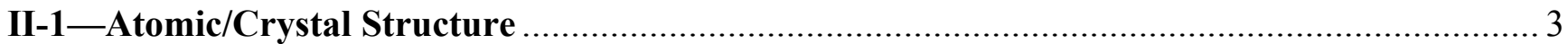

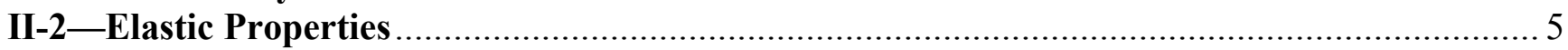

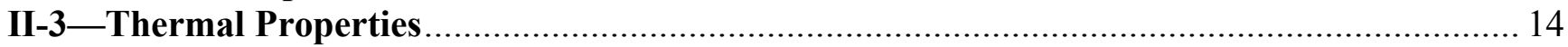

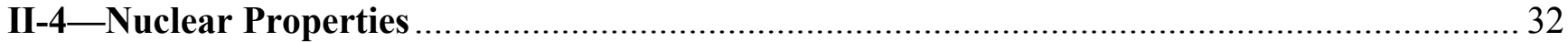

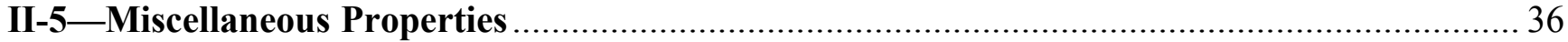

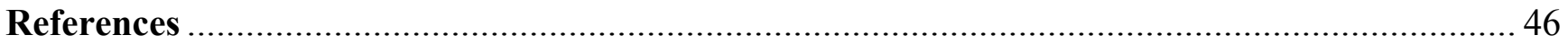




\section{Introduction}

This report is part of a series of documents that provide a background to those involved in the construction of beryllium components and their applications. Topics on beryllium that have been or will be presented in this series are the following:

I General Background

II Atomic, Crystal, Elastic, Thermal, Nuclear, and other Properties of Beryllium

III Extraction

IV Purification and Casting of Ingots

V Beryllium Powders

VI Consolidation and Grades of Beryllium

VII Mechanical Properties of Beryllium and the Factors Affecting these Properties

VIII Mechanical Working, and Forming, and Reduction

IX Joining

X Machining

XI Health Aspects

XII Examples of Production of Components

XIII Corrosion and Corrosion Protection of Beryllium

These reports will be combined as a handbook on beryllium. In the handbook, the subject of this report, "Atomic, Crystal, Elastic, Thermal, Nuclear, and other Properties of Beryllium" is identified as Section II with the prefix II being maintained for the sub-sections, figures, and tables. Accordingly, the same identification system is also used in this report. To date, in addition to this report, the reports on "Mechanical Properties of Beryllium and the Factors Affecting these Properties," "Consolidation and Grades of Beryllium," "Corrosion and Corrosion Protection of Beryllium," and "Joining of Beryllium" have been published. The second report (VI) includes room-temperature mechanical properties of the different beryllium grades.

The present report is divided into five sub-sections: Atomic/Crystal Structure, Elastic Properties, Thermal Properties, Nuclear Properties, and Miscellaneous Properties. In searching through different sources for the various properties to be included in this report, inconsistencies were at times observed between these sources. In such cases, the values reported by the Handbook of Chemistry and Physics 1 was usually used. In equations, except where indicated otherwise, temperature $(T)$ is in degrees Kelvin.

\section{$\underline{\text { II-1-Atomic/Crystal Structure }}$}

Beryllium normally exists in the close-packed hexagonal crystalline form, referred to as $\alpha$-beryllium, in contrast to $\beta$-beryllium, the body-centered cubic form that is stable between $1250^{\circ} \mathrm{C}$ and its melting point of $1287^{\circ} \mathrm{C}$. Some characteristics of beryllium related to the beryllium atom and crystal are listed in Table II-1-1. In the un-ionized state, beryllium has four electrons, $1 \mathrm{~s}^{2}$ and $2 \mathrm{~s}^{2}$. The orbital radii are 0.143 and $1.19 \AA$ for the $1 \mathrm{~s}$ and $2 \mathrm{~s}$ electrons, respectively. ${ }^{2}$ The first and second ionization potentials are 9.320 and $18.206 \mathrm{eV}$. The valence is 2 . The variation of the two lattice parameters (a- and c-axes) 
of $\alpha$-beryllium with temperature is given in Table II-1-2. ${ }^{2}$ Note that the c/a ratio decreases as the crystal (lattice) expands with increasing temperature.

A plot of the change in the crystal-lattice parameters with temperature is shown in Fig. II-1-1.

\begin{tabular}{|l|l|}
\hline \multicolumn{2}{|c|}{ Table II-1-1. Atomic/Crystal Structure/Characteristic of Beryllium. ${ }^{1,3-5}$} \\
\hline Atomic number & 4 \\
\hline Atomic radius & $1.125 \AA$ \\
\hline Atomic volume & $4.96 \mathrm{~cm}^{3} / \mathrm{g}$-atom \\
\hline Atomic weight & $9.01218 \mathrm{~g}$ \\
\hline Density & $1.8477 \mathrm{~g} / \mathrm{cm}^{3}$ (Commercial grades in range of 1.82 to $\left.1.85 \mathrm{~g} / \mathrm{cm}^{3}\right)$ \\
\hline Electronic structure & $1 \mathrm{~s}^{2} 2 \mathrm{~s}^{2}$ \\
\hline Crystal structure $<1250^{\circ} \mathrm{C}$ & Hexagonal close-packed $(\alpha \mathrm{Be})$ \\
\hline Crystal structure $>1250^{\circ} \mathrm{C}$ & Body-centered cubic $(\beta \mathrm{Be})$ \\
\hline Lattice constants & $\mathrm{a}=2.286 \AA$; $=3.583 \AA$ c $/ \mathrm{a}=1.568 ;$ ideal $=1.633$ \\
\hline
\end{tabular}

The density of beryllium between room temperature and $1227^{\circ} \mathrm{C}$ is given by the following expression: ${ }^{6}$ $\left(\mathrm{g} / \mathrm{cm}^{3}\right)=1.823-6.933 \times 10^{-5} \mathrm{~T}-1.513 \times 10^{-8} \mathrm{~T}^{2}\left(\mathrm{~T}\right.$ in $\left.{ }^{\circ} \mathrm{C}\right)$

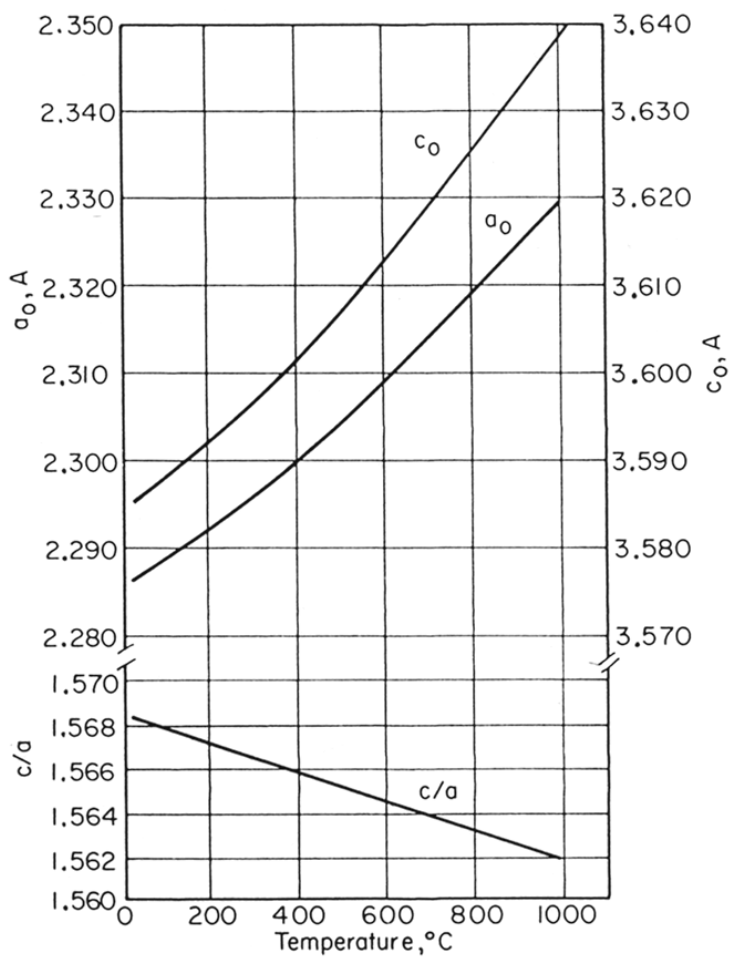

Fig. II-1-1. The effect of temperature on the lattice parameters of beryllium. ${ }^{7}$ 


\begin{tabular}{|c|c|c|c|}
\hline \multicolumn{4}{|c|}{ Table II-1-2. Variation of Lattice Parameters } \\
\multicolumn{4}{c|}{ with Temperature. } \\
\hline${ }^{\circ} \mathrm{C}$ & a-axis & c-axis & c/a \\
\hline 50 & 2.287 & 3.585 & 1.5679 \\
\hline 100 & 2.288 & 3.587 & 1.5676 \\
\hline 200 & 2.292 & 3.591 & 1.5670 \\
\hline 300 & 2.296 & 3.596 & 1.5664 \\
\hline 400 & 2.300 & 3.601 & 1.5658 \\
\hline 500 & 2.304 & 3.607 & 1.5652 \\
\hline 600 & 2.309 & 3.613 & 1.5646 \\
\hline 800 & 2.319 & 3.625 & 1.5633 \\
\hline 1000 & 2.330 & 3.639 & 1.5620 \\
\hline
\end{tabular}

\section{$\underline{\text { II-2-Elastic Properties }}$}

The elastic properties can be given either as a tensorial (matrix) representation or in terms of engineering constants. The elastic properties in the tensorial representation are defined by the stiffness $\left(c_{i j}\right)$ and compliance $\left(s_{i j}\right)$ matrices and individually referred to as elastic constants. The engineering elastic constants are Young's modulus (E), shear modulus (G), Poisson's ratio (v), bulk modulus $(\beta)$, and compressibility $(\kappa)$. Some variability is reported in elastic properties values, especially for Poisson's ratio. This can be attributed to the anisotropy of beryllium. Because of the anisotropic crystalline properties of the hexagonal beryllium crystal and the preferred orientation (texture) of the polycrystalline material, these properties should be related to the corresponding crystallographic axis. Unfortunately, this is not always done. The elastic properties at room temperature are listed in Table II-2-1.

\begin{tabular}{|l|l|}
\hline \multicolumn{2}{|c|}{ Table II-2-1. Elastic Properties of Beryllium at Room Temperature. $1,4,5,8$} \\
\hline Elastic constants $\left(10^{11} \mathrm{~Pa}\right)$ & $\mathrm{c}_{11}=2.923 ; \mathrm{c}_{12}=0.267 ; \mathrm{c}_{13}=0.140 ; \mathrm{c}_{33}=3.364 ; \mathrm{c}_{44}=1.625$ \\
\hline Young' modulus & $3.03 \times 10^{5} \mathrm{Mpa}\left[(2.87-3.21) 10^{5} \mathrm{Mpa}\right]$ \\
\hline Shear modulus & $1.35 \times 10^{5} \mathrm{Mpa}$ \\
\hline Bulk modulus & $1.10 \times 10^{5} \mathrm{Mpa}$ \\
\hline Poisson's ratio & 0.01 to 0.08 \\
\hline Isothermal compressibility & $0.0883 \times 10^{-10} \mathrm{~m}^{2} / \mathrm{N}^{\mathrm{a}}$ \\
\hline Adiabatic compressibility & $0.103 \times 10^{-10} \mathrm{~m}^{2} / \mathrm{N}$ \\
\hline a Stress/(change in volume)/(unit volume) $=$ stress \\
\hline
\end{tabular}

Young's modulus as a function of crystallographic orientation for a single crystal of beryllium is shown in Fig. II-2-1. ${ }^{8}$ Young's modulus as a function of temperature for various grades of beryllium is shown in Fig. II-2-2 ${ }^{6}$ and that for two hot-pressed beryllium grades, S-200E and S-65B are shown in Fig. II-2-3. ${ }^{9}$ At room temperature, Young's modulus is unaffected by strain rate. Above about $425^{\circ} \mathrm{C}$ $\left(797^{\circ} \mathrm{F}\right)$, it increases with increasing strain rate. This is illustrated in Fig. II-2-4, which also includes the change in dynamic modulus with temperature. ${ }^{8}$ The differences between the static and dynamic values are explained in terms of thermodynamics involving the difference between specific heats at 
constant pressure and at constant volume as well as being attributed to creep at the elevated temperatures. The dynamic Young's modulus of elasticity of beryllium for two different orientations as a function of temperature is shown in Fig. II-2-5. ${ }^{8}$ The change in modulus with temperature below $25^{\circ} \mathrm{C}$ is shown in Fig. II-2-6. ${ }^{8}$ The grades and histories of the metals for Figs. II-2-5 and II-2-6 were not given.

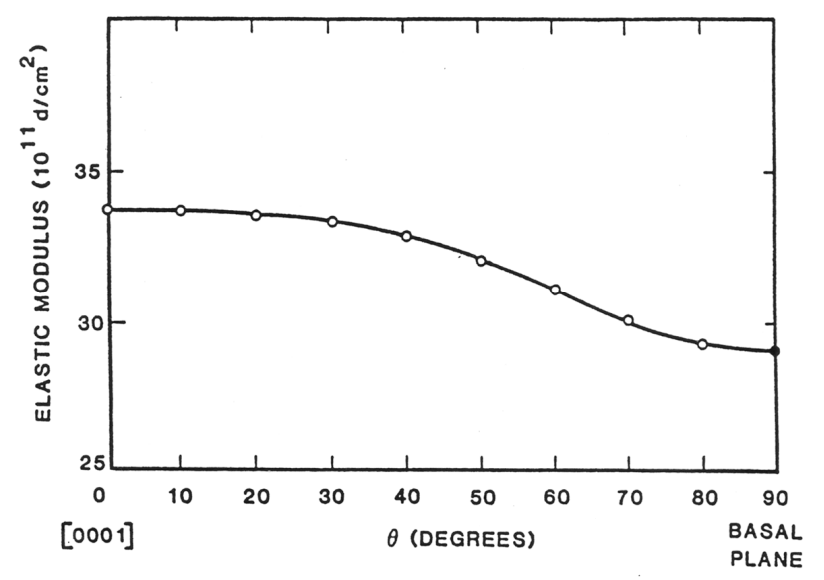

Fig. II-2-1. Young's modulus of a single crystal of beryllium as a function of the crystallographic orientation in a plane normal to the basal plane. 8

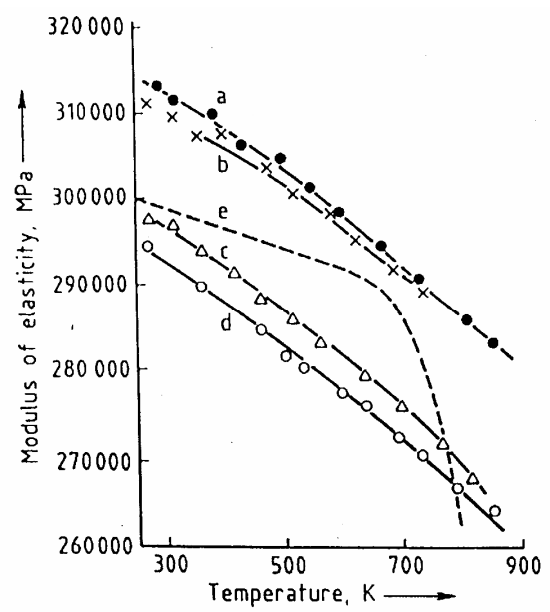

Fig. 2-2. Young's modulus of various grades of beryllium as a function of temperature: a) pressure sintered, b) cast and cross rolled, c) cast and extruded, d) powder metallurgy and extruded, e) pressure sintered $(1 \mathrm{wt} . \% \mathrm{BeO}){ }^{6}$

\footnotetext{
${ }^{a}$ Reference 8 is a report consisting of an extensive review of elastic properties; it does not include any original work.
} Inconsistencies between different figures may be due, at least to some extent, to results from different investigators. 


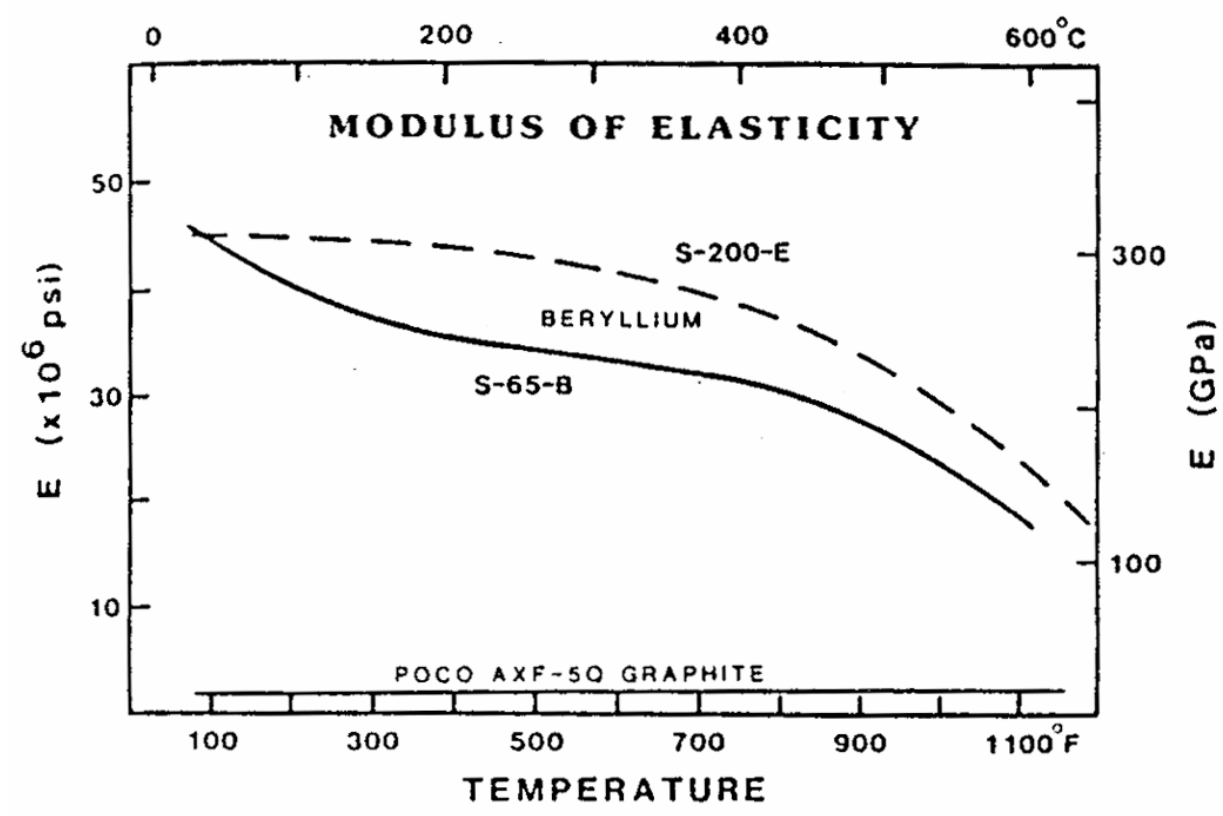

Fig. II-2-3. Young's modulus as a function of temperature for smooth-bar specimens from VHP blocks of S-65B and S-200E beryllium. Included are results of a competing graphite product. ${ }^{9}$

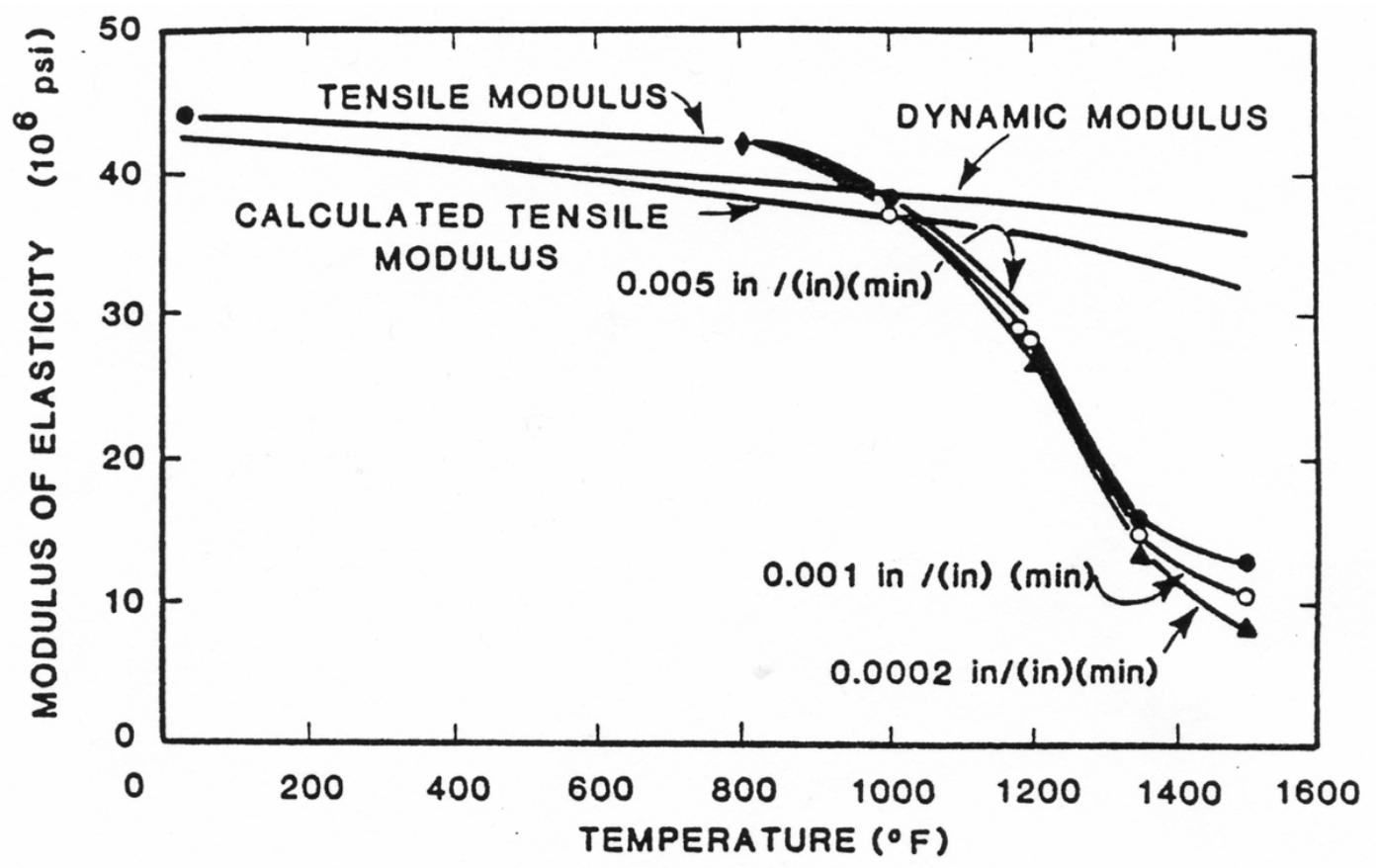

Fig. II-2-4. Comparison of dynamic modulus with static modulus of QMV Beryllium between room temperature and $1500^{\circ} \mathrm{F}\left(815^{\circ} \mathrm{C}\right){ }^{8}$ 


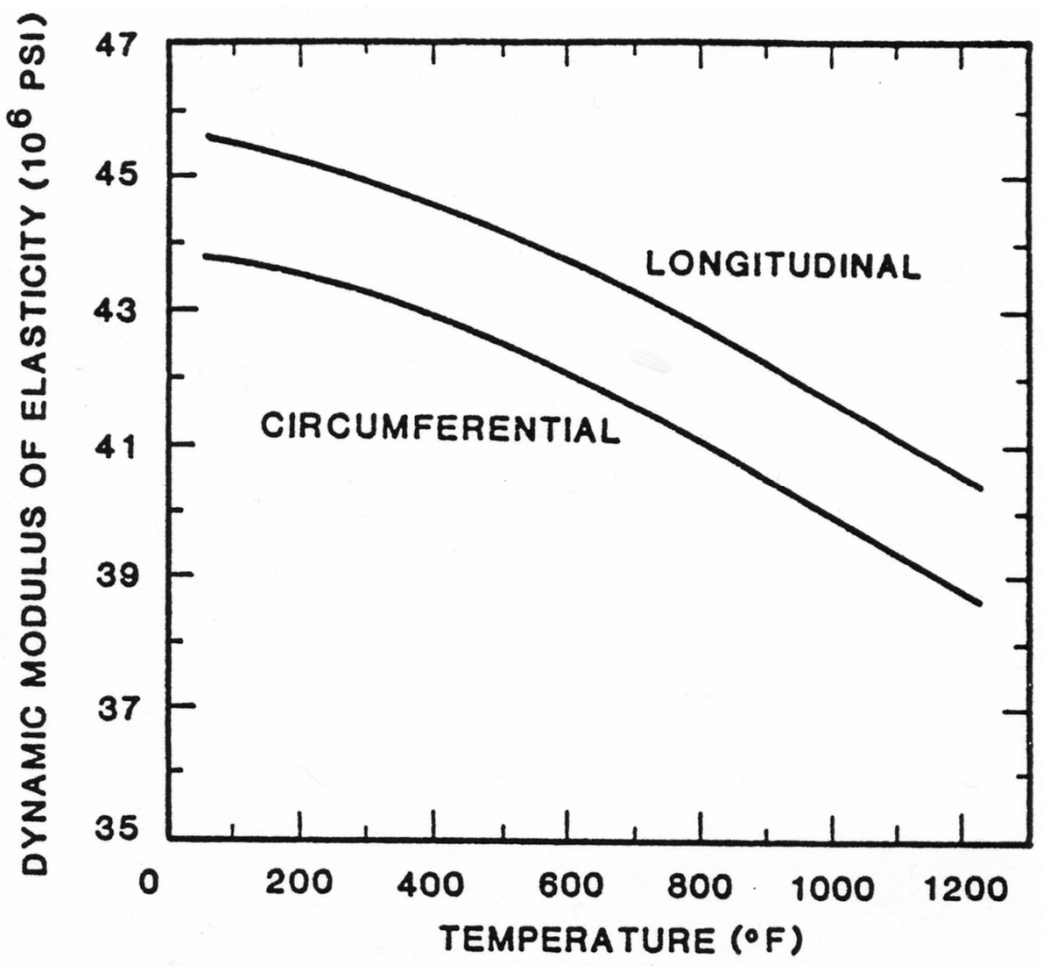

Fig. II-2-5. Dynamic Young's modulus between room temperature and $1200^{\circ} \mathrm{F}\left(649^{\circ} \mathrm{C}\right)$ for two different orientations of a beryllium sample. ${ }^{8}$

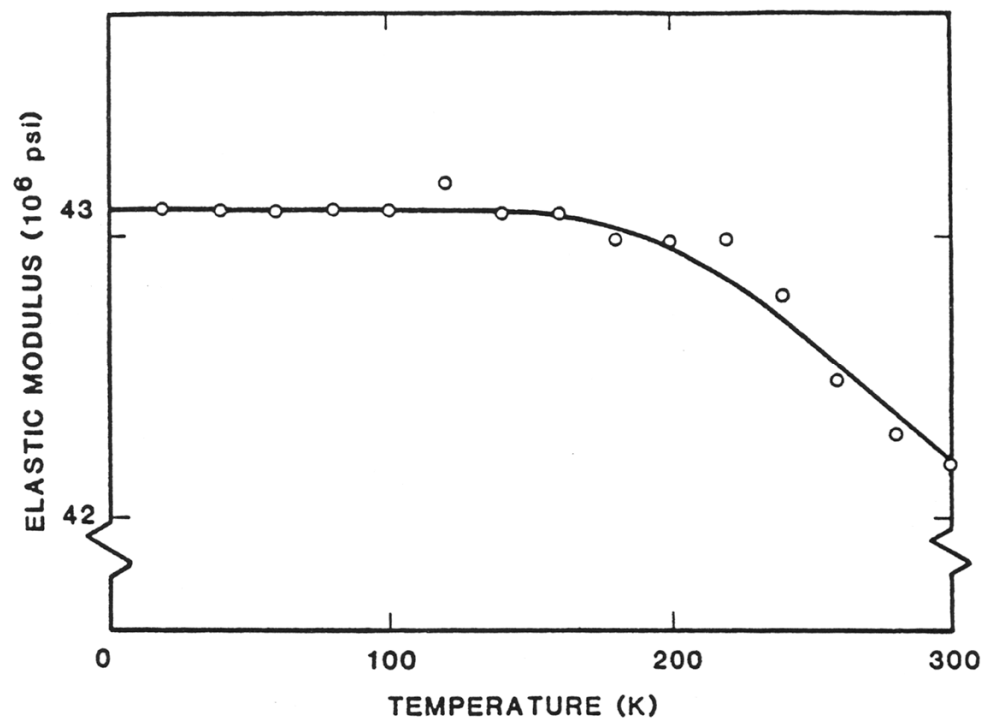

Fig. II-2-6. Dynamic Young's modulus as a function of temperature below 300K $\left(27^{\circ} \mathrm{C}\right){ }^{8}$

Precision elastic limit (P. E. L.), 0.01\% offset yield strength, and Young's modulus for the S-200F material are listed in Table II-2-2. The P. E. L. determination followed the MAB specification 
method. ' Young's modulus was obtained according to ASTM E-111. The P. E. L. is the stress required to produce a permanent strain of $10^{-6}$; it is also known as the microyield stress.

\begin{tabular}{|c|c|c|c|}
\hline \multicolumn{4}{|c|}{ Table II-2-2. Tensile Elastic Limits and Yield Strength at } \\
Room Temperature for VHP S-200F Beryllium.
\end{tabular}

The elastic properties are affected by porosity. Young's modulus (E) for a wide variety of asfabricated beryllium, containing less than 0.3 volume fraction of porosity and at temperatures below $1000^{\circ} \mathrm{C}$, can be represented to within $\pm 15 \%$ by:

$$
\mathrm{E}(\mathrm{MPa})=3.00 \times 10^{5} \mathrm{e}^{-4.574 \mathrm{p}}\left[1-2.016 \times 10^{-4}(\mathrm{~T}-293)\right],
$$

where $\mathrm{p}$ is the volume fraction of porosity and $\mathrm{T}$ is the temperature in degrees $\mathrm{K}$. ${ }^{11}$ The ultimate tensile strength for VHP S-200 beryllium can similarly be represented to within $\pm 10 \%$ by:

$$
\begin{aligned}
& \operatorname{UTS}(\mathrm{MPa})=324 \mathrm{e}^{-4.733 \mathrm{p}}\left[1-1.925 \times 10^{-4}(\mathrm{~T}-293)-1.750 \times 10^{-6}\right. \\
& \left.(\mathrm{T}-293)^{2}+9.198 \times 10^{-10}(\mathrm{~T}-293)^{3}\right] .
\end{aligned}
$$

The shear modulus and Poisson's ratio as a function of temperature for a cross-rolled cast beryllium are shown in Fig. II-2-7. ${ }^{6}$ The shear modulus and Poisson's ratio of beryllium as a function of temperature below $300 \mathrm{~K}\left(27^{\circ} \mathrm{C}\right)$ are shown in Figs. II-2-8 and II-2-9, respectively. ${ }^{8}$

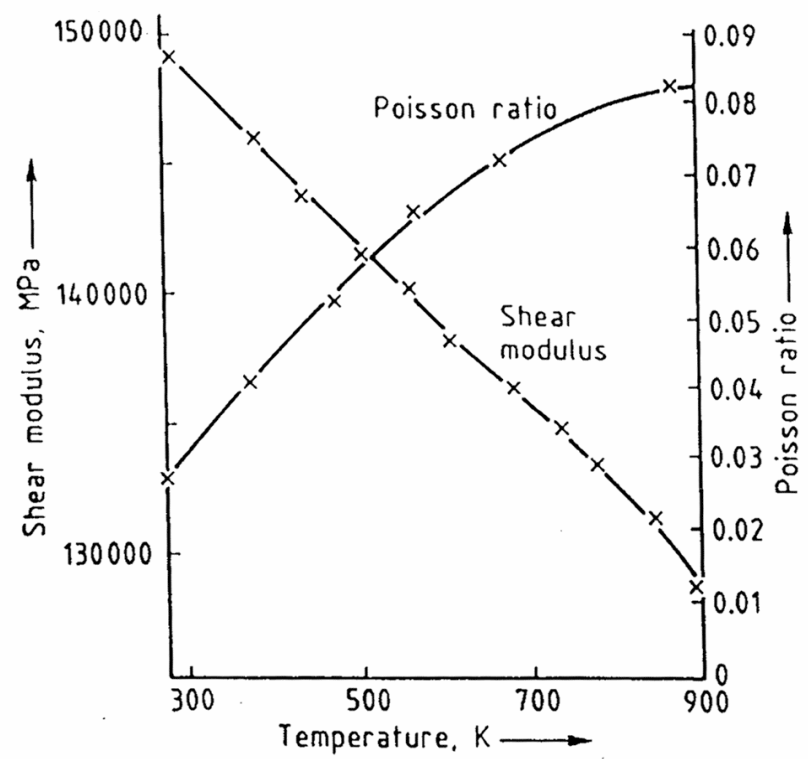

Fig. II-2-7. Shear modulus and Poisson's ratio of cross-rolled cast beryllium as a function of temperature. 6 
Inconsistencies can be seen between the values at 300K in Fig. II-2-7 compared to those in Figs. II-2-8 and II-2-9, namely, $148 \mathrm{GPa}$ versus $141 \mathrm{GPa}$ for the shear modulus and 0.027 versus 0.01 for Poisson's ratio. Such differences are probably due to material composition, processing history, and sample orientation. The room-temperature shear properties for VHP S-200F reported for torsion tests are listed in Table II-2-3. ${ }^{10}$ The shear values close to $300 \mathrm{~K}$ are given as $134 \mathrm{GPa}$.

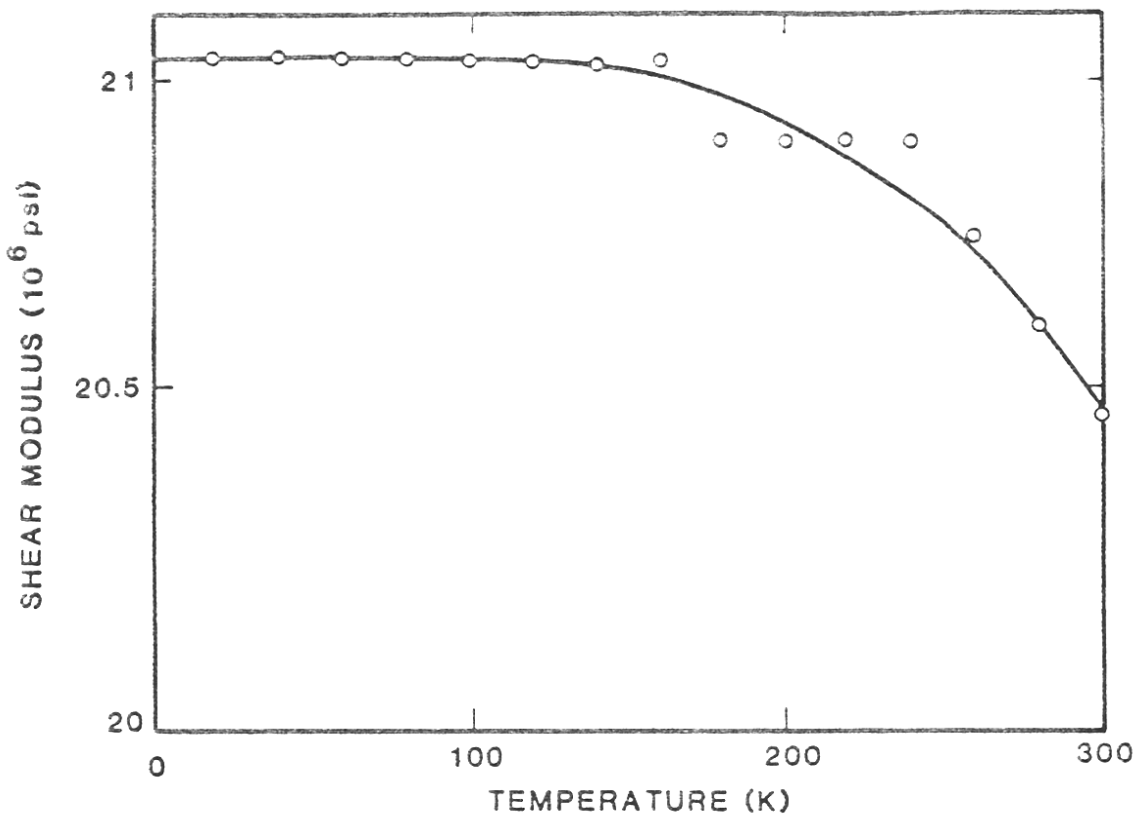

Fig. II-2-8. Shear modulus for beryllium between 0 and $300 \mathrm{~K}^{8}$

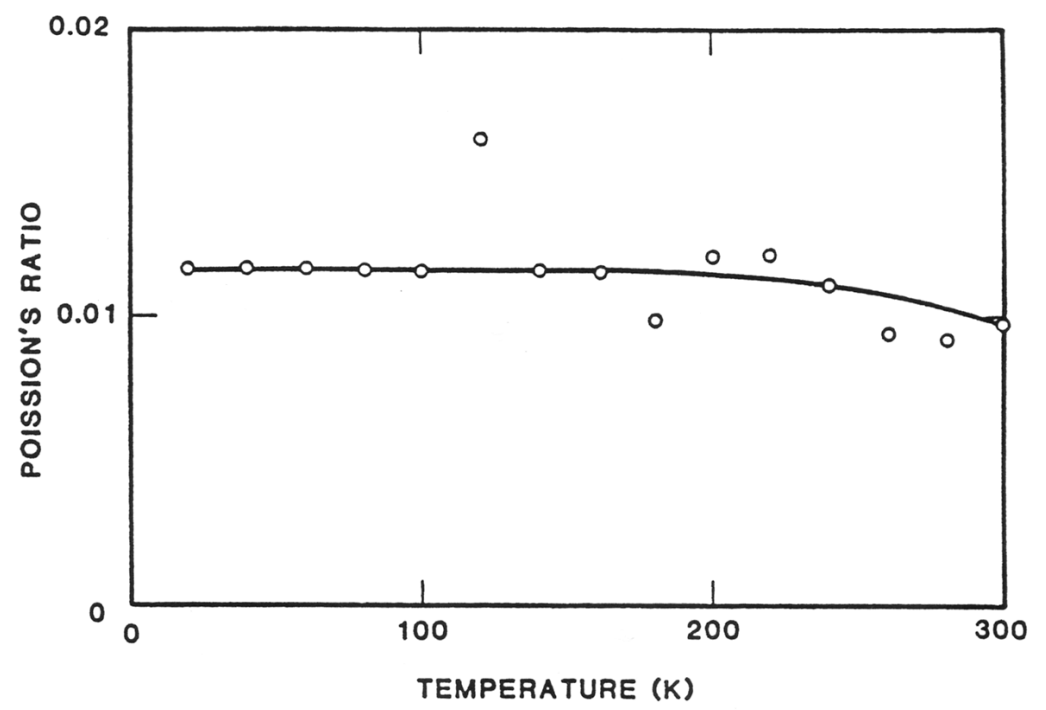

Fig. II-2-9. Poisson's ratio for beryllium between $0 \mathrm{~K}$ and $300 \mathrm{~K}{ }^{9}$ 
A number of elastic properties reported for VHP S-200E are listed in TableII-2-4. ${ }^{12}$ Tests were performed in the pressing direction and in two orthogonal directions perpendicular to the pressing direction. The measured values indicated that there was little anisotropy in the pressed

\begin{tabular}{|c|c|c|}
\hline \multicolumn{3}{|c|}{$\begin{array}{c}\text { Table II-2-3. Shear Properties of VHP S- } \\
\text { 200F Obtained from Torsion Tests at Room } \\
\text { Temperature. }\end{array}$} \\
\hline Orientation & $\begin{array}{c}\text { Shear modulus, } \\
\mathrm{GPa}\end{array}$ & $\begin{array}{l}\text { Shear rupture } \\
\text { modulus, MPa }\end{array}$ \\
\hline Longitudinal. & $134 \pm 5$ & $297 \pm 12$ \\
\hline Transverse & $134 \pm 3$ & $309 \pm 8$ \\
\hline
\end{tabular}

beryllium; however, the calculated values (Lamé's parameter ${ }^{\mathrm{a}}$ and Poisson's ratio) showed significant differences. The elastic stiffness constants from six different published sources were compared to illustrate the variable results obtained for beryllium. ${ }^{12}$ These data are tabulated in Table II-2-5. Table II-2-6 compares results obtained for compliance constants from four published sources. Table II-2-7 lists Poisson's-ratio values calculated for six different compliance directions.

\begin{tabular}{|c|c|c|}
\hline \multicolumn{2}{|c|}{ Table II-2-4 Elastic Properties of VHP S-200E Beryllium. } \\
\hline Property & \begin{tabular}{c} 
Pressing direction $^{(\mathrm{Z})}$ \\
\hline
\end{tabular} & $\begin{array}{c}\text { Average of transverse } \\
(\mathrm{X} \& \text { Y }) \text { directions }\end{array}$ \\
\hline Dilatational wave velocity, $\mathrm{mm} / \mu \mathrm{sec}$ & $12.84 \pm 0.04$ & $12.57 \pm 0.1$ \\
\hline Shear-wave velocity, $\mathrm{mm} / \mu \mathrm{sec}$ & $8.86 \pm 0.04$ & $8.82 \pm 0.1$ \\
\hline Shear modulus, $\mathrm{MPa}$ & $1.453 \times 10^{5}$ & $1.440 \times 10^{5}$ \\
\hline Bulk modulus, MPa & $1.114 \times 10^{5}$ & $1.005 \times 10^{5}$ \\
\hline Young's modulus, MPa & $3.038 \times 10^{5}$ & $2.923 \times 10^{5}$ \\
\hline Lamé's parameter & 145.6 & 44.8 \\
\hline Poisson's ratio & 0.046 & 0.015 \\
\hline
\end{tabular}

Fig. II-2-10 shows the shear modulus as a function of temperature calculated from experimental data of Young's modulus for three different values of Poison's ratio. ${ }^{8}$ Averaging published data from 14 different sources, gave a value of 0.0476 , which was suggested as the most probable value for Poisson's ratio. The shear modulus as a function of temperature for three different values of Poisson's ratio is shown in Fig. II-2-11. The compressibility, which is the reciprocal of the bulk modulus, is shown in Fig. II-2-12 as a function of temperature.

Assuming isotropic properties, the shear modulus $(\mathrm{G})$ can be calculated from Young's modulus (E) and Poison's ratio $(v)$ using the relationship:

$$
\mathrm{E}=2 \mathrm{G}(1+v)
$$

\footnotetext{
${ }^{a}$ Lamé's parameter, $\lambda$, is defined as: $\lambda=v E /(1+v)(1-2 v)$, where $v$ is Poisson's ratio.
} 


\begin{tabular}{|c|c|c|c|c|c|}
\hline \multicolumn{6}{|c|}{$\begin{array}{l}\text { Table II-2-5. Beryllium Stiffness Constants at Room } \\
\text { Temperature Reported by Six Different Sources. }{ }^{8}\left(10^{10} \mathrm{~Pa}\right)\end{array}$} \\
\hline $\mathrm{C}_{11}$ & $\mathrm{C}_{12}$ & $\mathrm{C}_{13}$ & $\mathrm{C}_{33}$ & $\mathrm{C}_{44}$ & $\mathrm{C}_{66}$ \\
\hline 29.23 & 2.67 & 1.40 & 33.64 & 16.25 & 13.28 \\
\hline 30.8 & $\begin{array}{l}-5.8 \\
\end{array}$ & 8.7 & 35.7 & 1.0 & 17.5 \\
\hline 29.54 & 2.59 & -0.10 & 35.61 & 17.06 & 13.48 \\
\hline 30.87 & 2.16 & 1.05 & 34.25 & 15.54 & 14.04 \\
\hline 29.39 & 2.69 & 1.4 & 33.78 & 16.33 & 13.35 \\
\hline 29.2 & 2.4 & 0.6 & 34.9 & 16.3 & 13.4 \\
\hline 29.65 & 2.50 & 0.87 & 34.44 & 16.30 & 13.51 \\
\hline \multicolumn{6}{|c|}{$\begin{array}{l}\text { The bottom row consists of averages (of five rows) excluding the } \\
\text { second row. The author excluded this row since its values differed } \\
\text { considerably from the other reported values. } \mathrm{C}_{66} \text { is calculated by: } \\
\mathrm{C}_{66}=1 / 2\left(\mathrm{C}_{11}-\mathrm{C}_{12}\right) ; \mathrm{C}_{66} \text { is calculated by: } \mathrm{C}_{66}=1 / 2\left(\mathrm{C}_{11}-\mathrm{C}_{12}\right) \text {. }\end{array}$} \\
\hline
\end{tabular}

\begin{tabular}{|c|c|c|c|c|c|}
\hline \multicolumn{6}{|c|}{$\begin{array}{l}\text { Table II-2-6. Beryllium Compliance Constants at Room Temperature Reported by } \\
\text { Four Different Sources. }{ }^{8}\left(10^{-11} \mathrm{~Pa}^{-1}\right)\end{array}$} \\
\hline $\mathrm{S}_{11}$ & $\mathrm{~S}_{12}$ & $\mathrm{~S}_{13}$ & $\mathrm{~S}_{33}$ & $\mathrm{~S}_{44}$ & $\mathrm{~S}_{66}$ \\
\hline 0.341 & -0.0299 & 0.001 & 0.2808 & 0.5862 & 0.7420 \\
\hline 0.35 & $\begin{array}{l}-0.03 \\
\end{array}$ & -0.01 & 0.30 & 0.61 & 0.76 \\
\hline 0.326 & -0.023 & -0.009 & 0.292 & 0.644 & 0.712 \\
\hline 0.345 & -0.028 & -0.005 & 0.287 & 0.616 & 0.746 \\
\hline 0.341 & -0.0 .028 & -0.006 & 0.290 & 0.614 & 0.740 \\
\hline
\end{tabular}

Table II-2-7. Poisson's Ratio (v) for Different Directions in Beryllium Single Crystals. $^{8}$

\begin{tabular}{|l|l|}
\hline$v_{12}=\mathrm{E}_{100} \times \mathrm{S}_{12}=0.07$ & $v_{31}=\mathrm{E}_{001} \times \mathrm{S}_{13}=0.03$ \\
\hline$v_{21}=\mathrm{E}_{101} \times \mathrm{S}_{12}=0.07$ & $\mathrm{v}_{23}=\mathrm{E}_{010} \times \mathrm{S}_{23}=0.03$ \\
\hline$v_{13}=\mathrm{E}_{100} \times \mathrm{S}_{13}=0.03$ & $v_{32}=\mathrm{E}_{001} \times \mathrm{S}_{23}=0.03$ \\
\hline
\end{tabular}




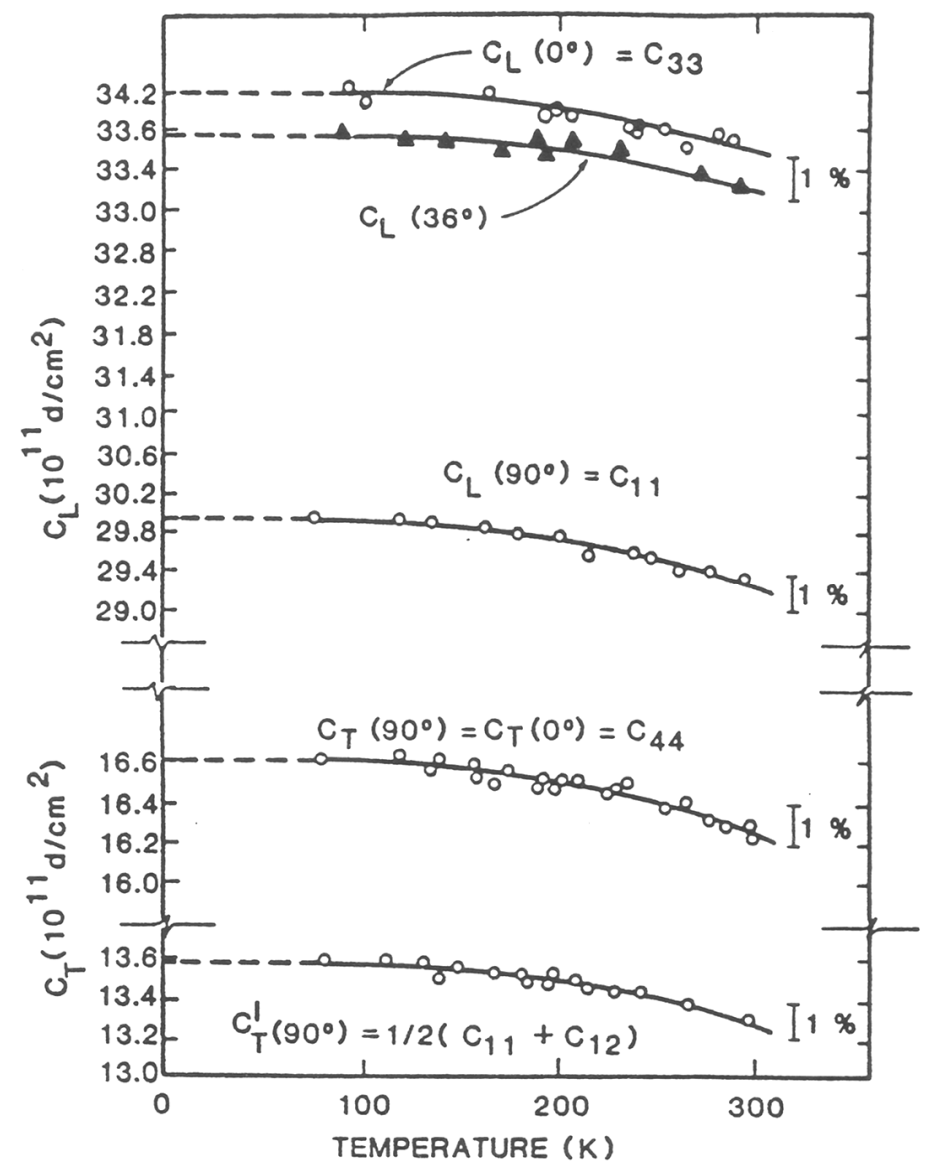

Fig. II-2-10. Shear modulus as a function of temperature calculated from experimental Young's-modulus values for different values of Poisson's ratio. ${ }^{8}$

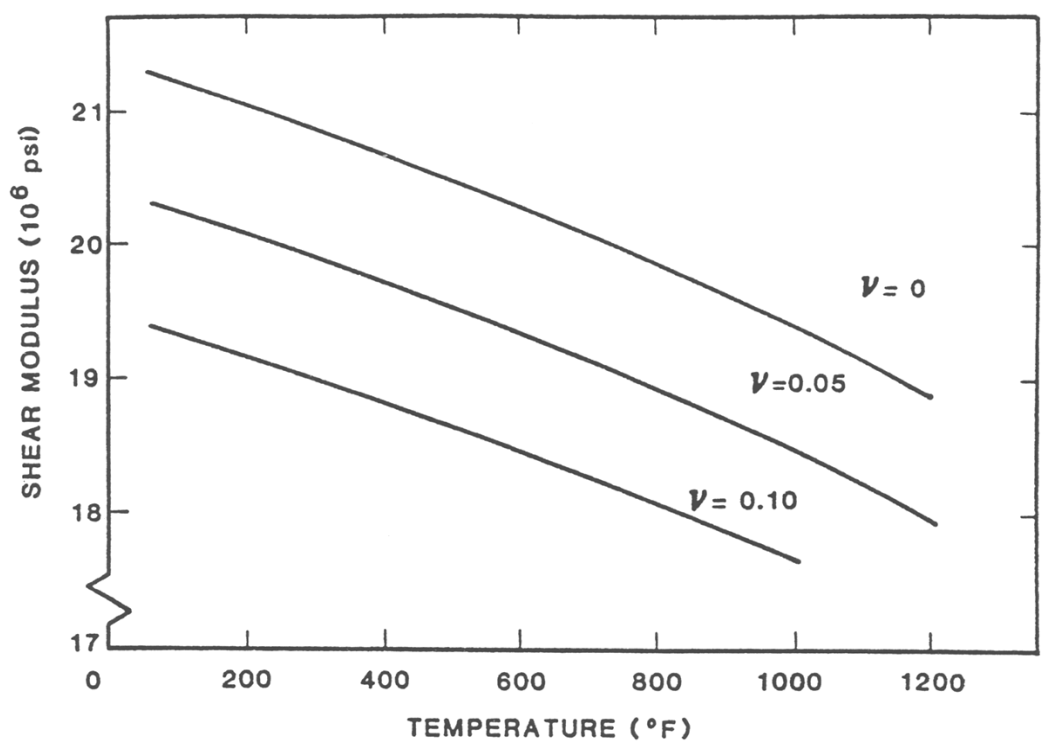

Fig. II-2-11. Shear modulus of beryllium as a function of temperature for three different values of Poisson's ratio. ${ }^{8}$ 


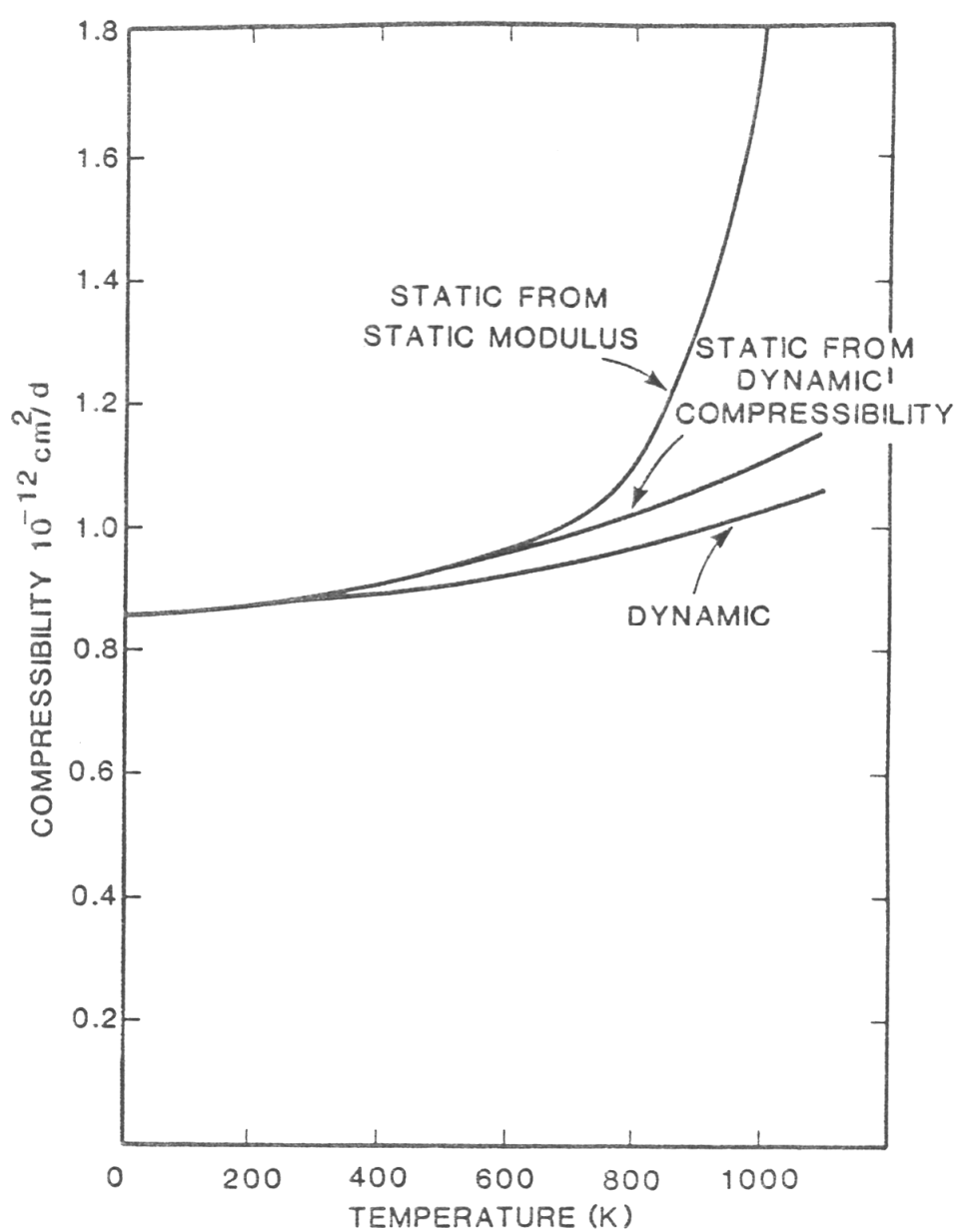

Fig. II-2-12. Typical compressibility curves for beryllium as a function of temperature. ${ }^{8}$

\section{II-3-Thermal Properties}

Some room-temperature thermal properties of beryllium are listed in Table II-3-1. Results of several thermal-property measurements of grade S-65-B beryllium are listed in Table II-3-2. ${ }^{9}$

The mean coefficient of thermal expansion from room temperature to $900^{\circ} \mathrm{C}$ is shown in Fig. II-3-1. ${ }^{13}$ The average coefficient of thermal-expansion values for VHP S-200E and S-200F over the range of 5 to $65^{\circ} \mathrm{C}(278$ to $338 \mathrm{~K})$ for the longitudinal and two transverse directions are listed in Table II-3-3. ${ }^{10}$ The author points out that measurements were made on only one sample of each material. ${ }^{10}$ Table II3-4 lists the change in length relative to the length at $20^{\circ} \mathrm{C}$ and the coefficient of thermal expansion over a range of temperatures from -268 to $-27^{\circ} \mathrm{C}(5$ to $300 \mathrm{~K})$ for HIP beryllium. The specimens were manufactured by Brush Wellman from material designated as "0-50 HIP." Average coefficients of thermal expansion of beryllium over temperature ranges from 25 to $100^{\circ} \mathrm{C}$ up to 25 to $1000^{\circ} \mathrm{C}$ are listed in Table II-3-5. The coefficients of thermal expansion of beryllium single crystals at low temperatures, perpendicular and parallel to the c-axis, are reported in Table II-3-6. ${ }^{2,14}$ 


\begin{tabular}{|c|c|}
\hline Table II-3-1. Some Room-Temperature Thermal Properties of Beryllium. & $1,3-5,15$ \\
\hline Melting point & $1287^{\circ} \mathrm{C}$ \\
\hline Latent heat of fusion & $1.89(1.89$ to 2.92$) \mathrm{kcal} / \mathrm{g}$-atom \\
\hline Boiling point (760Torr) & $2471^{\circ} \mathrm{C}$ \\
\hline Heat of sublimation & $75.56(75.5$ to 78.8$) \mathrm{kcal} / \mathrm{g}$-atom \\
\hline Heat of evaporation & $53.55(53.5-74.1) \mathrm{kcal} / \mathrm{g}$-atom \\
\hline Specific heat $\left(25^{\circ} \mathrm{C}\right.$, constant pressure) & $3.92 \mathrm{cal} / \mathrm{g}$-atom $/{ }^{\circ} \mathrm{C}$ \\
\hline Enthalpy at $25^{\circ} \mathrm{C}$ & $465 \mathrm{cal} / \mathrm{g}$-atom \\
\hline Heat of transformation $(\alpha$ to $\beta)$ & $1.80 \mathrm{cal} / \mathrm{g}$-atom \\
\hline Entropy $\left(25^{\circ} \mathrm{C}\right)$ & $2.28 \mathrm{cal} / \mathrm{g}$-atom \\
\hline Thermal conductivity & $216 \mathrm{~W} / \mathrm{m} /{ }^{\circ} \mathrm{C}$ \\
\hline Thermal diffusivity (room temperature $)$ & $0.18 \mathrm{~m} / \mathrm{h}$ \\
\hline Temperature coefficient of linear expansion & $11.3 \times 10^{-6} /{ }^{\circ} \mathrm{C}\left(0-50^{\circ} \mathrm{C}\right)$ \\
\hline Temperature coefficient of resistivity & $0.025 \Delta \rho / \rho_{\mathrm{o}}{ }^{\circ} \mathrm{C}$ \\
\hline Contraction on solidification & $3 \%$ \\
\hline
\end{tabular}

\begin{tabular}{|c|c|c|c|c|}
\hline \multicolumn{6}{|c|}{ Table II-3-2. Some Thermal-Property Measurements of Grade S-65-B } \\
\multicolumn{7}{|c|}{$\begin{array}{c}\text { Beryllium covering a Range of Temperatures. } \\
\text { Temperature, } \\
{ }^{\mathrm{O}} \mathrm{C}(\mathrm{K})\end{array}$} & $\begin{array}{c}\text { Thermal } \\
\text { conductivity, } \\
\mathrm{W} / \mathrm{cm}^{\mathrm{O}} \mathrm{C}\end{array}$ & $\begin{array}{c}\text { Heat } \\
\text { capacity, } \\
\text { cal/g }{ }^{\mathrm{C}} \mathrm{C}\end{array}$ & $\begin{array}{c}\text { Thermal } \\
\text { diffusivity, } \\
\mathrm{cm}^{2} / \mathrm{s}\end{array}$ & $\begin{array}{c}\text { Density, } \\
\mathrm{g} / \mathrm{cm}^{3}\end{array}$ \\
\hline $51(324 \mathrm{~K})$ & 1.873 & 0.455 & 0.540 & 1.820 \\
\hline $139(412 \mathrm{~K})$ & 1.523 & 0.535 & 0.376 & 1.814 \\
\hline $183(456 \mathrm{~K})$ & 1.438 & 0.560 & 0.339 & 1.808 \\
\hline $242(415 \mathrm{~K})$ & 1.338 & 0.583 & 0.304 & 1.806 \\
\hline $291(564 \mathrm{~K})$ & 1.288 & 0.604 & 0.283 & 1.801 \\
\hline $336(609 \mathrm{~K})$ & 1.252 & 0.624 & 0.267 & 1.797 \\
\hline $400(673 \mathrm{~K})$ & 1.166 & 0.637 & 0.244 & 1.791 \\
\hline $464(737 \mathrm{~K})$ & 1.104 & 0.653 & 0.225 & 1.785 \\
\hline $543(816 \mathrm{~K})$ & 1.018 & 0.664 & 0.206 & 1.777 \\
\hline $619(892 \mathrm{~K})$ & 0.961 & 0.683 & 0.190 & 1.769 \\
\hline $700(973 \mathrm{~K})$ & 0.884 & 0.702 & 0.171 & 1.760 \\
\hline $854(1127 \mathrm{~K})$ & $0.758^{\mathrm{a}}$ & $0.737^{\mathrm{a}}$ & 0.141 & 1.742 \\
\hline $996(1269 \mathrm{~K})$ & $0.638^{\mathrm{a}}$ & $0.769^{\mathrm{a}}$ & 0.115 & 1.725 \\
\hline a & & & & \\
\hline
\end{tabular}




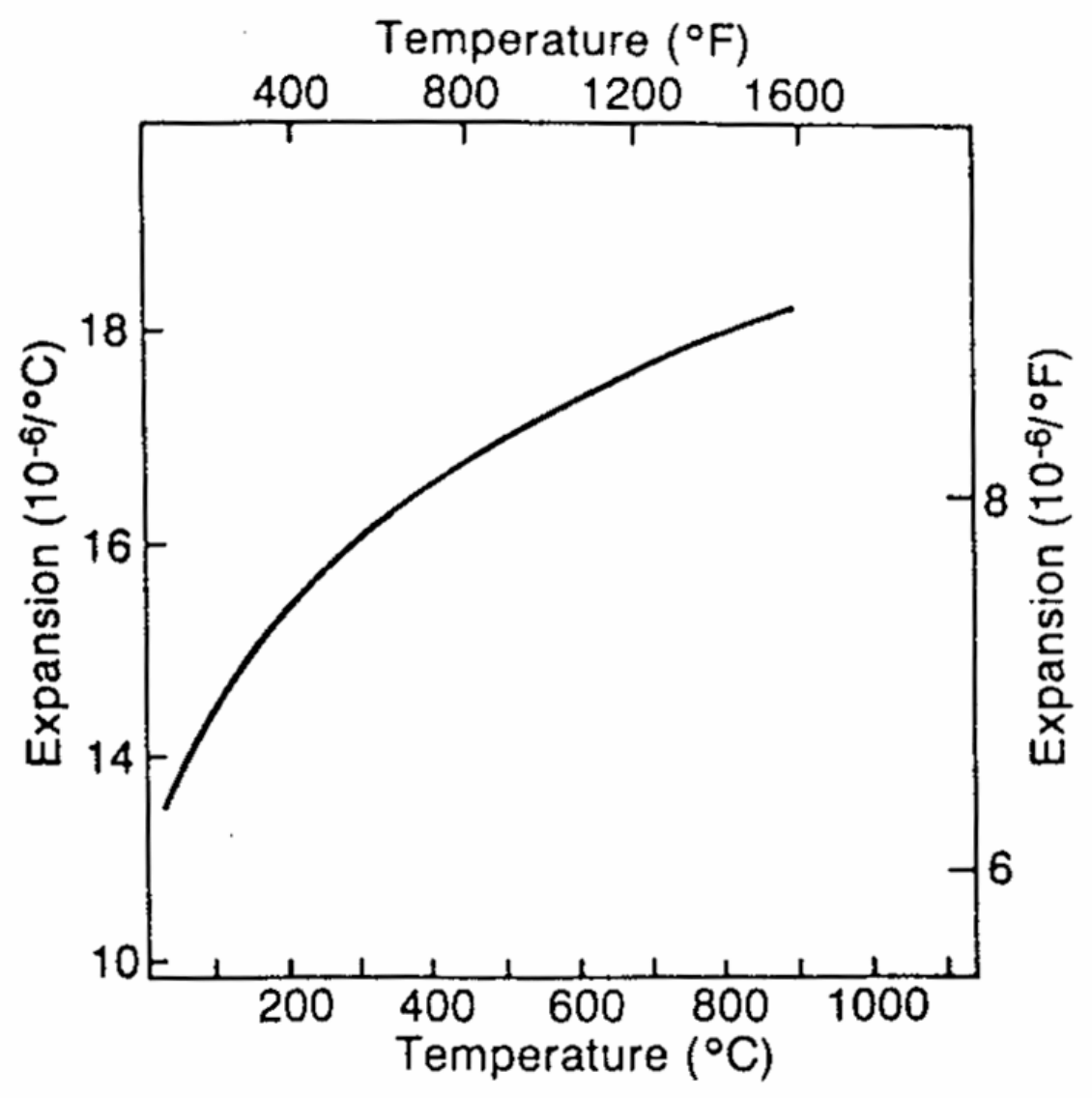

Fig. II-3-1. Mean coefficient of thermal expansion from room temperature to indicated temperature of normal-purity beryllium block and sheet. ${ }^{13}$

\begin{tabular}{|c|c|c|}
\hline \multicolumn{3}{|c|}{$\begin{array}{l}\text { Table II-3-3 Average Coefficient of } \\
\text { Thermal Expansion }(\alpha) \text { for Vacuum-HotPressed } \\
\text { S-200E and S-200F from } 5 \text { to } 65^{\circ} \mathrm{C} .\end{array}$} \\
\hline Direction & $\begin{array}{c}\mathrm{S}-200 \mathrm{E} \\
\alpha\left(10^{-6} /{ }^{\circ} \mathrm{C}\right)\end{array}$ & $\begin{array}{c}\mathrm{S}-200 \mathrm{~F} \\
\alpha\left(10^{-6} /{ }^{\mathrm{o}} \mathrm{C}\right)\end{array}$ \\
\hline Longitudinal & 11.39 & 11.39 \\
\hline Transverse-1 & 11.57 & 11.76 \\
\hline Transverse- 2 & 11.45 & 11.82 \\
\hline
\end{tabular}




\begin{tabular}{|c|c|c|c|c|c|}
\hline \multicolumn{6}{|c|}{$\begin{array}{l}\text { Table II-3-4. Coefficient of Thermal Expansion ( } \alpha) \text { and Length Change } \\
\text { Relative to } 293.16 \mathrm{~K} \text { for HIP Beryllium Metal }\end{array}$} \\
\hline $\begin{array}{c}\mathrm{T} \\
\left({ }^{\mathrm{o}} \mathrm{K}\right)\end{array}$ & $\begin{array}{c}\alpha \\
\left(\mathrm{K}^{-1}\right)\end{array}$ & $\begin{array}{c}\Delta \mathrm{L} / \mathrm{L}^{293} \\
\left(10^{-6}\right)\end{array}$ & $\begin{array}{c}\mathrm{T} \\
(\mathrm{K})\end{array}$ & $\begin{array}{c}\alpha \\
\left(K^{-1}\right)\end{array}$ & $\begin{array}{c}\Delta \mathrm{L} / \mathrm{L}_{29} \\
3 \\
\left(10^{-6}\right)\end{array}$ \\
\hline 0 & 0.00 & -1298 & 110 & $1.77 \times 10^{-6}$ & -1254 \\
\hline 5 & $3.16 \times 10^{-10}$ & -1298 & 120 & 2.27 & -1234 \\
\hline 10 & 9.60 & -1298 & 130 & 2.82 & -1209 \\
\hline 15 & $2.31 \times 10^{-9}$ & -1298 & 140 & 3.41 & -1178 \\
\hline 20 & 4.83 & -1298 & 150 & 4.01 & -1140 \\
\hline 25 & 9.14 & -1298 & 160 & 4.62 & -1097 \\
\hline 30 & $1.61 \times 10^{-8}$ & -1298 & 170 & 5.24 & -1048 \\
\hline 35 & 4.83 & -1298 & 180 & 5.84 & -993 \\
\hline 40 & 4.24 & -1298 & 190 & 6.43 & -931 \\
\hline 45 & 6.48 & -1298 & 200 & 7.00 & -864 \\
\hline 50 & 9.61 & -1297 & 210 & 7.54 & -791 \\
\hline 55 & $1.38 \times 10^{-7}$ & -1297 & 220 & 8.07 & -713 \\
\hline 60 & 1.94 & -1296 & 230 & 8.57 & -630 \\
\hline 65 & 2.66 & -1295 & 240 & 9.04 & -542 \\
\hline 70 & 3.56 & -1293 & 250 & 9.50 & -449 \\
\hline 75 & 4.67 & -1292 & 260 & 9.94 & -352 \\
\hline 80 & 5.99 & -1289 & 270 & $1.04 \times 10^{-5}$ & -251 \\
\hline 85 & 7.52 & -1286 & 273.16 & 1.05 & -218 \\
\hline 90 & 9.26 & -1281 & 280 & 1.08 & -145 \\
\hline 95 & $1.12 \times 10^{-6}$ & -1276 & 290 & 1.11 & -35 \\
\hline 100 & 1.32 & -1270 & 293.16 & 1.13 & 0 \\
\hline 105 & 1.54 & -1263 & 300 & 1.15 & +78 \\
\hline
\end{tabular}

\begin{tabular}{|c|c|}
\hline \multicolumn{2}{|c|}{$\begin{array}{c}\text { Table. II-3-5. Average Coefficients of Thermal } \\
\text { Expansion of Beryllium for Several Ranges of } \\
\text { Temperature. } 4\end{array}$} \\
\hline $\begin{array}{l}\text { Temperature } \\
\text { range, }{ }^{\mathrm{O}} \mathrm{C}\end{array}$ & $\begin{array}{l}\text { Average coefficient of expansion } \\
\left(10^{-6}\right)\end{array}$ \\
\hline 25 to 100 & 11.6 \\
\hline 25 to 300 & 14.5 \\
\hline 25 to 600 & 16.5 \\
\hline 25 to 1000 & 18.4 \\
\hline
\end{tabular}

Low-temperature results of the thermal expansion relative to $300 \mathrm{~K}$ and the coefficient of thermal expansion are shown in Figs. II-3-2 and II-3-3, respectively, for VHP S-200F beryllium. Only one sample was used that had been machined, stress relieved at $788^{\circ} \mathrm{C}$ for one hour, final machined, etched to remove any machine damage, nickel plated, and finally polished to a $1 / 4$-wavelength finish. ${ }^{17}$ The thermal expansion results reported for HIP'ed beryllium made using impact-ground powder is shown 
in Fig. II-3-4. The process was evaluated in its use for large precision mirrors (space applications) where anisotropy cannot be tolerated. ${ }^{11}$

\begin{tabular}{|c|c|c|c|}
\hline \multicolumn{4}{|c|}{$\begin{array}{l}\text { Table. II-3-6. Coefficients of Thermal Expansion of Beryllium } \\
\text { Single Crystals at Low Temperatures. } 2,14\end{array}$} \\
\hline Temp., ${ }^{\mathrm{O}} \mathrm{K}$ & $\begin{array}{l}\text { Perpendicular to } \\
\text { c-axis }\left(10^{-6}\right)\end{array}$ & $\begin{array}{c}\text { Parallel to } \\
\text { c-axis }\left(10^{-6}\right)\end{array}$ & $\begin{array}{c}\text { Volume } \\
\text { coefficient }\left(10^{-6}\right)\end{array}$ \\
\hline 273 to 270 & 10.6 & 7.7 & 29.0 \\
\hline 265 to 260 & 10.2 & 7.3 & 27.6 \\
\hline 255 to 250 & 9.5 & 6.9 & 26.0 \\
\hline 250 to 245 & 9.2 & 6.7 & 25.1 \\
\hline 240 to 235 & 8.5 & 6.3 & 23.4 \\
\hline 230 to 225 & 7.9 & 5.9 & 21.7 \\
\hline 225 to 220 & 7.6 & 5.7 & 20.9 \\
\hline 220 to 215 & 7.3 & 5.5 & 20.1 \\
\hline 210 to 205 & 6.7 & 5.0 & 18.3 \\
\hline 200 to 195 & 6.1 & 4.6 & 16.9 \\
\hline 190 to 185 & 5.6 & 4.1 & 15.2 \\
\hline 180 to 175 & 5.0 & 3.6 & 13.5 \\
\hline 175 to 170 & 4.7 & 3.3 & 12.7 \\
\hline 165 to 160 & 4.1 & 2.7 & 10.9 \\
\hline 160 to 155 & 3.8 & 2.5 & 10.1 \\
\hline 150 to 145 & 3.2 & 1.9 & 8.3 \\
\hline 140 to 135 & 2.7 & 1.5 & 6.8 \\
\hline 130 to 125 & 2.1 & 1.0 & 5.3 \\
\hline 125 to 120 & 1.9 & 0.9 & 4.6 \\
\hline 115 to 110 & 1.3 & 0.5 & 3.2 \\
\hline 105 to 100 & 0.9 & 0.3 & 2.1 \\
\hline 100 to 95 & 0.7 & 0.2 & 1.6 \\
\hline 95 to 90 & 0.6 & 0.1 & 1.3 \\
\hline 85 to 80 & 0.4 & --- & 0.8 \\
\hline
\end{tabular}

Figure II-3-5 compares the thermal linear expansion between a polycrystalline beryllium and that of a single beryllium crystal in directions parallel to the a-axis and c-axis, respectively. The curves are based on the equations shown in Table II-3-7. ${ }^{18}$ Figure II-3-6 shows expansion-versus temperature curves recommended for polycrystalline beryllium and single crystals of beryllium. The curves are based on data obtained from 38 sources. ${ }^{18}$ Figure II-3-7 compares the average degree of anisotropy of thermal expansion for beryllium of essentially constant chemical composition for a structural grade beryllium (indicated as "comp A") produced by five different fabrication techniques. ${ }^{19}$ Also included is an instrument-grade hot-pressed beryllium having a high oxide content and a very fine grain size (indicated as "comp B"). ${ }^{20}$ The results are based on two specimens per material with 12 determinations on each specimens. The authors state that the thermal expansion results are consistent with the degree of preferred orientation that was observed. 


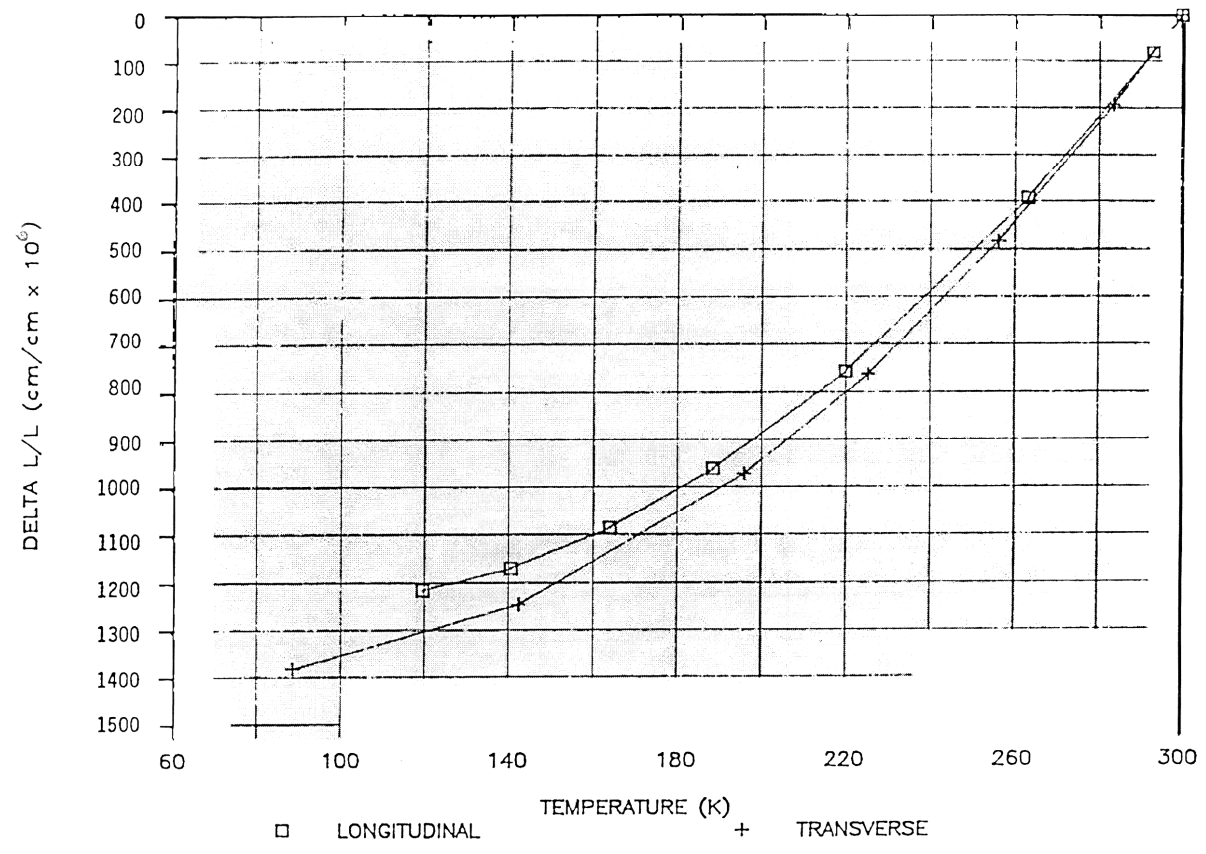

Fig. II-3-2 Low temperature thermal expansion, $\Delta \mathrm{L} / \mathrm{L}_{300 \mathrm{~K}}$, for VHP S-200F relative to $300 \mathrm{~K}\left(27^{\circ} \mathrm{C}\right) .{ }^{17}$

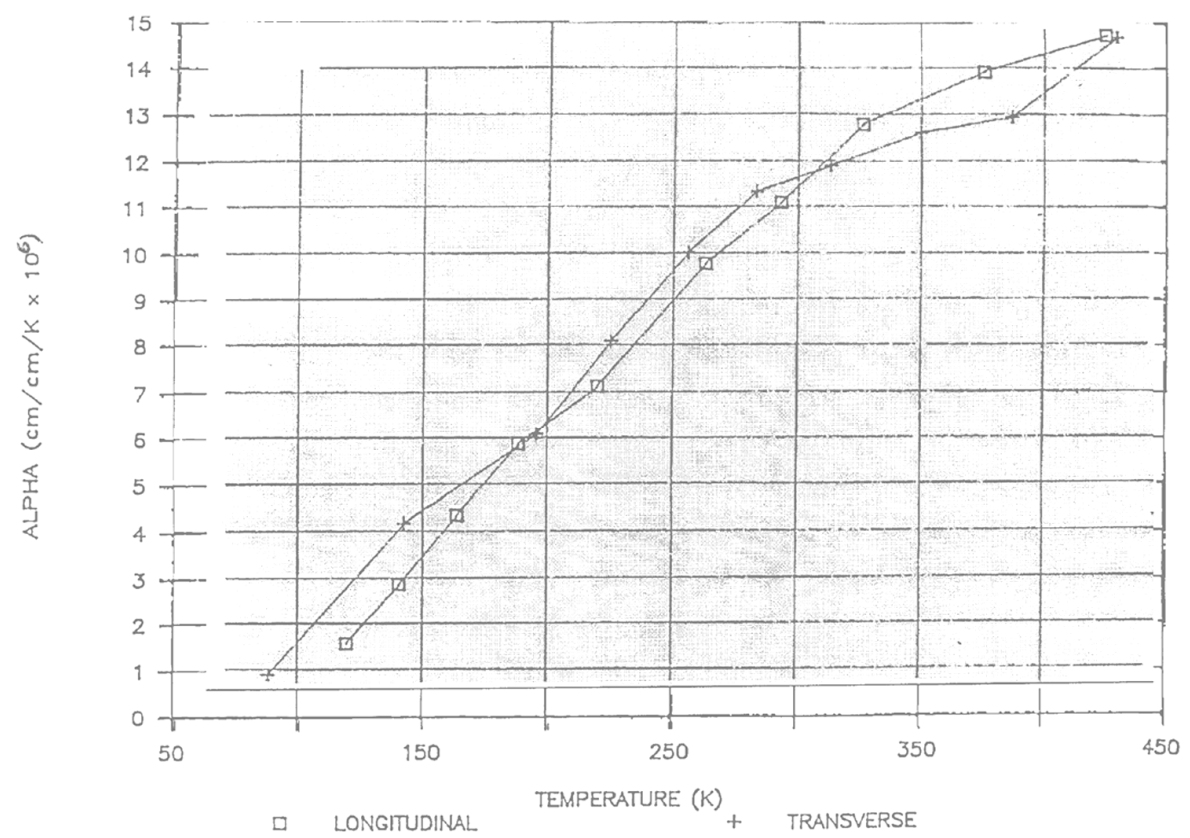

Fig. II-3-3 Coefficient of thermal expansion of beryllium versus temperature for VHP S-200F. ${ }^{17}$ 


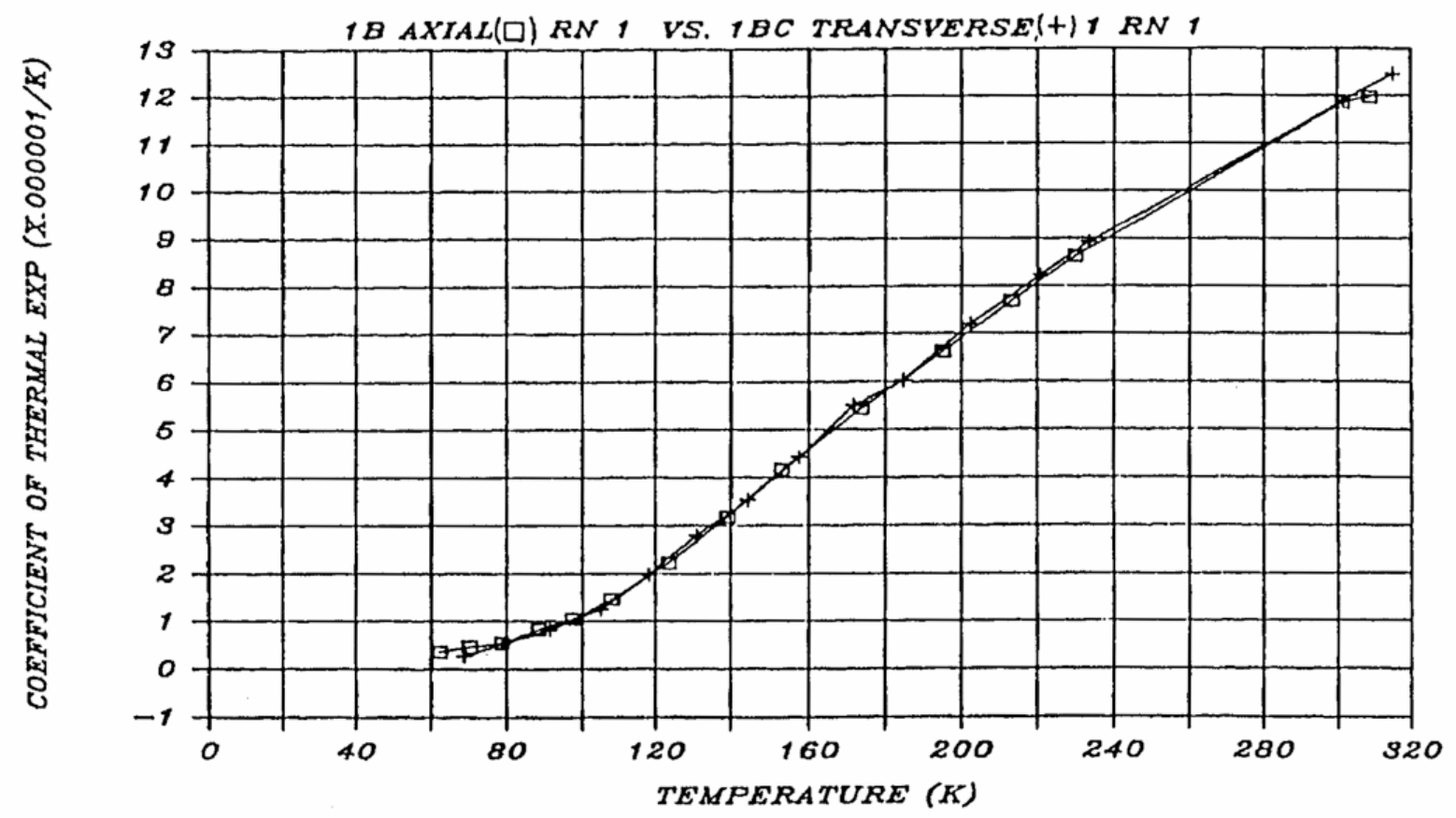

Fig. II-3-4. Coefficient of thermal expansion of a beryllium cube in two orthogonal directions showing excellent isotropy. The cube was HIP'd beryllium using impactground powder. ${ }^{11}$

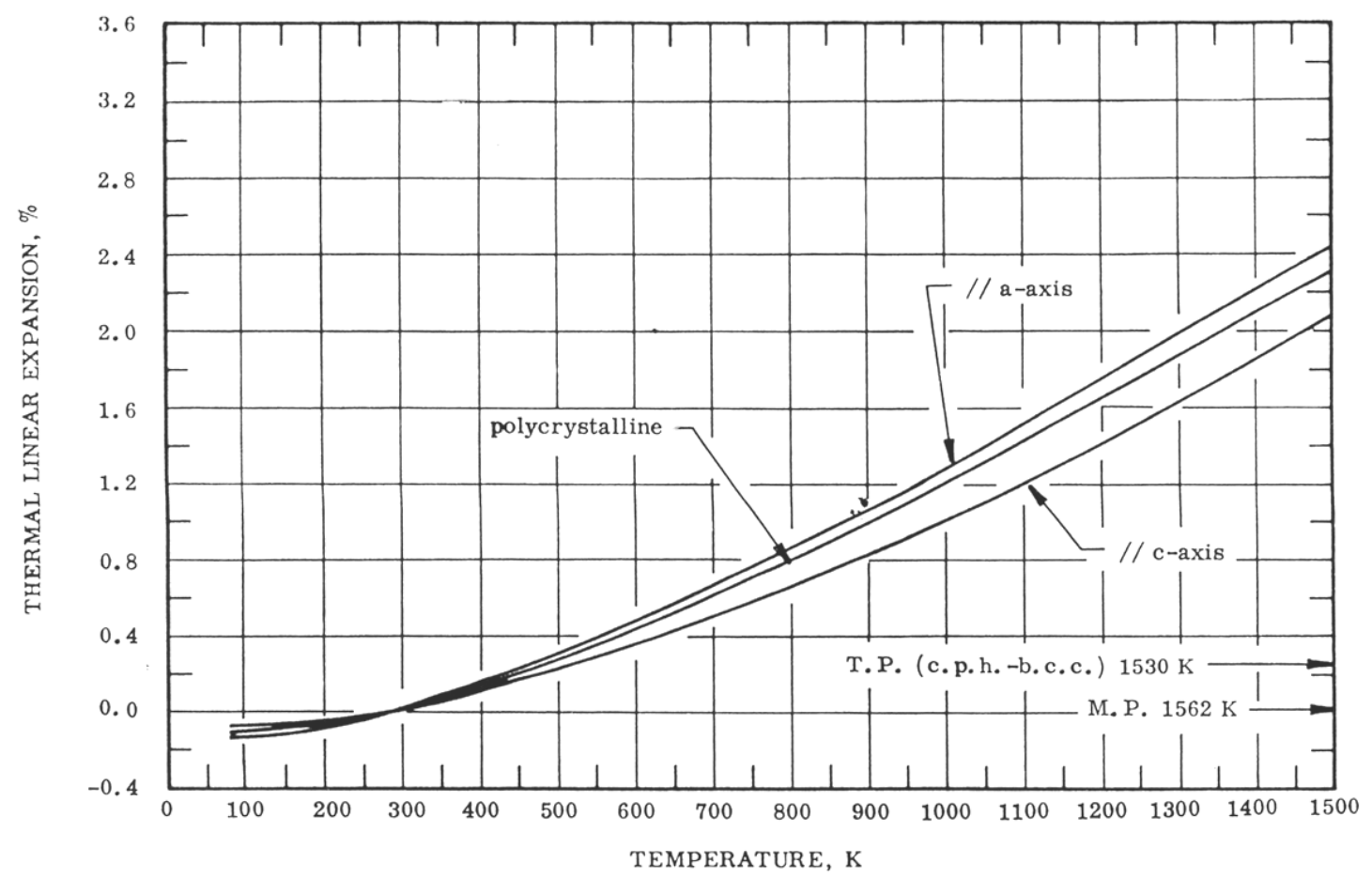

Fig. II-3-5. Thermal linear expansion relative to $293 \mathrm{~K}$ of polycrystalline beryllium and of a beryllium single-crystal parallel to the a-axis and c-axis, respectively. ${ }^{18}$ 


\begin{tabular}{|c|c|c|}
\hline \multicolumn{3}{|c|}{ TABLE II-3-7 EQUATIONS for CURVES SHOWN in FIGURE II-3-5 } \\
\hline $\begin{array}{l}\text { Orientation/ } \\
\text { type }\end{array}$ & Thermal linear expansion, $\left(\mathrm{L}-\mathrm{L}_{0}\right) / \mathrm{L}_{0}$ & $\begin{array}{c}\text { Temperature range, } \\
\mathrm{K}\end{array}$ \\
\hline $\begin{array}{c}\text { 1l a-axis } \\
\text { Single crystal }\end{array}$ & $\begin{array}{c}1.242 \times 10^{-3}(\mathrm{~T}-293)+1.144 \times 10^{-6}(\mathrm{~T}-293)^{2}-4.567 \times \\
10^{-10}(\mathrm{~T}-293)^{3}\end{array}$ & 293 to 895 \\
\hline $\begin{array}{c}\text { 1l a-axis } \\
\text { Single crystal }\end{array}$ & $\begin{array}{c}1.063+2.123 \times 10^{-3}(\mathrm{~T}-895)+3.197 \times 10^{-7} \\
(\mathrm{~T}-895)^{2}-1.373 \times 10^{-10}(\mathrm{~T}-895)^{3}\end{array}$ & 895 to 1500 \\
\hline $\begin{array}{c}\text { ll c-axis } \\
\text { Single crystal }\end{array}$ & $\begin{array}{l}9.881 \times 10^{-4}(\mathrm{~T}-293)+5.475 \times 10^{-7} \\
(\mathrm{~T}-293)^{2}+7.916 \times 10^{-11}(\mathrm{~T}-293)^{3}\end{array}$ & 293 to 895 \\
\hline $\begin{array}{c}11 \text { c-axis } \\
\text { Single crystal }\end{array}$ & $\begin{array}{l}0.809+1.733 \times 10^{-3}(\mathrm{~T}-895)+6.904 \times 10^{-7} \\
(\mathrm{~T}-895)^{2}-1.519 \times 10^{-10}(\mathrm{~T}-895)^{3}\end{array}$ & 895 to 1500 \\
\hline Polycrystalline & $\begin{array}{l}1.148 \times 10^{-3}(\mathrm{~T}-293)+9.724 \times 10^{-7} \\
(\mathrm{~T}-293)^{2}-2.978 \times 10^{-10}(\mathrm{~T}-293)^{3}\end{array}$ & 293 to 895 \\
\hline Polycrystalline & $\begin{array}{l}0.978+1.995 \times 10^{-3}(\mathrm{~T}-895)+4.346 \times 10^{-7} \\
(\mathrm{~T}-895)^{2}-1.307 \times 10^{-10}(\mathrm{~T}-895)^{3}\end{array}$ & 895 to 1500 \\
\hline
\end{tabular}

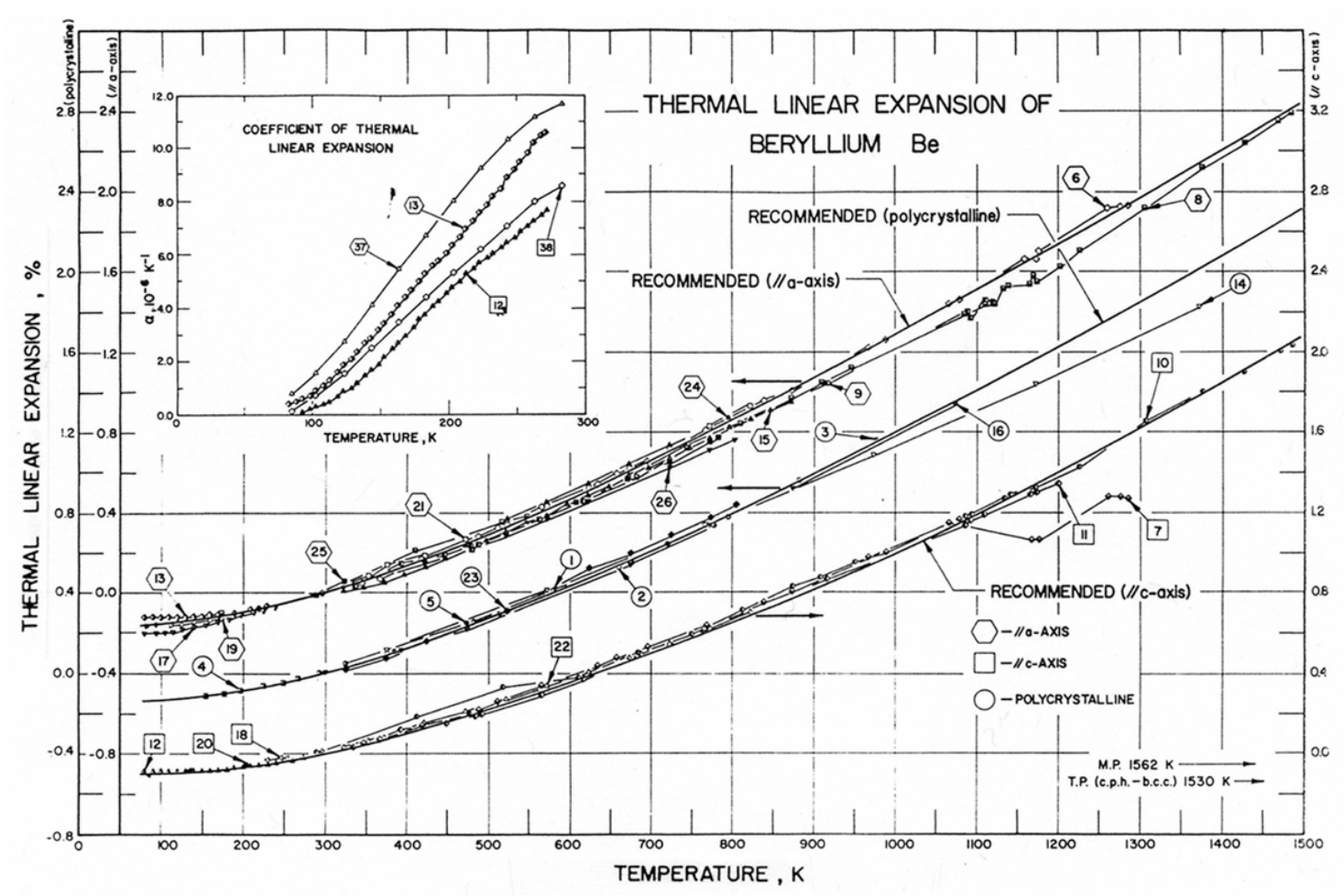

Fig. II-3-6 Recommended thermal linear expansion curves for beryllium based on a large number (38) of investigations. The vertical axes from left to right are for polycrystalline material and for single crystals parallel to a-axis and c-axis, respectively. Details on the temperature ranges, the materials evaluated, and the original references are presented in the current reference. ${ }^{18}$ 


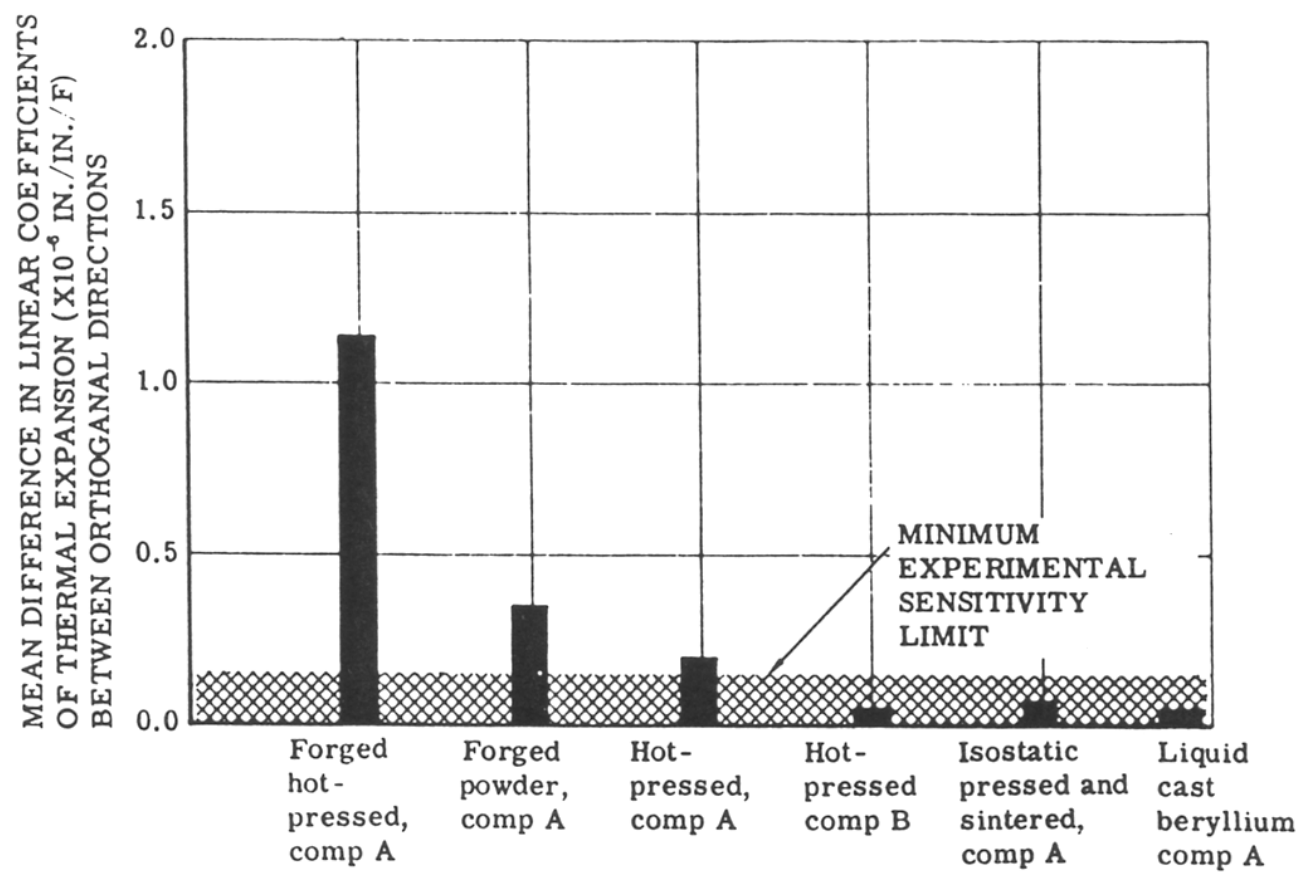

Fig. II-3-7 Comparison of the degree of thermal expansion anisotropy for beryllium fabricated by several techniques: $\mathrm{A}-2 \%$ maximum $\mathrm{BeO}, \mathrm{B}-4 \%$ minimum $\mathrm{BeO}{ }^{20}$

The temperature coefficients for unrelaxed thermal microstresses ${ }^{\mathrm{b}}$ that were calculated for beryllium are listed in Table II-3-8 together with values reported for other HCP polycrystalline materials. ${ }^{21}$, The authors suggest that in beryllium the residual stresses may greatly influence cracking in textured materials, for example, in rolled or extruded plate.

\begin{tabular}{|c|c|c|c|c|}
\hline \multicolumn{5}{|c|}{$\begin{array}{c}\text { Table II-3-8 Temperature Coefficient of } \\
\text { Thermal Microstresses in HCP Polycrystals. } \\
\end{array}$} \\
\hline Material & $\begin{array}{l}\sigma_{11} / \Delta \mathrm{T} \\
10^{2} \mathrm{Mpa}\end{array}$ & $\begin{array}{l}\sigma_{33} / \Delta \mathrm{T}, \\
10^{2} \mathrm{Mpa}\end{array}$ & $\begin{array}{l}\tau_{\max } / \Delta \mathrm{T}, \\
10^{2} \mathrm{Mpa}\end{array}$ & $\begin{array}{l}\sigma_{\max } / \Delta \mathrm{T}, \\
10^{2} \mathrm{Mpa}\end{array}$ \\
\hline $\mathrm{Cd}$ & 2.8 & -21 & 2.5 & 6.3 \\
\hline $\mathrm{Zn}$ & 4.9 & -3.7 & 4.3 & 12.2 \\
\hline $\mathrm{Mg}$ & 0.17 & -0.34 & 0.26 & 0.67 \\
\hline $\mathrm{Be}$ & -0.74 & 1.55 & -1.14 & -2.3 \\
\hline $\mathrm{BeO}$ & -0.635 & 1.27 & -0.95 & -2.3 \\
\hline
\end{tabular}

The thermal expansion relative to $298 \mathrm{~K}\left(25^{\circ} \mathrm{C}\right)$ of beryllium, having 100-percent density, in the range of 298 to $1500 \mathrm{~K}\left(25\right.$ to $\left.1227^{\circ} \mathrm{C}\right)$ is given as: ${ }^{11}$

$$
\Delta \mathrm{l} / \mathrm{l}_{298}=8.43 \times 10^{-4}\left(1+1.36 \times 10^{-3} \mathrm{~T}-3.53 \times 10^{-7} \mathrm{~T}^{2}\right)(\mathrm{T}-298) \text {. }
$$

\footnotetext{
${ }^{\mathrm{b}}$ Anisotropic dimensional changes occur during heating or cooling of hexagonal close-packed metals. In polycrystalline materials, microstrains and corresponding microstresses are developed by the mutual restrictions of adjacent grains to these dimensional changes.
} 
The mean coefficient of thermal expansion for a near-isotropic S-65B beryllium over the temperature range from 20 to $1200^{\circ} \mathrm{C}$ is given as: ${ }^{6}$

$$
\alpha\left(10^{-6} \mathrm{~K}^{-1}\right)=11.0388+1.0859 \times 10^{-2} \mathrm{~T}-4.4735 \times 10^{-6} \mathrm{~T}^{2}+8.6305 \times 10^{-10} \mathrm{~T}^{3} .
$$

In both expressions, $\mathrm{T}$ is temperature in degrees $\mathrm{K}$.

A study on thermal expansion and dimensional stability that was performed on several different beryllium histories showed that cast, hot-pressed, and isopressed forms were found to have nearly isotropic expansion properties. By contrast, the difference between anisotropic and isotropic thermal expansion ranged from $0.09 \times 10^{-6} /{ }^{\circ} \mathrm{C}$ for hot-pressed beryllium to $2.07 \times 10^{-6} /{ }^{\circ} \mathrm{C}$ for heavily forged beryllium. The average value for the hot-pressed material was $11.5 \times 10^{-6} /{ }^{\circ} \mathrm{C}{ }^{20}$ For isotropic sintered blocks such as S-65, differences in thermal expansion in different directions are small (not more than a few percent); for heavily deformed grades differences in thermal expansion could exceed 20 percent. ${ }^{6}$

Both the specific heat and thermal conductivity of beryllium are claimed to be relatively insensitive to fabrication method, low levels of impurity, and, to a certain extent, radiation in a neutron environment above room temperature. ${ }^{6}$ Small levels of impurities and displacement damage have little effect on thermal conductivity. ${ }^{11}$ However, the presence of as-fabricated porosity and/or helium bubbles can cause a large reduction in the effective thermal conductivity. The following expression is claimed to be a relatively good fit to data of both vacuum-hot-pressed and foam (low-density) beryllium for porosities up to $50 \%:^{11}$

$$
\mathrm{k}_{\mathrm{eff}}=(1-\mathrm{p})\left(1+3.7 \mathrm{p}^{2}\right)^{-1} \mathrm{k}_{\mathrm{O}}
$$

where $k_{\text {eff }}$ is the effective thermal conductivity, $\mathrm{p}$ is the volume fraction of porosity, and $\mathrm{k}_{\mathrm{o}}$ is the thermal conductivity for virtually zero porosity. Plasma-sprayed beryllium shows a significantly lower value than that predicted by this expression. The thermal conductivity of a normally dense beryllium over the temperature range from $27 \mathrm{t} 0550^{\circ} \mathrm{C}$ is given as: ${ }^{11}$

$$
\mathrm{k}_{\mathrm{o}}=291\left(1-1.650 \times 10^{-3} \mathrm{~T}+1.464 \times 10^{-6} \mathrm{~T}^{2}-5.125 \times 10^{-10} \mathrm{~T}^{3}\right) \mathrm{W} / \mathrm{m} /{ }^{\circ} \mathrm{C}
$$

A number of expressions reported for the specific heat at constant pressure $\left(C_{p}\right)$ of beryllium are presented here. The temperature range for the first expression was not given. The next two expressions cover the range between room temperature and $1283^{\circ} \mathrm{C}$; the fourth between 327 and $1287^{\circ} \mathrm{C}$; the fifth between 1287 and $1927^{\circ} \mathrm{C}$ (As previously indicated, throughout this report, except where noted, T refers to degrees $\mathrm{K})$ :

$$
\begin{aligned}
& \mathrm{C}_{\mathrm{p}}=4.54+2.12 \times 10^{-3} \mathrm{~T}-0.82 \times 10^{5} \mathrm{~T}^{-2} \mathrm{cal} /{ }^{\circ} \mathrm{C} / \mathrm{g} \text {-atom, }{ }^{5} \\
& \mathrm{C}_{\mathrm{p}}=5.238+13.378 \times 10^{-4} \mathrm{~T}-15.31 \times 10^{4} \mathrm{~T}^{-2} \mathrm{cal} /{ }^{\circ} \mathrm{C} / \mathrm{g} \text {-atom, }{ }^{11}
\end{aligned}
$$




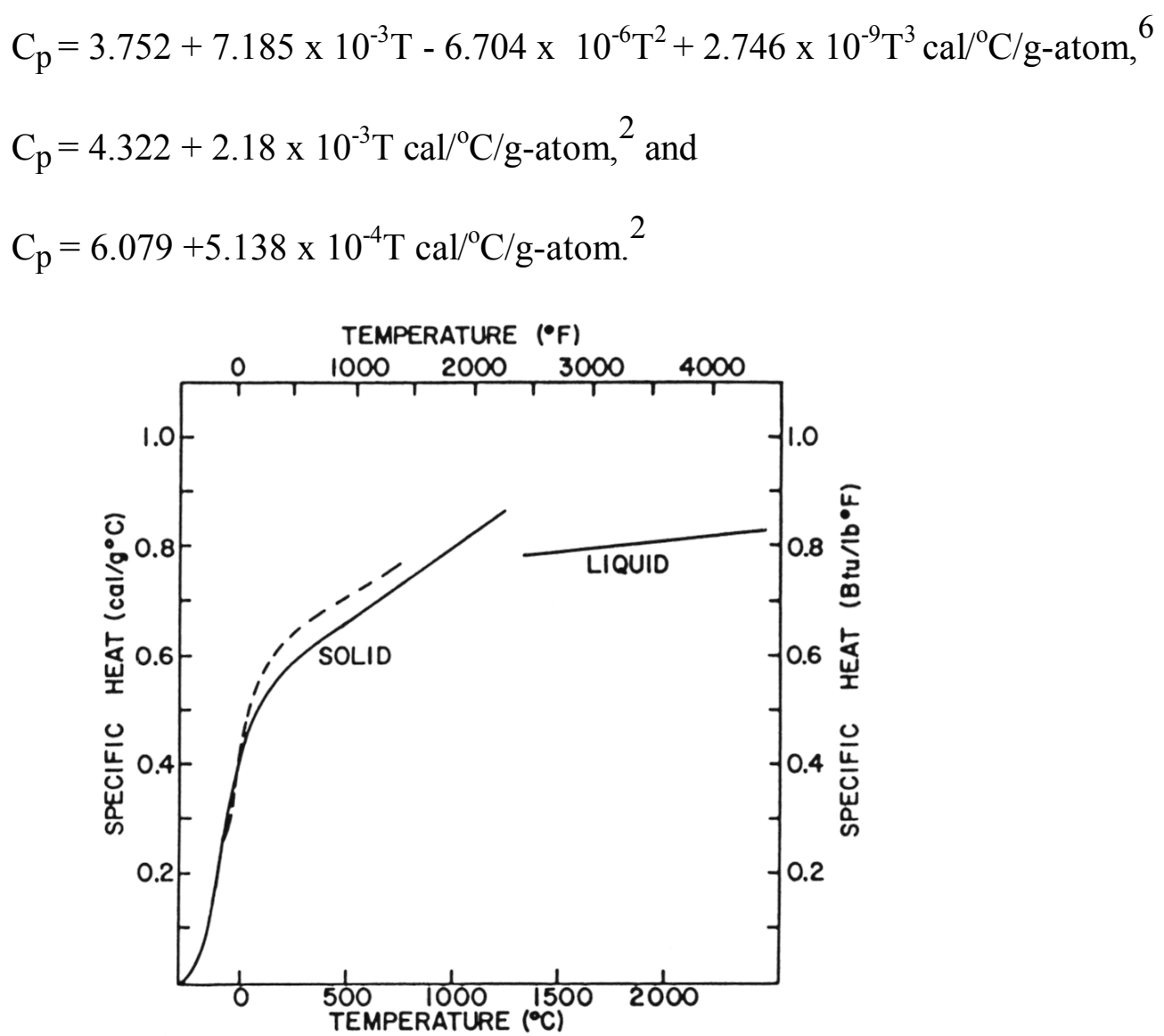

Fig. II-3-8. Specific heat of beryllium as a function of temperature. Results from two different sources. Dashed line is for a brake grade of normal-purity block. ${ }^{13}$

The specific heat as a function of temperature covering both solid and liquid beryllium is shown in Fig. II-3-8 ${ }^{13}$ A plot of specific heat as a function of temperature is also shown in Fig. II-3-9. ${ }^{7}$ The plot consists of data reported for nine different investigations and shows excellent agreement between these various studies. Some low-temperature results reported for specific heat and enthalpy are shown in Table II-3-9. ${ }^{2}$ Figures $10^{22}$ and $11^{23}$ show the specific heat as a function of temperature covering both solid and liquid regions, with the curve in Fig. 11 extending down below $40 \mathrm{~K}$. 


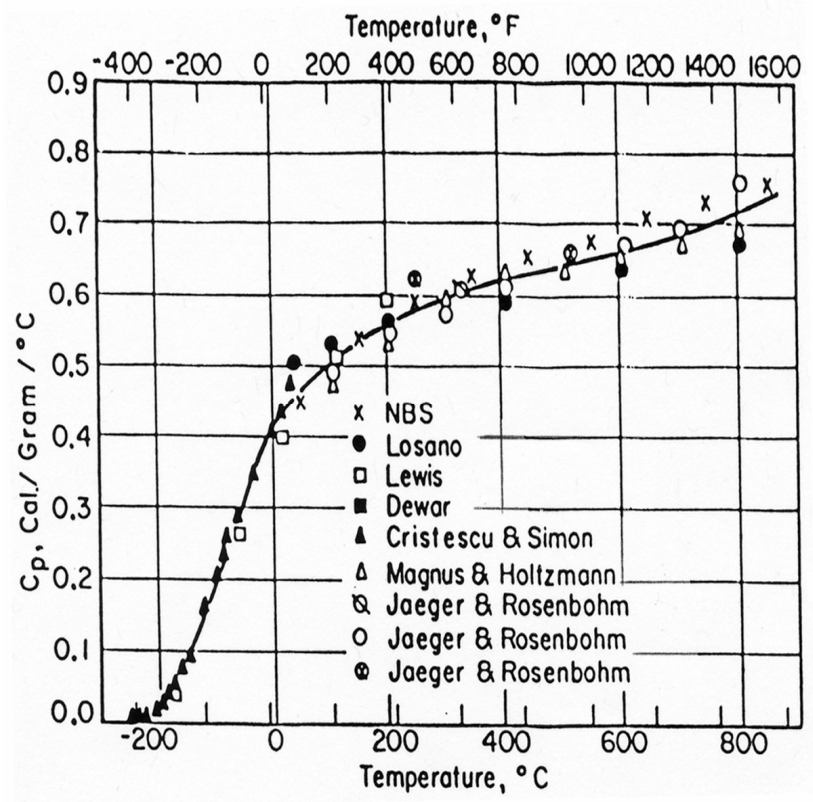

Fig. II-3-9 The specific heat of beryllium (per gram) as a function of temperature. ${ }^{7}$

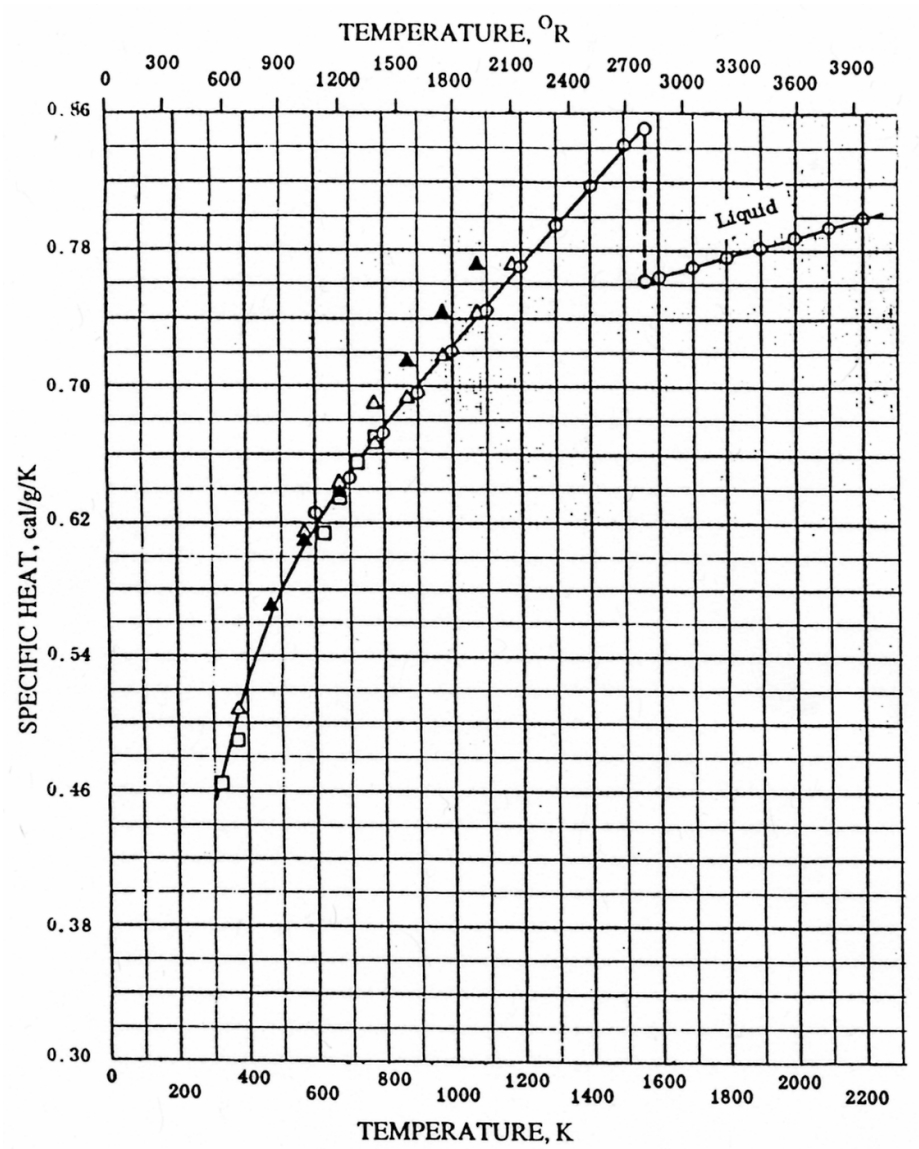

Fig. II-3-10. Specific heat of beryllium as a function of temperature from four different sources for both solid and liquid regions: $\mathrm{O},-99 \square \% \mathrm{Be} ; \Delta, \sigma-99.5 \% \mathrm{Be}^{22}$ 
The thermal conductivity as a function of temperature for several different sources of beryllium is shown in Figs. II-3-12 ${ }^{13}$ and II-3-13. ${ }^{7}$ The thermal conductivity as a function of temperature of beryllium from six different sources plotted on the same graph is shown in Fig. II- 3-14. ${ }^{22}$ The thermal conductivity as a function of temperature for well annealed high-purity beryllium over a wide range of temperatures $(2$ to $1000 \mathrm{~K}$ ) is shown in Fig. 15. A peak value in the conductivity is seen at about $35 \mathrm{~K}$ $\left(-238^{\mathrm{O}} \mathrm{C}\right)$.

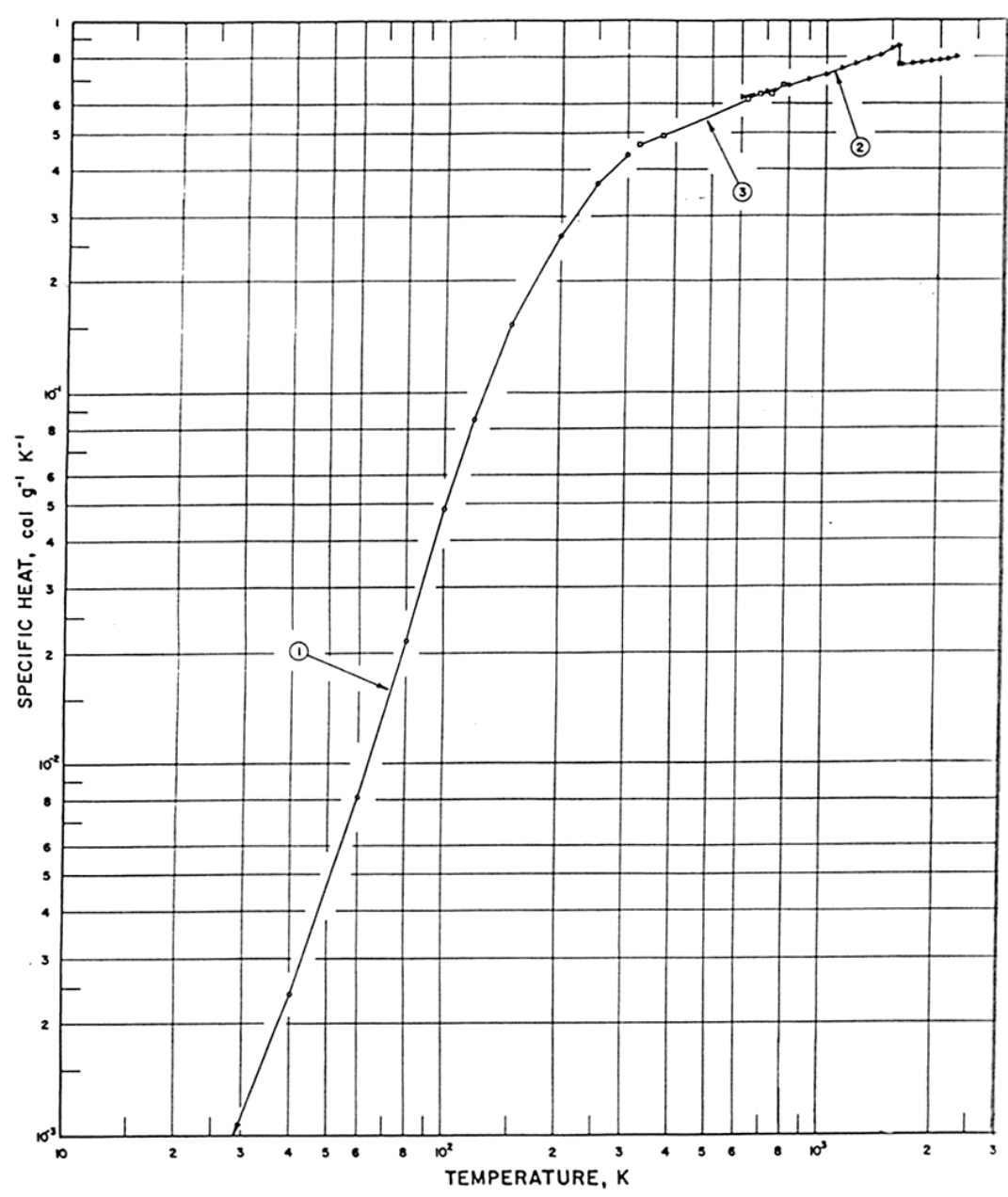

Fig. II-3-11 The specific heat of beryllium covering a wide temperature range, from $40 \mathrm{~K}$ up to $2200 \mathrm{~K}$ : $1-0$ to $300 \mathrm{~K}, 99.5 \% \mathrm{Be}$, high-temp. extrusion of powder; $2-600$ to 2200 $\mathrm{K}, 99.8 \% \mathrm{Be}$, pulverized and tightly filled into ampoules; 3 - 323 to $773 \mathrm{~K}, 99.8 \% \mathrm{Be}$, history not given. ${ }^{23}$

Thermal diffusivity $\left(\mathrm{m}^{2} / \mathrm{h}\right)$ as a function of temperature is shown in Fig. II- 3-16. The thermal diffusivity determines the rate of heat propagation by conduction. It can be calculated by the following expression:

$$
\alpha=\lambda / \rho C_{p}
$$


where $\alpha$ is the thermal diffusivity, $\lambda$ is the thermal conductivity, $\rho$ is the density, and $C_{p}$ is the specific heat. $^{13}$

\begin{tabular}{|c|c|c|c|c|c|}
\hline \multicolumn{6}{|c|}{ Table II-3-9. Specific Heat and Enthalpy at Low Temperatures. } \\
\hline Temp. ${ }^{\circ} \mathrm{K}$ & $\mathrm{C}_{\mathrm{p}}, \mathrm{cal} / \mathrm{g} /{ }^{\circ} \mathrm{K}$ & $\Delta \mathrm{H}, \mathrm{cal} / \mathrm{g}$ & $\mathrm{Temp} .{ }^{\circ} \mathrm{K}$ & $\mathrm{C}_{\mathrm{p}}, \mathrm{cal} / \mathrm{g} /{ }^{\circ} \mathrm{K}$ & $\Delta \mathrm{H}, \mathrm{cal} / \mathrm{g}$ \\
\hline 1 & 0.000006 & 0.000003 & 80 & 0.0217 & 0.404 \\
\hline 3 & 0.000019 & 0.000028 & 100 & 0.0476 & 1.08 \\
\hline 6 & 0.000043 & 0.000119 & 140 & 0.125 & 4.42 \\
\hline 10 & 0.000093 & 0.00038 & 180 & 0.220 & 11.3 \\
\hline 20 & 0.00038 & 0.0025 & 220 & 0.308 & 21.9 \\
\hline 40 & 0.00238 & 0.026 & 260 & 0.392 & 36.1 \\
\hline 60 & 0.0081 & 0.125 & 300 & 0.471 & 53.3 \\
\hline
\end{tabular}

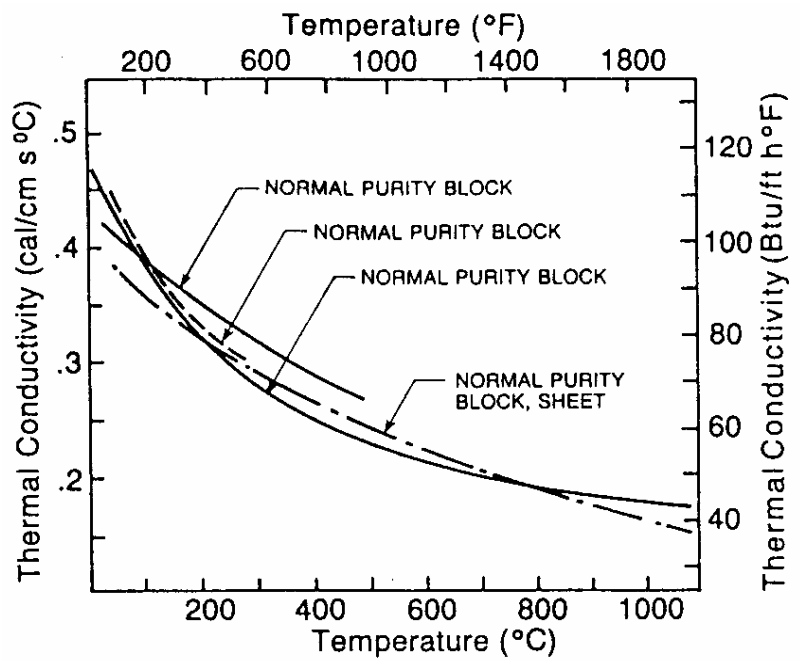

Fig.II-3-12 Thermal conductivity of normal-purity beryllium block and sheet as a function of temperature. ${ }^{13}$

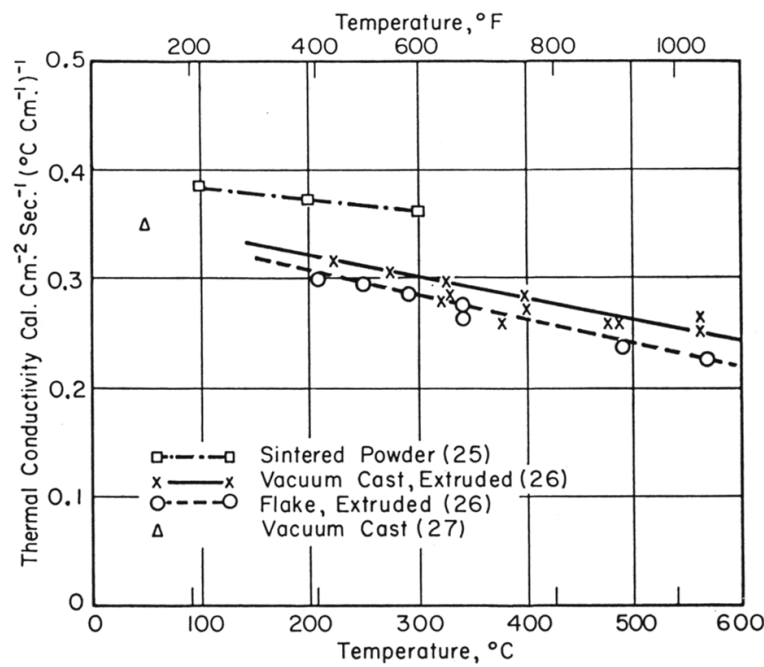

Fig. II-3-13. Thermal conductivity of several types of beryllium as a function of temperature. ${ }^{7}$ 


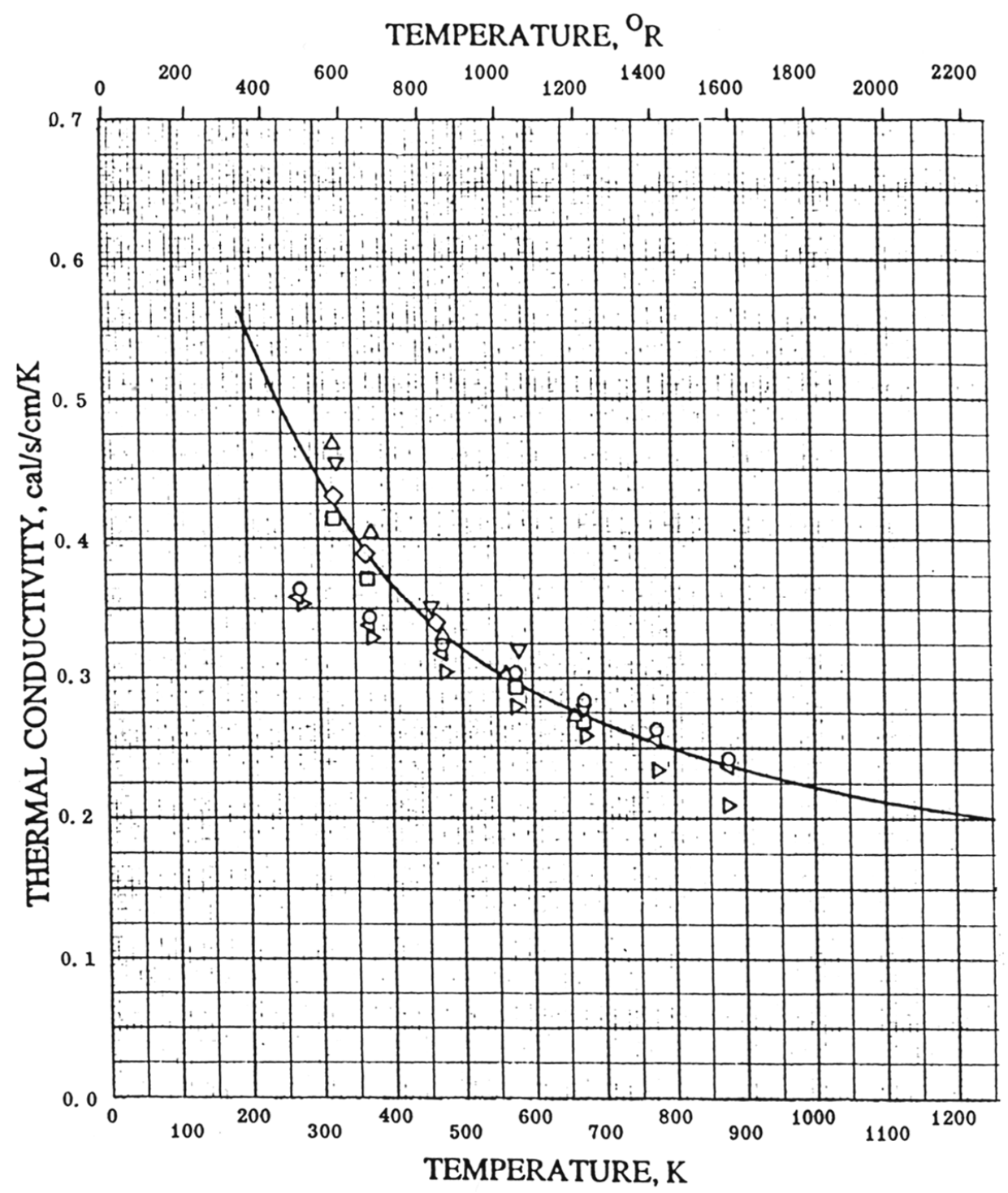

Fig. II-3-14. Thermal conductivity of beryllium as a function of temperature:- data from 322 to $672 \mathrm{~K}$, listed as as-received condition with a density of $1.829 \mathrm{~g} / \mathrm{cm}^{3} ; \Delta-322$ to $672 \mathrm{~K}$, as previous plus heat treated to above $700{ }^{\circ} \mathrm{C}$; $\diamond-322$ to $672 \mathrm{~K}$, listed as asreceived condition with a density of $1.865 \mathrm{~g} / \mathrm{cm}^{3} ; \nabla-322$ to $672 \mathrm{~K}$, as previous plus heat treated to above $700{ }^{\circ} \mathrm{C}$; O -273 to $875 \mathrm{~K}$, no additional information; -273 to $875 \mathrm{~K}$ vacuum-cast and exted pure Be; -273 to $875 \mathrm{~K}$, flake, extruded pure Be. ${ }^{22}$ 


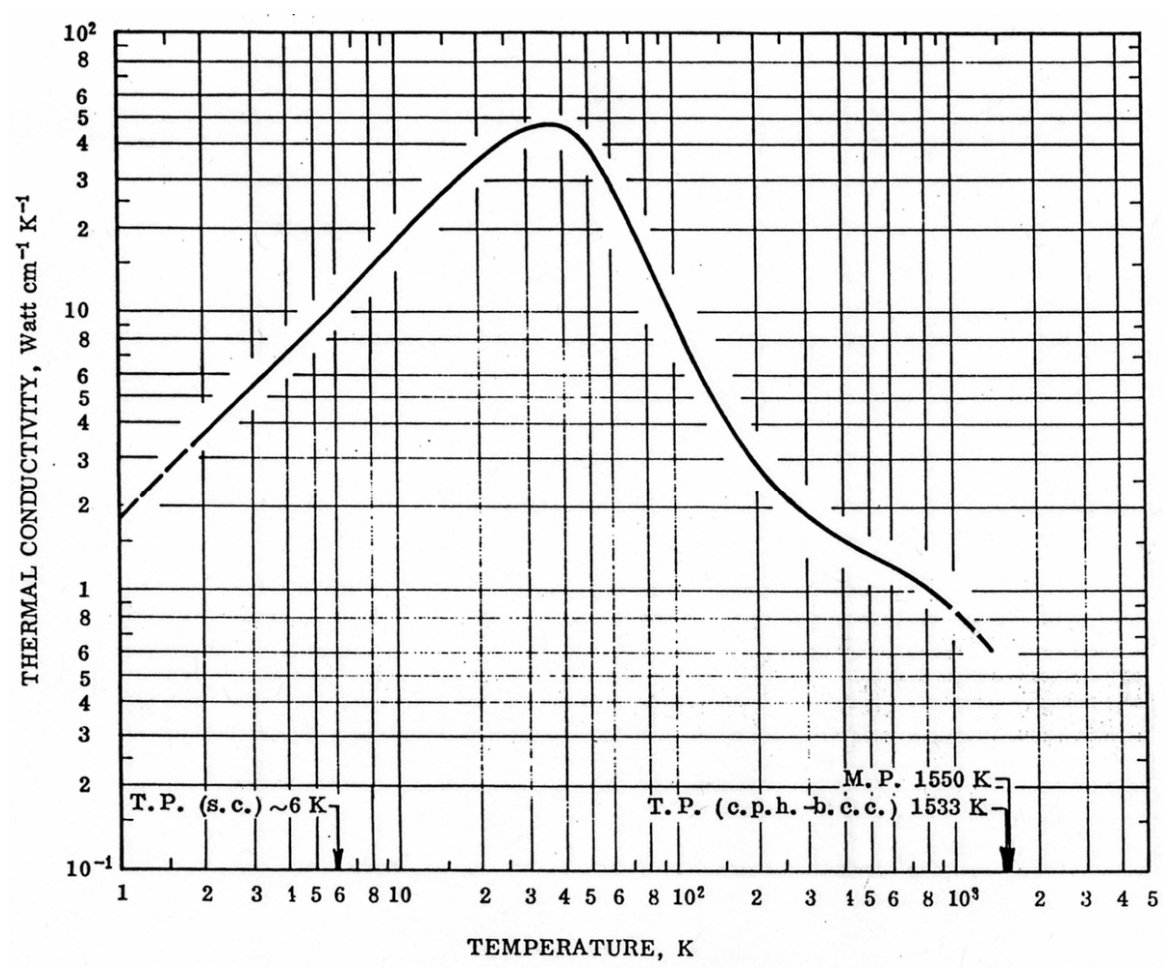

Fig. II-3-15. Thermal conductivity for well annealed high-purity beryllium showing a maximum in conductivity at about $360 \mathrm{~K}$. Data is believed to be accurate to $5 \%$ near room temperature and from 5 to $15 \%$ at other temperatures. ${ }^{25}$

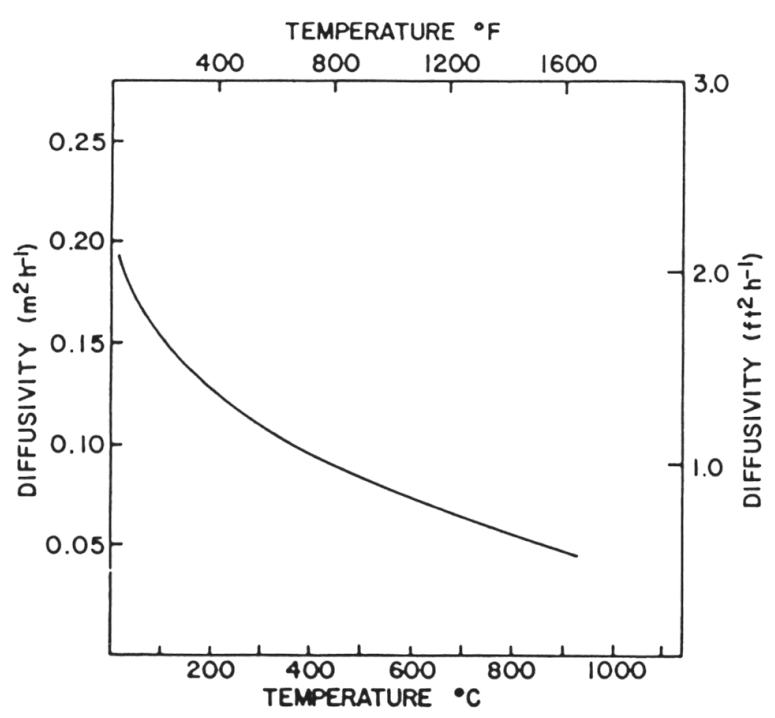

Fig. II-3-16 Thermal diffusivity of normal-purity block and instrument-grade block of beryllium. ${ }^{13}$

Thermal diffusivity as a function of temperature for well annealed high-purity beryllium is shown in Fig. II-3-17. ${ }^{24}$ 


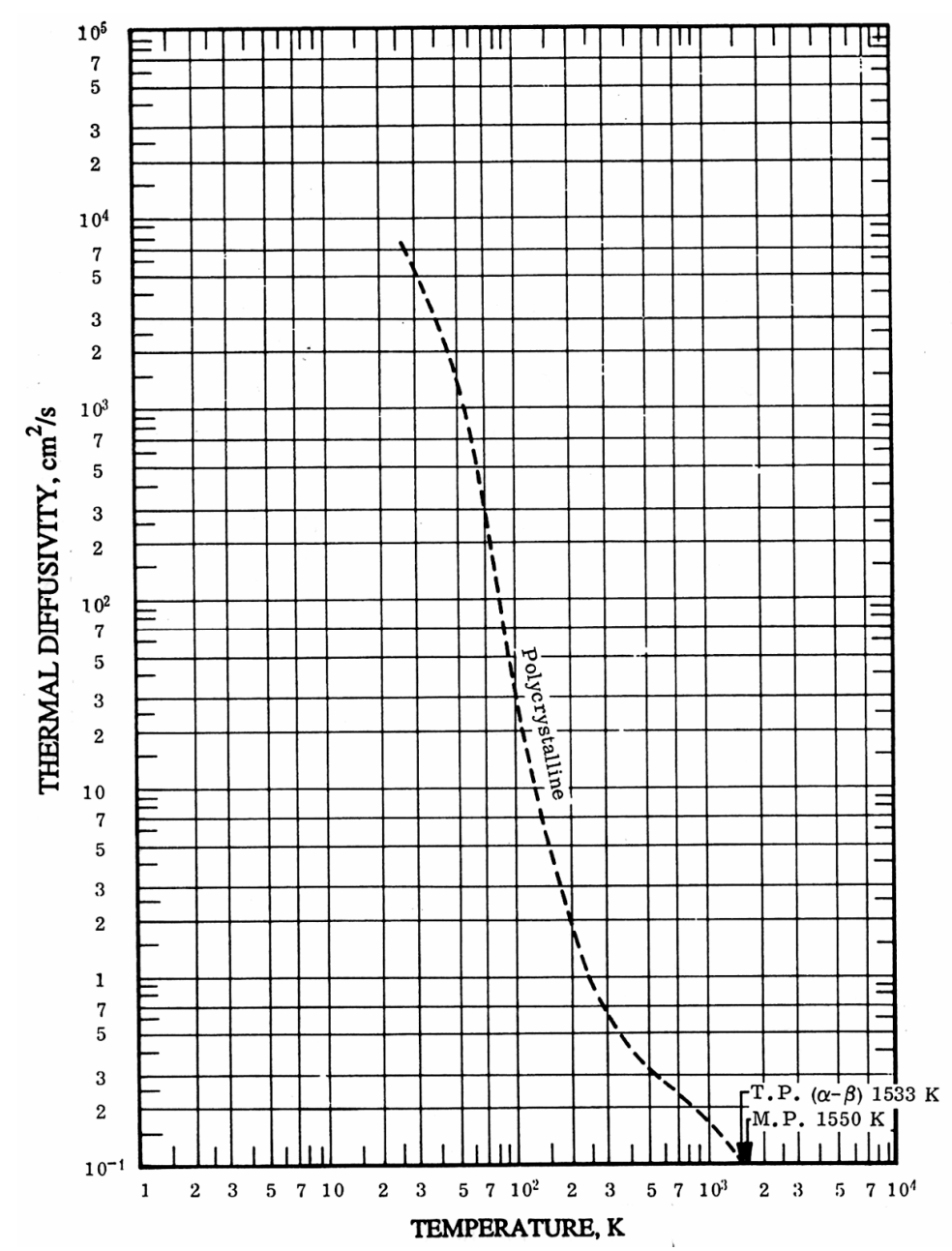

Fig. II-3-17. Thermal diffusivity as a function of temperature for well annealed highpurity beryllium. Uncertainty of $\pm 15 \%$ above room temperature and $\pm 25 \%$ below, where values are only applicable to beryllium having a residual electrical resistivity of 0.0135 $\mu \Omega \mathrm{cm}^{24}$

The self-diffusion in beryllium single crystals perpendicular to the basal plane over a series of temperatures are listed in Table II-3-10. A plot of D versus 1/RT yields a straight line with the following expression: ${ }^{26}$

$$
\mathrm{D}_{\perp}=0.19 \times \exp (-38,600 / \mathrm{RT}),
$$

where $\mathrm{D}_{\perp}$ is the self diffusion perpendicular to the basal plane. In a different investigation the expressions for self diffusion of beryllium perpendicular and parallel $\left(\mathrm{D}_{11}\right)$ to the basal plane are given as: $^{27}$

$$
\begin{aligned}
& \mathrm{D}_{\perp}=(0.62 \pm 0.15) \times \exp [(-39,400 \pm 700) / \mathrm{RT}], \text { and } \\
& \mathrm{D}_{11}=(0.52 \pm 0.15) \times \exp [(-37,600 \pm 700) / \mathrm{RT}]
\end{aligned}
$$


The authors note that the ratio $\mathrm{D}_{11} / \mathrm{D}_{\perp}$ is greater than 1 . This is consistent with the ratio of c/a being less than c/a ideal for beryllium. The authors also discuss diffusion of iron and silver in beryllium. ${ }^{27}$

\begin{tabular}{|c|c|c|}
\hline \multicolumn{3}{|c|}{ Table II-3-10 Diffusivities in Beryllium Single Crystals Perpendicular to the } \\
Basal Plane.
\end{tabular}

The vapor pressure of beryllium as a function of reciprocal temperature between 900 and $1283^{\circ} \mathrm{C}$ is shown in Fig. II-3-18 for three different beryllium processes, ${ }^{7}$ and in Fig. II-3-19 ${ }^{22}$ for two different beryllium compositions. Both figures cover about the same temperature range $\left(900\right.$ to $\left.1283^{\circ} \mathrm{C}\right)$. The vapor pressure over this temperature region, which is in the range of $10^{-10}$ to $10^{2} \mathrm{~Pa}$, is given by the following expression: ${ }^{6}$

$\log p(P a)=11.192+1.45 \times 10^{-4} \mathrm{~T}-1.6734 \times 10^{4} \mathrm{~T}^{-1}(\mathrm{~T}, \mathrm{~K})$

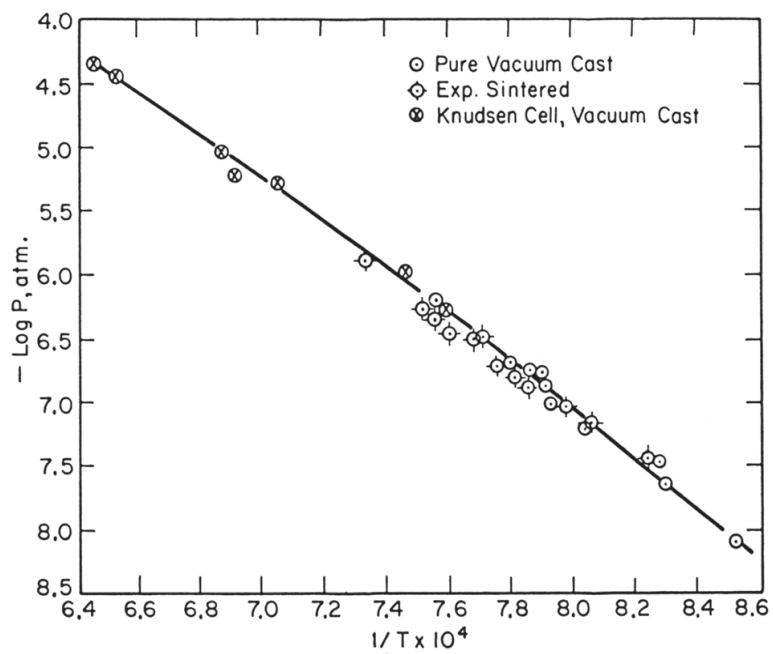

Fig. II-3-18 Vapor pressure of beryllium as a function of $1 / \mathrm{T}\left({ }^{\mathrm{O}} \mathrm{K}\right){ }^{7}$ 


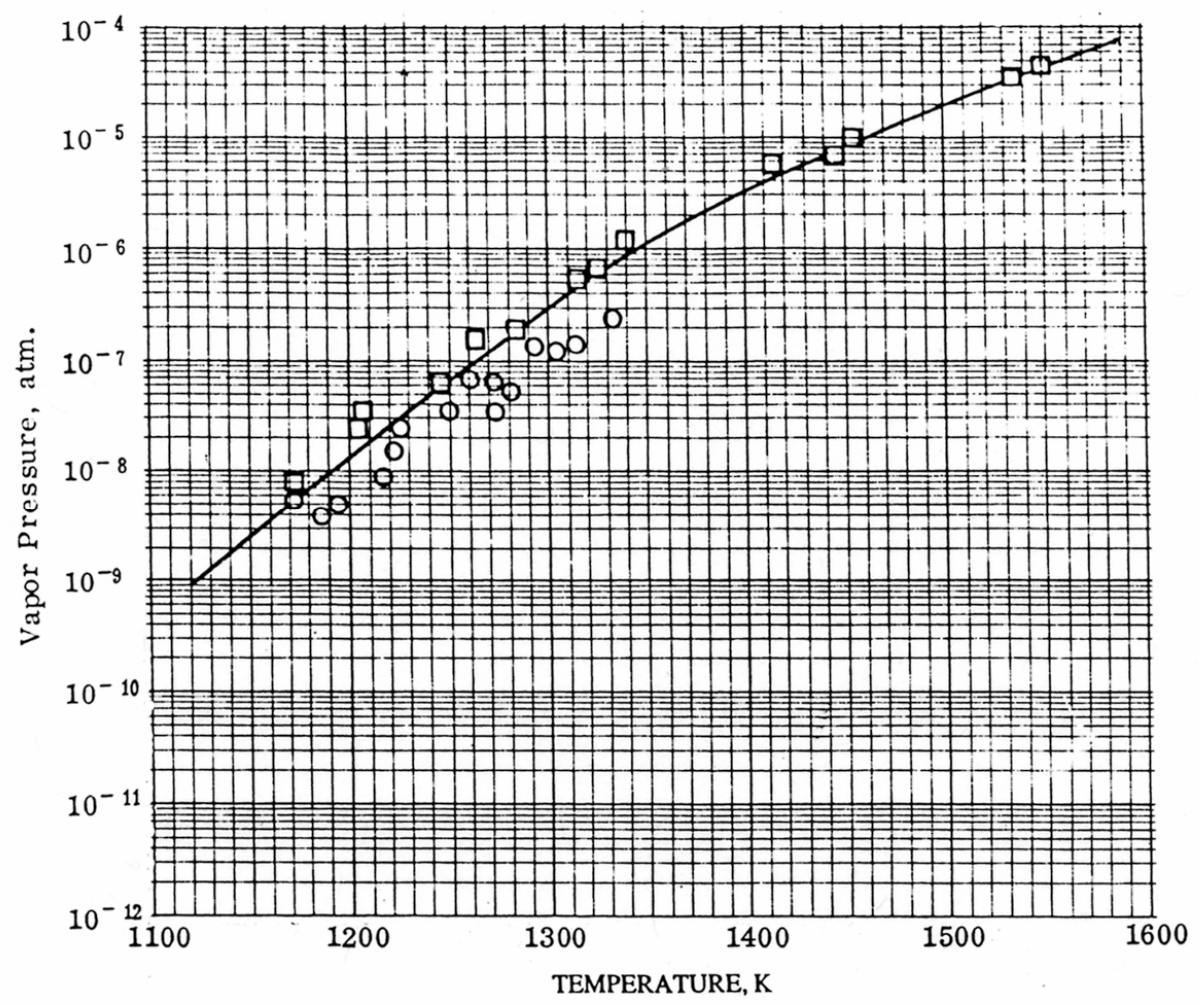

Fig. II-3-19. Vapor pressure of beryllium as a function of temperature:

$\mathrm{O}-1174$ to $1336 \mathrm{~K}, 0.03 \mathrm{Fe} .0 .022 \mathrm{Si}, 0.008 \mathrm{Al}, 0.004 \mathrm{Mg}$;

$\longrightarrow 172$ to $1552 \mathrm{~K}$, vacuum cast, $0.14 \mathrm{Al}, 0 . \mathrm{Fe}, 0.04 \mathrm{Si}$,

$0.02 \mathrm{Mg}, 0.01$ each of $\mathrm{Cr}, \mathrm{Cu}, \mathrm{Na}, \mathrm{Ni}, \mathrm{Zn}^{22}$

\section{$\underline{\text { II-4-Nuclear Properties }}$}

Natural beryllium contains $100 \%$ of the ${ }^{9} \mathrm{Be}$ isotope. The principal isotopes of beryllium that have been identified are: ${ }^{6} \mathrm{Be},{ }^{7} \mathrm{Be},{ }^{8} \mathrm{Be},{ }^{9} \mathrm{Be}$, and ${ }^{10} \mathrm{Be} .{ }^{5}$ Additional isotopes listed are: ${ }^{11} \mathrm{Be},{ }^{12} \mathrm{Be}$, and ${ }^{14} \mathrm{Be}^{28}$ Some properties of the principal beryllium isotopes are listed in Table II-4-1 and II-4-2. In searching for data on beryllium isotopes, the published data could, in some cases, differ significantly. Irradiated beryllium yields gas-producing nuclear reactions. The major nuclear reactions are given in Table II-4-3. The nuclear reactions listed in Table II-4-3, ${ }^{5}$ are calculated to produce about 2.2 to 2.6 $\mathrm{cm}^{3}$ of gas per $\mathrm{cm}^{3}$ of beryllium following a fluence of $10^{21} \mathrm{~N} / \mathrm{cm}^{2}$. The first of these reactions has a threshold of about $12 \mathrm{MeV}$. The second one has a threshold of $600 \mathrm{keV}$, as well as a strong resonance at $3 \mathrm{MeV}{ }^{29}$

The beryllium atom has a reluctance to acquire additional neutrons while readily parting with one of its neutrons. It has a low neutron-capture cross-section (probability of capture) and a high neutronscattering (large number of collisions with direction change and energy loss) cross section making the 
metal an excellent moderating material. Both of these cross-section areas ${ }^{\mathrm{c}}$ are dependent on the energy of the neutrons and the condition of the metal (e. g., impurities and grain size). The effect of impurities on the thermal neutron-capture (absorption) cross section is illustrated in Table II-4-4. ${ }^{19}$ With these nuclear properties, beryllium is used as a neutron moderator in nuclear-chain reactions, as a source of neutrons, and as a window in X-ray tubes.

The $(\mathrm{n}, 2 \mathrm{n})$ reaction with a high reaction cross-section, enables beryllium to function as a neutron multiplier. Beryllium is the leading neutron-multiplier candidate material for fusion applications. The combination of high neutron multiplication, low absorption, and high scattering characteristics provide excellent neutron thermalization. Therefore, beryllium can provide a high performance-breeding blanket for fusion systems. ${ }^{5}$ The absorption cross section for thermal neutrons is 0.008 barns ${ }^{\mathrm{d}}$; the scattering cross section for fast neutrons is 6 barns. $^{28}$ The resonance integral ${ }^{\mathrm{e}}$ is 0.004 barns. The mass-absorption coefficient for copper $\mathrm{K}$-alpha radiation is $1.007 \mathrm{~cm}^{2} / \mathrm{g}$.

The adsorption and desorption of deuterium have been measured on clean and on oxidized beryllium surfaces corresponding to the basal plane. The oxidized surfaces released all the adsorbed deuterium by about $177^{\circ} \mathrm{C}$. By contrast, for the clean surfaces, the desorption was not complete until the temperature was above $327^{\circ} \mathrm{C}$. The electron-affinity energy (difference between the ground state of the neutral atom and the lowest state of the corresponding negative ion) is indicated as being unstable for beryllium. ${ }^{1}$

Irradiated beryllium exhibits an increase in yield strength with a loss in ductility and a decrease in fracture toughness. Nil ductility is obtained when tested below $100^{\circ} \mathrm{C}$, whereas a small increase in yield strength with only a small decrease in ductility are obtained above $350^{\circ} \mathrm{C}$. Although the fracture toughness decreases with an increase of neutron fluence, the trend reverses at high fluences. It is suggested that all the beryllium grades exhibit approximately the same fracture toughness response to irradiation. At the lower temperatures, the helium atoms remain in the matrix; at the higher temperatures, the atoms diffuse and agglomerate causing swelling. As the fluence increases, the temperature required to produce complete annealing appears to increase and the temperature to produce $1 \%$ swelling decreases. 5 .

\footnotetext{
${ }^{\mathrm{c}}$ The neutron cross section measures the probability of interaction of a neutron with matter. The cross section is visualized as a target area presented to the neutron by the nucleus. It is usually measured in units of barns $\left(10^{-24} \mathrm{~m}^{2}\right.$ per atom). Absorption and scattering cross section refers to the capture and scattering of neutrons, respectively. The thermal-neutron absorption cross section is the sum of the cross sections of all reactions except that of the scattering cross section. d A "barn" is a unit of $10^{-24} \mathrm{~m}^{2}$ /atom.

${ }^{\mathrm{e}}$ Narrow peaks (at exceptionally high rates of reaction) in a plot of cross section versus energy are referred to as resonances. The resonance integral is the integral of the cross section as a function of neutron energy multiplied by the flux density.
} 


\begin{tabular}{|c|c|c|c|}
\hline \multicolumn{4}{|c|}{ Table II-4-1 Some Properties of Beryllium IsotopesL ${ }^{30}$} \\
\hline Isotope & Half-life & Radiation, $\mathrm{MeV}$ & Source \\
\hline${ }^{6} \mathrm{Be}$ & $0.4 \mathrm{~s}\left(3 \times 10^{-21} \mathrm{~s}\right) \mathrm{dn}$ & - & - \\
\hline \multirow[t]{5}{*}{$7 \mathrm{Be}$} & 53.5 days & $\gamma$ & ${ }^{6} \operatorname{Li}(d, n)$ \\
\hline & & $0.453-0.485$ & ${ }^{7} \operatorname{Li}(p, n)$ \\
\hline & & & ${ }^{10} \mathrm{~B}(\mathrm{p}, \mathrm{d})$ \\
\hline & & & ${ }^{10} \mathrm{~B}(\mathrm{p}, \alpha)$ \\
\hline & & & ${ }^{10} \mathrm{~B}(\mathrm{~d}, \alpha, \mathrm{n})$ \\
\hline \multirow[t]{2}{*}{${ }^{8} \mathrm{Be}$} & $1.4 \times 10^{-16}$ seconds & $\alpha$ & ${ }^{9} \mathrm{Be}(\gamma, \mathrm{n})$ \\
\hline & & 0.055 & $9 \mathrm{Be}(\mathrm{n}, 2 \mathrm{n})$ \\
\hline${ }^{9} \mathrm{Be}$ & Stable & - & - \\
\hline \multirow[t]{5}{*}{${ }^{10} \mathrm{Be}$} & $2.7 \times 10^{6}$ years & $\beta$ & ${ }^{9} \operatorname{Be}(\alpha, p)$ \\
\hline & & $0.56-0.65$ & $9 \mathrm{Be}(\mathrm{d}, \mathrm{p})$ \\
\hline & & & $9 \mathrm{Be}(\mathrm{n}, \gamma)$ \\
\hline & & & ${ }^{10} \mathrm{Be}(\mathrm{n}, \mathrm{p})$ \\
\hline & & & ${ }^{13} \mathrm{C}(\mathrm{n}, \alpha)$ \\
\hline \multicolumn{4}{|c|}{$\begin{array}{ll}\text { Gamma-ray bombardment } & \mathrm{Be}(\gamma, \mathrm{n}) \mathrm{Be} \\
\text { Neutron bombardment } & { }_{9}^{9} \mathrm{Be}(\mathrm{n}, \alpha){ }^{6} \mathrm{He}\end{array}$} \\
\hline
\end{tabular}

\begin{tabular}{|c|c|c|c|c|}
\hline \multicolumn{5}{|c|}{ Table II-4-2 Some Additional Properties of Beryllium Isotopes } \\
\hline Isotope & Half life & $\begin{array}{c}\text { Thermal-neutron } \\
\text { cross section, } \\
\text { barns }\end{array}$ & $\begin{array}{c}\text { Resonance integral } \\
(\mathrm{RI}), \text { barns }\end{array}$ & $\begin{array}{c}\text { Coherent scatter } \\
\text { length }(\mathrm{fm}){ }^{\mathrm{a}}\end{array}$ \\
\hline${ }^{7} \mathrm{Be}$ & 53.28 days & $\begin{array}{c}\sigma_{\mathrm{p}}=3.9 \times 10^{4} \mathrm{~b} \\
\sigma_{\mathrm{a}}=0.1 \mathrm{~b}\end{array}$ & $\mathrm{RI}_{\mathrm{p}}=1.75 \times 10^{4} \mathrm{~b}$ & \\
\hline${ }^{9} \mathrm{Be}$ & stable & $8.8 \mathrm{mb}$ & $3.9 \mathrm{mb}$ & 7.79 \\
\hline${ }^{10} \mathrm{Be}$ & $1.52 \times 10^{6}$ years & $<1.0 \mathrm{mb}$ & \\
\hline \multicolumn{5}{|c|}{${ }^{\mathrm{a}}\left(\mathrm{fm}=10^{-13} \mathrm{~cm}\right) .{ }^{\mathrm{b}} \sigma_{\mathrm{p}}$ and $\sigma_{\mathrm{a}}$ proton and alpha production, respectively. } \\
\hline
\end{tabular}

The total neutron cross section of beryllium is a function of neutron energy and the grain size. This is illustrated in Fig. II-4-1, which shows the much greater transparency of the coarser-grained material in the lower energy range. ${ }^{19}$ Apparently, there is no difference in the transparency at the higher energies. The figure depicts the behavior over the low-energy thermal range, where the neutrons are in thermal equilibrium with the moderator and where the cross section area increases with energy, and in the intermediate region, where the neutrons have been moderated but have not yet reached equilibrium. In the latter region, also known as the "slowing-down region", the cross section changes little with energy. In this range, the neutrons have wavelengths 


\begin{tabular}{|l|l|}
\hline \multicolumn{2}{|c|}{$\begin{array}{c}\text { Table II-4-3 Irradiated beryllium } \\
\text { yielding gas-producing nuclear } \\
\text { reactions }\end{array}$} \\
\hline $\begin{array}{c}\text { Irradiation } \\
\text { source }\end{array}$ & \multicolumn{1}{|c|}{ Reaction } \\
\hline Fast neutrons & $\begin{array}{l}\mathrm{Be}^{9}+\mathrm{n}_{\mathrm{f}} \rightarrow \mathrm{Li}^{7}+\mathrm{H}^{3} \\
\mathrm{Be}^{9}+\mathrm{n}_{\mathrm{f}} \rightarrow \mathrm{Be}^{8}+2 \mathrm{n} \\
\mathrm{Be}^{8} \rightarrow 2 \mathrm{He}^{4} \\
\mathrm{Be}^{9}+\mathrm{n}_{\mathrm{f}} \rightarrow \mathrm{He}^{6}+\mathrm{He}^{4} \\
\end{array}$ \\
& $\mathrm{He}^{6} \rightarrow \mathrm{Li}^{6}$ \\
\hline Thermal neutrons & $\mathrm{Li}^{6}+\mathrm{n}_{\mathrm{t}} \rightarrow \mathrm{H}^{3}+\mathrm{He}^{4}$ \\
\hline
\end{tabular}

\begin{tabular}{|c|c|c|}
\hline \multicolumn{3}{|c|}{$\begin{array}{l}\text { Various Impurities on the Thermal Neutrol } \\
\text { Cross Section of Beryllium. }\end{array}$} \\
\hline Impurity & $\begin{array}{l}\text { Thermal neutron cross } \\
\text { section, barns }\end{array}$ & $\begin{array}{l}\text { Addition cross section to } \\
\mathrm{Be}, \mathrm{mb}\end{array}$ \\
\hline Boron & 766 & 638 \\
\hline Cobalt & 37.0 & 5.7 \\
\hline Manganese & 13.2 & 2.2 \\
\hline Nickel & 4.8 & 0.7 \\
\hline Iron & 2.73 & 0.44 \\
\hline Calcium & 0.44 & 0.10 \\
\hline Aluminum & 0.24 & 0.08 \\
\hline Magnesium & 0.07 & 0.03 \\
\hline
\end{tabular}

comparable with the crystal lattice spacings and thus diffraction plays a role here with interactions occurring between incoming and scattered neutron wave fronts due to coherent scattering. For beryllium, a pronounced backward scattering occurs for neutrons having an energy of $0.00525 \mathrm{eV}$ and a wave length of $3.96 \AA$, which is twice the longest lattice spacing of $1.98 \AA$ for beryllium. ${ }^{31}$ In the "fast region" (above about $1 \mathrm{eV}$ ), where the neutrons are produced by fission, the cross section decreases significantly with increasing energy. Other reactions, which may be similarly discussed, are nuclear reactions produced by gamma rays, alpha particles, deuterons, and protons. ${ }^{31}$ 


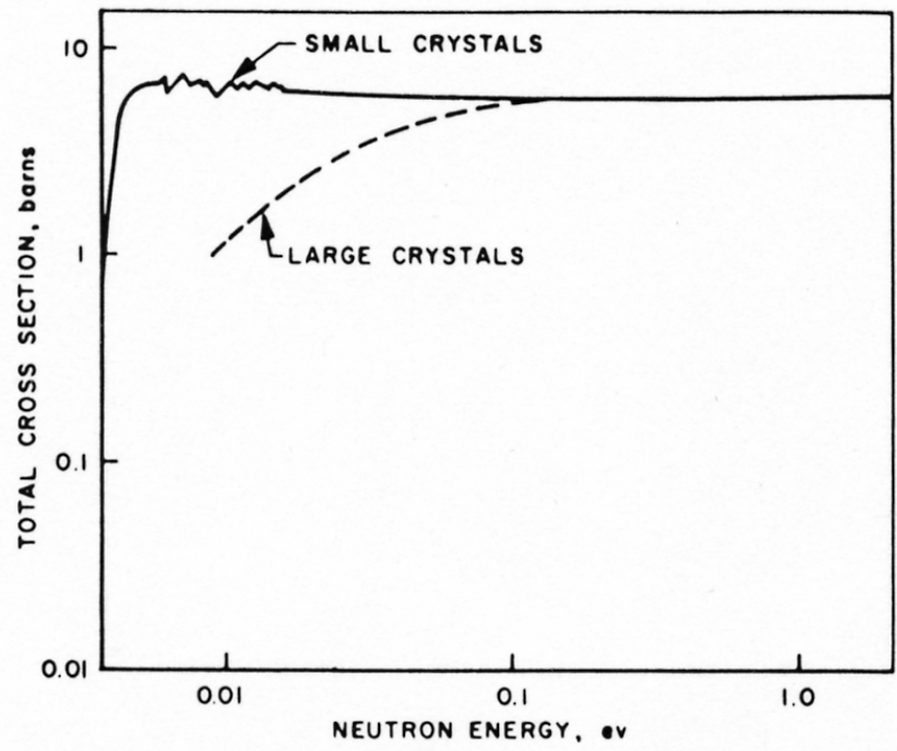

Fig. II-4-1 Total neutron cross-section as a function of neutron energy of fine-grained and coarse-grained beryllium. The coarse grains were obtained by heat treatment. ${ }^{19}$

\section{II-5-Miscellaneous Properties}

Properties that were not presented in the previous sections are listed in Table II-5-1.

\begin{tabular}{|c|c|}
\hline Table II-5-1 Room-Temperature Values of Miscellaneous Properties of Beryllium. & ${ }^{1-4}$ \\
\hline Sonic velocity & $12,588 \mathrm{~m} / \mathrm{s}$ \\
\hline Optical reflectivity (white light) & 50 to $55 \%$ \\
\hline Ultraviolet reflectivity & $50 \%$ \\
\hline Infrared reflectivity $(10.6 \mu \mathrm{m})$ & $98 \%$ \\
\hline Solar absorptivity (polished plate surface) & $46 \%$ \\
\hline Electrical conductivity & $40.7 \%$ of IACS $(0.24 \mathrm{mho} / \mathrm{cm})$ \\
\hline Electrical resistivity $\left(25^{\circ} \mathrm{C}\right)$ & $3.70 \times 10^{-8} \Omega-\mathrm{m}\left(4.31 \times 10^{-8} \Omega-\mathrm{m}\right)$ \\
\hline Magnetic susceptibility, $\chi_{\text {mass }}\left(20^{\circ} \mathrm{C}\right)$ & $-1.00 \times 10^{-6} \mathrm{~cm}^{3} / \mathrm{g}($ diamagnetic $)$ \\
\hline Photoelectric work function & $3.92 \mathrm{eV}$ \\
\hline Electron work function (polycrystal) & $4.98 \mathrm{eV}(\mathrm{depends} \mathrm{on} \mathrm{surface} \mathrm{cleanliness}$ \\
\hline Ionization potential for neutral atom & $9.3227 \mathrm{eV}$ \\
\hline Electron-binding energy for Is $(\mathrm{K})$ level & $111.5 \mathrm{eV}$ \\
\hline
\end{tabular}

The electrical resistance of beryllium as a function of temperature from room temperature to $1080^{\circ} \mathrm{C}$ is shown in Fig. II-5-1. ${ }^{13}$ A similar plot is shown in Fig. II-5-2. ${ }^{7}$ The data in the two figures are similar at the lower temperatures but differ at the higher temperatures, for example, these values at $800^{\circ} \mathrm{C}$ are about 26 and 31 microhom centimeters in Figs II-5-1 and II-5-2, respectively, The author ${ }^{7}$ states that the electrical conductivity (or resistivity) varies considerably with purity and method of fabrication (as is generally the case for essentially all metals and their alloys). He also states that the conductivity 
values for beryllium range from 35 to $42 \%$ of the IACS values. Figure II-5-3 shows a significant spread in resistivity values of beryllium having various densities $\left(1.823\right.$ to $\left.1.865 \mathrm{~g} / \mathrm{cm}^{3}\right)$, impurity level, and processing levels. $^{22}$

Table II-5-2 lists the electrical resistivities of polycrystalline beryllium over a range of temperatures from -263 to $673^{\circ} \mathrm{C}(10$ to $900 \mathrm{~K})$. Electrical resistivity measurements were reported on 4-mm beryllium rods, grades CR and CS (French). Billets were extruded into rods in the temperature range between 1000 and $1050^{\circ} \mathrm{C}$ and then annealed at $800^{\circ} \mathrm{C}$ producing a recrystallized structure with polygonization (substructure within the grains). The extruded rods had similar textures that were not "appreciably altered" by the anneal. Both as-swaged and swaged-and-annealed rods were evaluated at four temperatures. The results are shown in Table II-5-3. ${ }^{32}$ The author points out that the resistivity varies considerably with metallic impurity, and, the lower the temperature the greater is this variation.

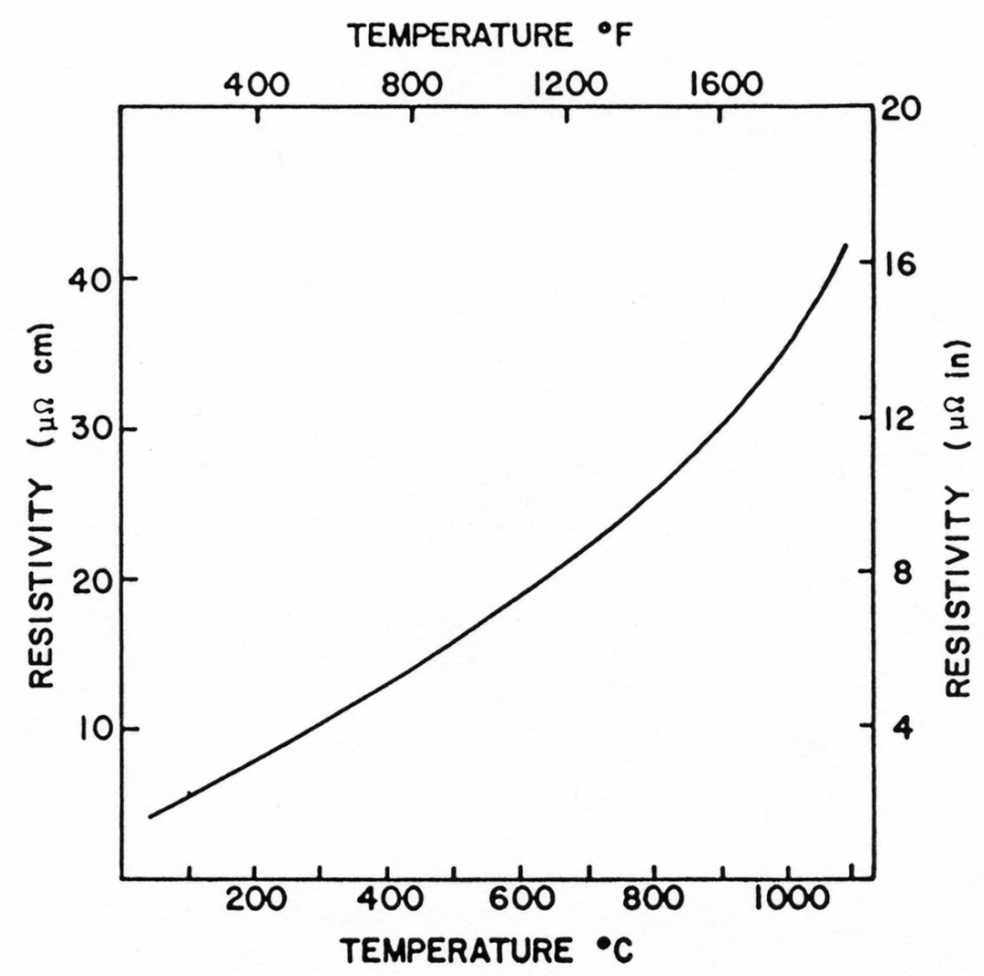

Fig. II-5-1 Electrical resistivity as a function of temperature of normal-purity beryllium block. ${ }^{13}$ 


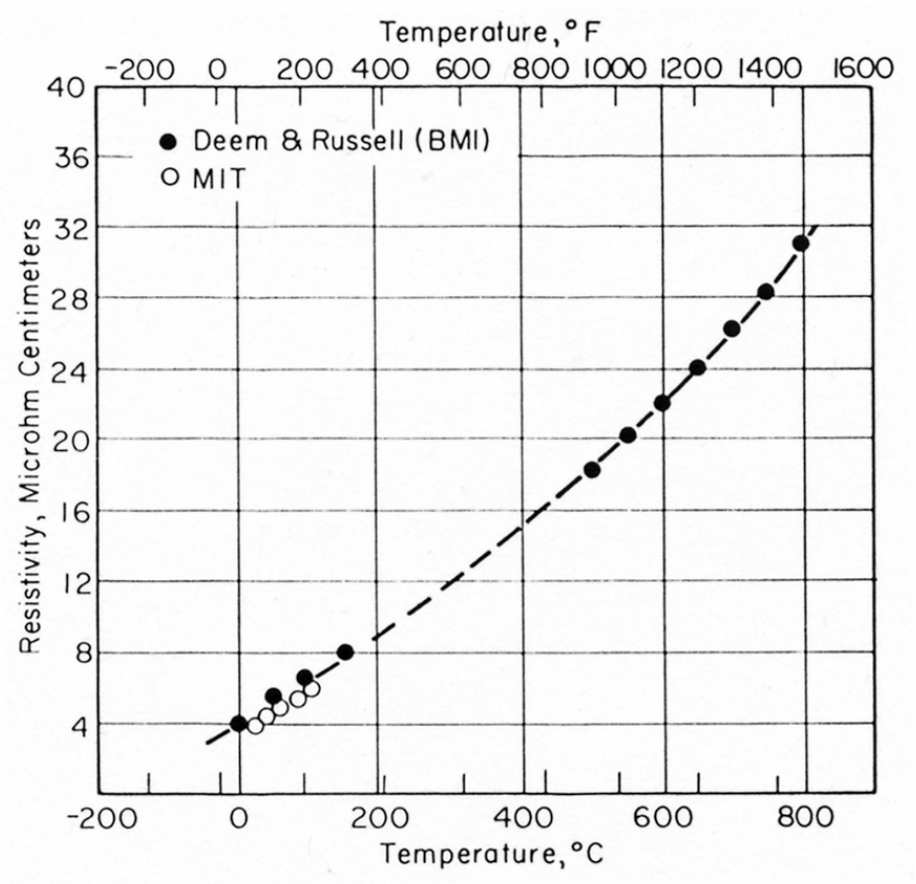

Fig. II-5-2 Effect of temperature on the resistivity of beryllium for two investigations. ${ }^{7}$

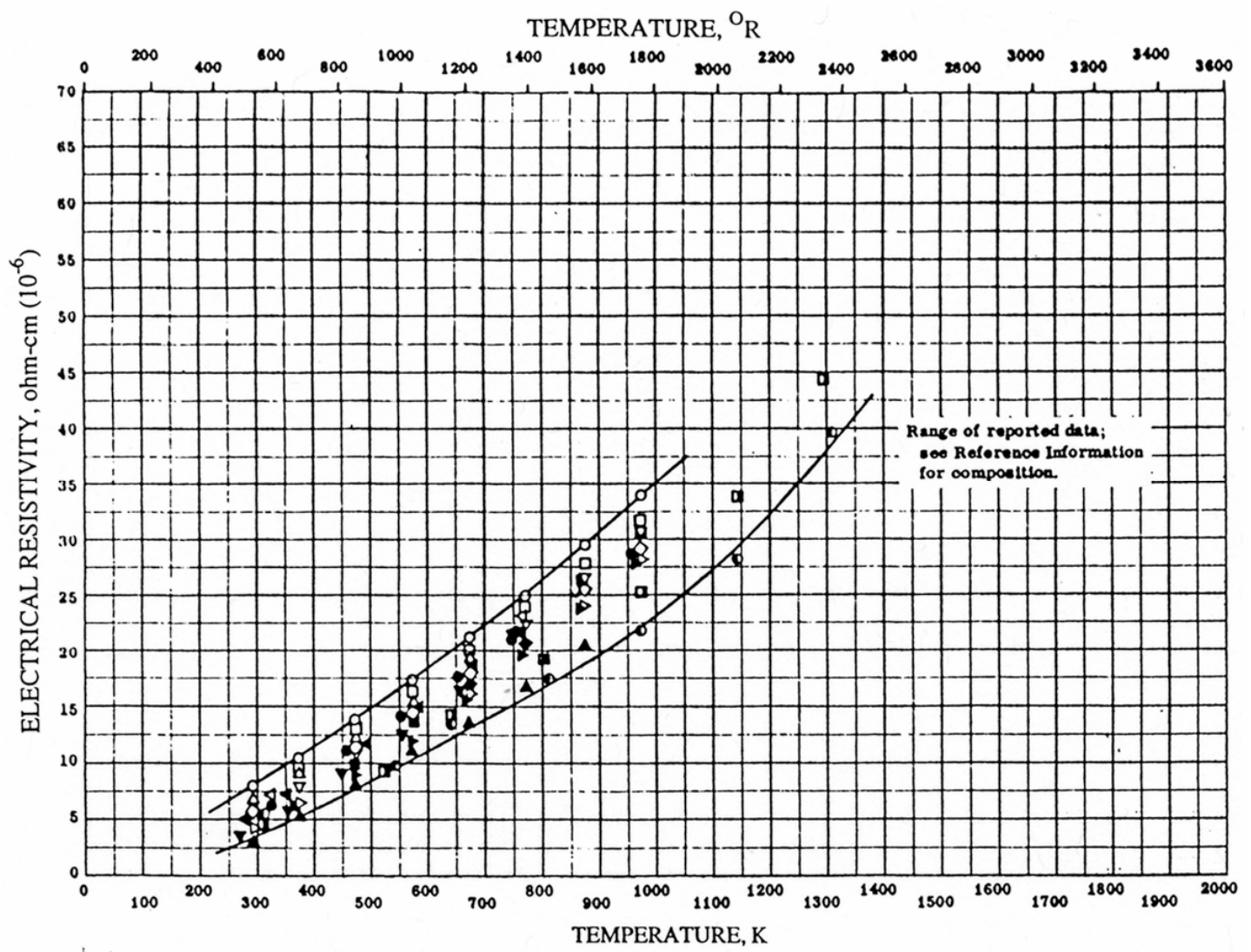

Fig. II-5-3 Electrical resistivity as a function of temperature of beryllium having various densities (1.823 to $1.865 \mathrm{~g} / \mathrm{cc}$ ), impurity levels, and processing histories. ${ }^{22}$ 


\begin{tabular}{|c|c|c|c|c|c|c|c|c|c|c|c|}
\hline \multicolumn{10}{|c|}{ Table II-5-2 Electrical Resistivity of Polycrystalline Beryllium } \\
\hline $\mathrm{T}$, & $10^{-8}$ & $\mathrm{~T}$, & $10^{-8}$ & $\mathrm{~T}, \mathrm{~K}$ & $10^{-8}$ & $\mathrm{~T}$, & $10^{-8}$ & $\mathrm{~T}, \mathrm{~K}$ & $10^{-8}$ & $\mathrm{~T}$, & $10^{-8}$ \\
$\mathrm{~K}$ & $\Omega \mathrm{m}$ & $\mathrm{K}$ & $\Omega \mathrm{m}$ & & $\Omega \mathrm{m}$ & $\mathrm{K}$ & $\Omega \mathrm{m}$ & & $\Omega \mathrm{m}$ & $\mathrm{K}$ & $\Omega \mathrm{m}$ \\
\hline 10 & 0.0332 & 60 & 0.067 & 150 & 0.510 & 293 & 3.56 & 400 & 6.76 & 700 & 16.5 \\
\hline 20 & 0.0336 & 80 & 0.075 & 200 & 1.29 & 298 & 3.70 & 500 & 9.9 & 800 & 20.0 \\
\hline 40 & 0.0367 & 100 & 0.133 & 273 & 3.02 & 300 & 3.76 & 600 & 13.2 & 900 & 23.7 \\
\hline
\end{tabular}

\begin{tabular}{|c|c|c|c|c|c|c|c|c|c|}
\hline \multicolumn{8}{|c|}{ Table II-5-3 Electrical Resistivity of Beryllium Rods at Different Temperatures. } \\
\hline Rod history \\
& $\begin{array}{c}\text { Rod } \\
\text { No. }\end{array}$ & Grade & $\begin{array}{c}\text { BeO, } \\
\%\end{array}$ & $\begin{array}{c}\text { Total metallic } \\
\text { impurities }\end{array}$ & \multicolumn{2}{c|}{$\begin{array}{c}\text { Grain } \\
\text { size, } \mu \mathrm{m}\end{array}$} & \multicolumn{3}{|c|}{ Resistivity, microhm-cm } \\
$273^{\circ} \mathrm{K}$ & $77.4^{\circ} \mathrm{K}$ & $20.3^{\circ} \mathrm{K}$ & $4.2^{\circ} \mathrm{K}$ \\
\hline \multirow{4}{*}{$\begin{array}{c}\text { As- } \\
\text { extruded }\end{array}$} & 1 & $\mathrm{CR}$ & 0.9 & 0.18 & $10-80$ & 3.92 & 1.09 & 1.03 & 1.03 \\
\cline { 2 - 11 } & 2 & $\mathrm{CR}$ & 1.2 & 0.10 & $10-80$ & 3.49 & 0.65 & 0.61 & 0.61 \\
\cline { 2 - 10 } & 3 & $\mathrm{CR}$ & 0.1 & 0.08 & $30-200$ & 3.28 & 0,55 & 0.51 & 0.51 \\
\cline { 2 - 10 } & 4 & $\mathrm{SR}$ & 0.2 & 0.02 & $30-200$ & 2.79 & 0.066 & 0.037 & 0.037 \\
\hline $\begin{array}{c}\text { Extruded } \\
\text { and } \\
\text { annealed }\end{array}$ & 1 & $\mathrm{CR}$ & 0.9 & 0.18 & $10-80$ & 3.72 & 0.96 & 0.88 & 0.88 \\
\cline { 2 - 10 } & 2 & $\mathrm{CR}$ & 1.2 & 0.10 & $10-80$ & 3.17 & 0.41 & 0.37 & 0.37 \\
\cline { 2 - 10 } & 3 & $\mathrm{CR}$ & 0.1 & 0.08 & $30-200$ & 3.15 & 0.50 & 0.45 & 0.45 \\
\cline { 2 - 10 } & 4 & $\mathrm{SR}$ & 0.2 & 0.02 & $30-200$ & 2.85 & 0.063 & 0.37 & 0.37 \\
\hline
\end{tabular}

The electrical resistivity at room temperature and at $4.2 \mathrm{~K}$ and the residual resistance ratios ${ }^{\mathrm{f}}$ for various purity levels of beryllium are listed in Table II-5-4. The purity level appears to have an appreciate affect on the resistance at $4.2 \mathrm{~K}$, while only a minor affect at room temperature. Significant effects are seen for the relative resistance ratios $\left[\Omega_{\mathrm{RT}} / \Omega_{4.2(\mathrm{~K})}\right]{ }^{2}$ Different processing histories are also indicated in Table II-5-4

\begin{tabular}{|l|l|l|l|}
\hline \multicolumn{4}{|c|}{$\begin{array}{c}\text { Table. II-5-4 Electrical Resistivity and Residual Resistance Ratios } \\
\text { (Relative Resistance) for Various Purity Levels of Beryllium. }\end{array}$} \\
\hline & $\begin{array}{l}\text { Resistivity, } \mu \Omega \text {-cm, } \\
\text { Room Temp. }\end{array}$ & $\begin{array}{l}\text { Resistivity, } \\
\mu \Omega \text {-cm, } 4.2 \mathrm{~K}\end{array}$ & $\begin{array}{l}\text { Relative resistance, } \\
\Omega_{\mathrm{RT}} / \Omega_{4.2 \mathrm{~K}}\end{array}$ \\
\hline Specimen history & 1.068 & 5.01 \\
\hline $\begin{array}{l}\text { Commercial purity, rolled sheet, } \\
\text { longitude }\end{array}$ & 5.350 & 0.967 & 5.03 \\
\hline $\begin{array}{l}\text { Commercial purity, rolled sheet, } \\
\text { transverse }\end{array}$ & 4.864 & 1.167 & 4.75 \\
\hline Commercial purity, hot pressed & 5.543 & 0.394 & 11.94 \\
\hline Intermediate purity, hot pressed & 4.706 & 0.027 & 158 \\
\hline $\begin{array}{l}\text { High purity Pechiney SR, } \\
\text { hot pressed }\end{array}$ & 4.266 & - & 80 to 750 \\
\hline $\begin{array}{l}\text { Vacuum-melted Pechiney flake, } \\
\text { single distilled }\end{array}$ & - & - & 200 to 900 \\
\hline $\begin{array}{l}\text { Vacuum-melted Pechiney flake, } \\
\text { double distilled }\end{array}$ & - & & \\
\hline
\end{tabular}

\footnotetext{
${ }^{\mathrm{f}}$ The residual resistance ratio is the ratio of the resistance at room temperature to that at $4.2 \mathrm{~K}$.
} 
The electrical resistance as a function of pressure relative to the resistance at $10 \mathrm{GPa}$ and $25^{\circ} \mathrm{C}$ is shown in Fig. II-5-4. 33

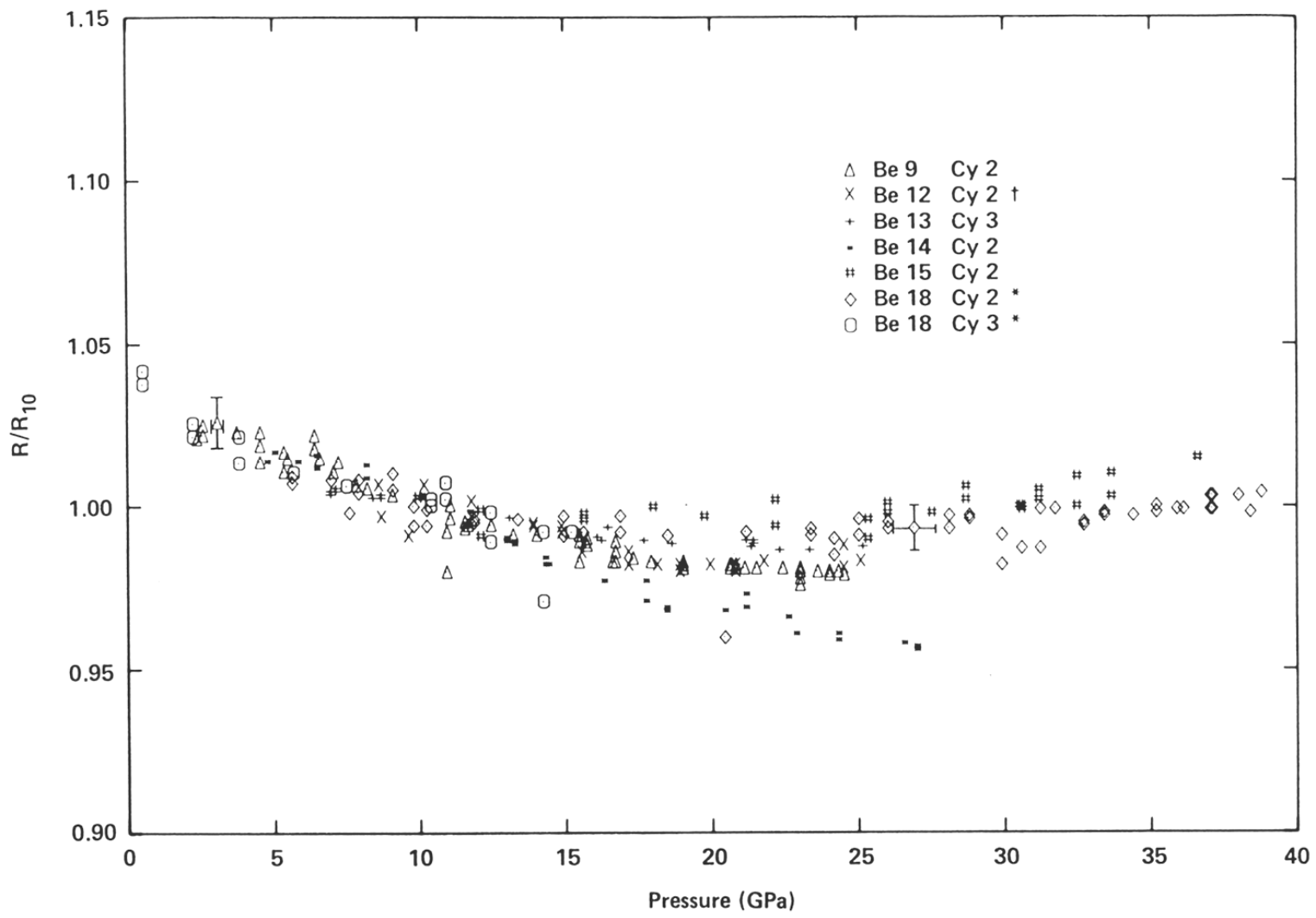

Fig. II-5-4 Residual (relative) resistance, $\mathrm{R} / \mathrm{R}_{10}$, of beryllium as a function of pressure taken during the second or third cycle (as indicated) while increasing pressure. ${ }^{33}$

The thermo-electric power of hot-pressed beryllium relative to copper as a function of temperature at low temperatures is shown in Fig. II-5-5. Curves for both parallel and perpendicular to the pressing direction are presented. ${ }^{2}$ The thermo-electric power of beryllium against platinum is given as 1.6 and $2.6 \mu \mathrm{V} /{ }^{\circ} \mathrm{C}$ for 99.96 and $99.78 \%$ purity, respectively. A straight-line increase from $8.2 \mu \mathrm{V} /{ }^{\circ} \mathrm{C}$ at $336^{\circ} \mathrm{C}$ to $18 \mu \mathrm{V} /{ }^{\circ} \mathrm{C}$ at $800^{\circ} \mathrm{C}$ is reported for beryllium against platinum as shown in Fig. II-5-6. ${ }^{2,7}$ 


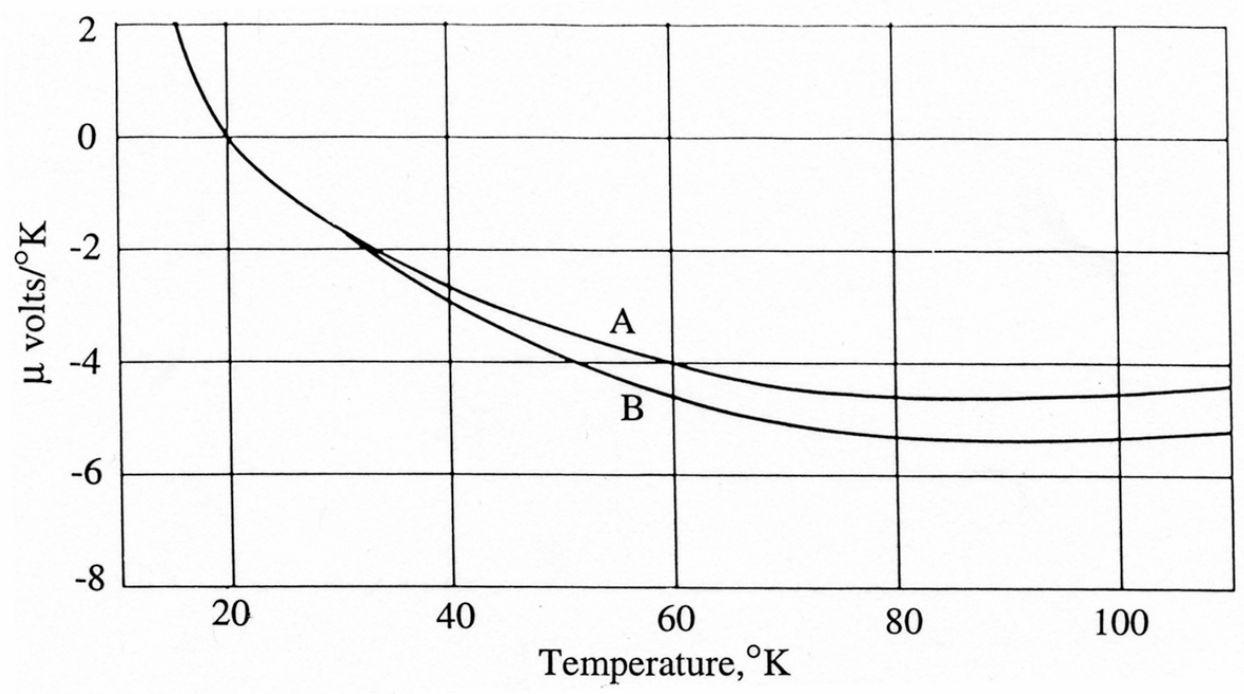

Fig. II-5-5 The thermo-electric power of hot-pressed beryllium against copper: A - specimen axis parallel to pressing direction, B - specimen axis perpendicular to pressing direction. ${ }^{2}$

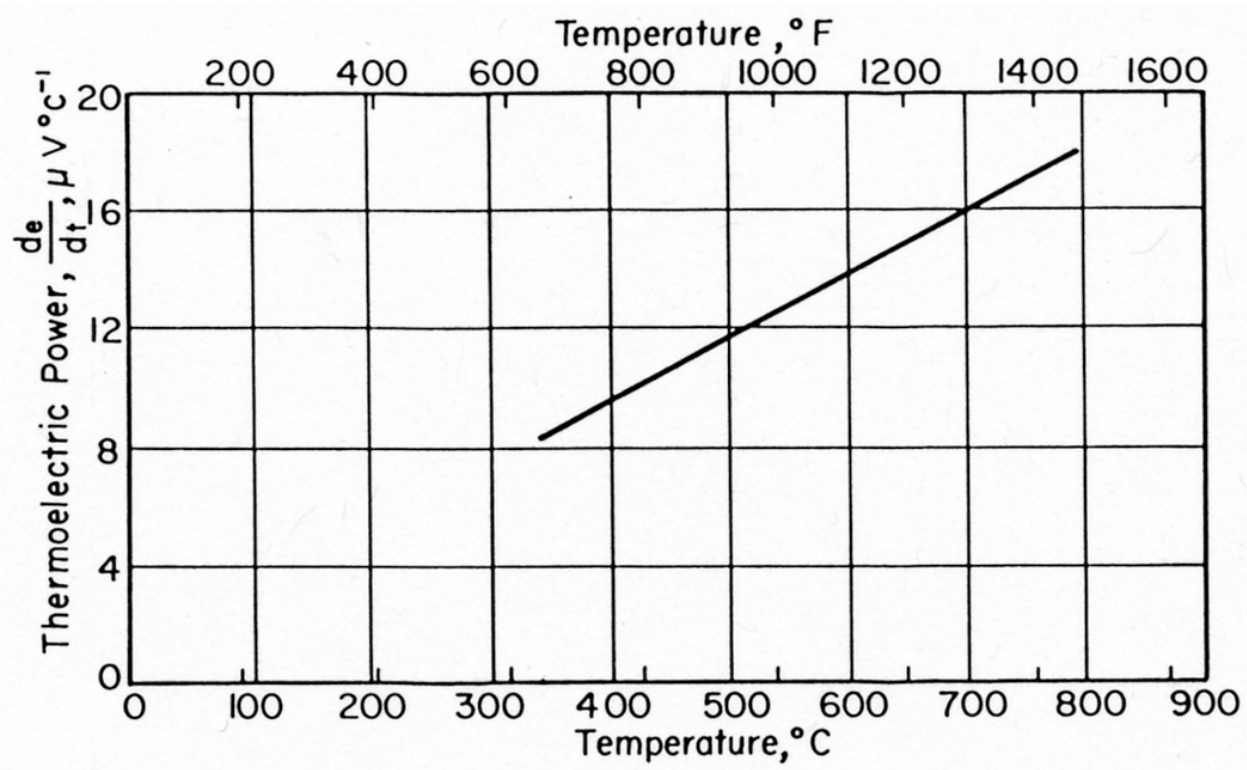

Fig. II-5-6 Thermoelectric power of beryllium against platinum as a function of temperature. ${ }^{7}$

The normal spectral reflectance at a series of wave lengths of anodized beryllium anodized by two different methods are listed in Table II-5-5. ${ }^{2}$ Figure II-5-7 is a plot of normal spectral reflectance of beryllium as a function of wave length using 0.625 -mm-thick samples. ${ }^{22}$ The data reflects the use of three different hohlraum (target chamber) temperatures (523, 773, and $1273 \mathrm{~K}$ ). 


\begin{tabular}{|c|c|c|}
\hline \multicolumn{3}{|c|}{$\begin{array}{c}\text { Table II-5-5 Normal Spectral Reflectance of Anodized Beryllium } \\
\text { at a Series of Temperatures. }\end{array}$} \\
\hline Wavelength, $\mu \mathrm{m}$ & Anodized in chromic acid & Anodized in sodium hydroxide \\
\hline 0.4 & 0.172 & 0.075 \\
\hline 0.6 & 0.179 & 0.052 \\
\hline 0.8 & 0.168 & 0.058 \\
\hline 1.0 & 0.165 & 0.68 \\
\hline 2.0 & 0.280 & 0.203 \\
\hline 4.0 & 0.355 & 0.286 \\
\hline 6.0 & 0.335 & 0.514 \\
\hline 8.0 & 0.317 & 0.772 \\
\hline 10 & 0.560 & 0.773 \\
\hline 15 & 0.673 & 0.606 \\
\hline 20 & 0.494 & 0.899 \\
\hline
\end{tabular}

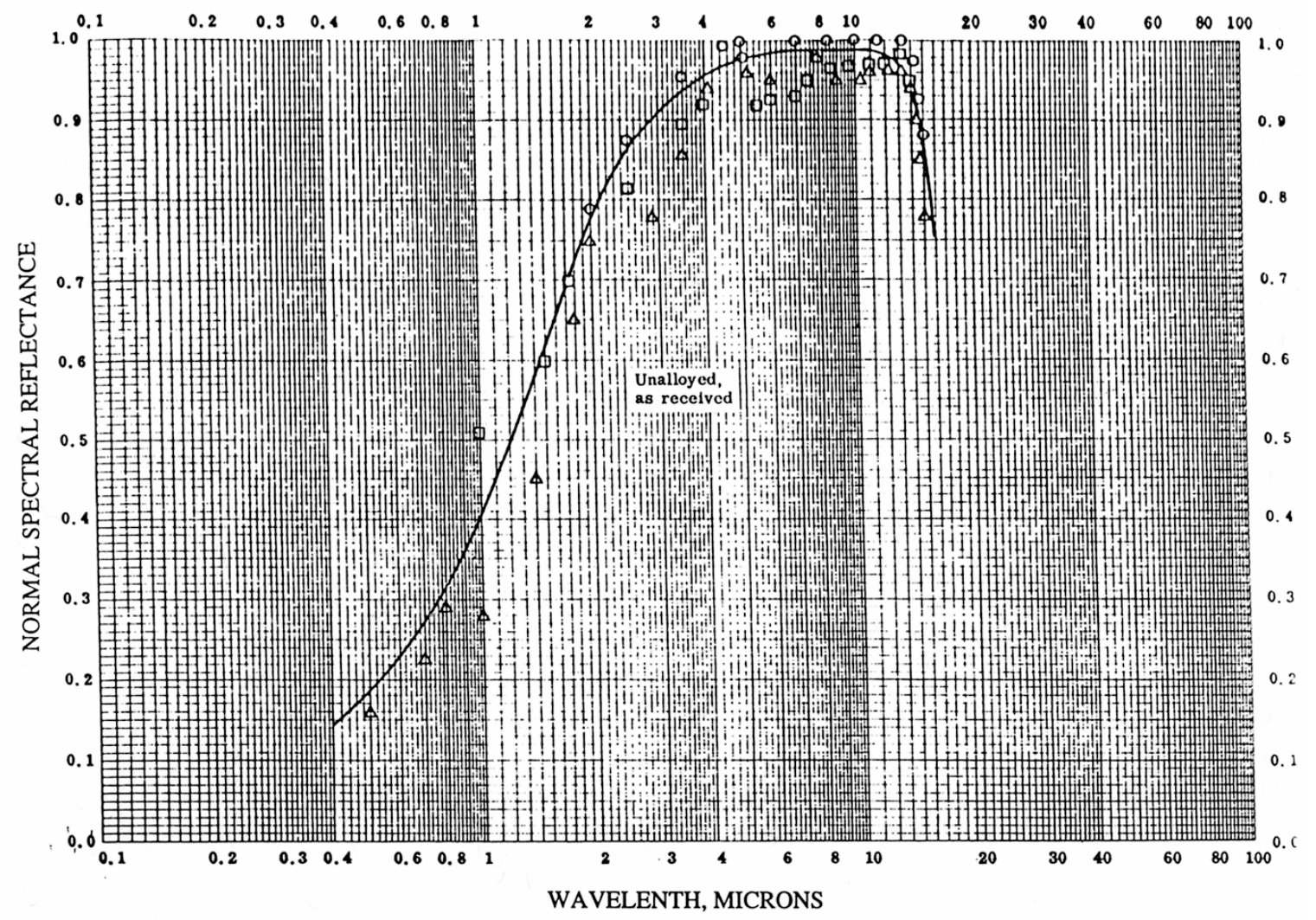

Fig. II-5-7 Normal spectral reflectance of as-re $\square$ ived, washed, unalloyed,0.635 mm-thick beryllium as a function of wave length :O-hohlraum (h) at $523 \mathrm{~K}$, measuring temperature $(\mathrm{mt})<322 \mathrm{~K}$, wavelength range (wr) 2.00 to $15.00 \mu \mathrm{m}$; - $\mathrm{h}$ at $773 \mathrm{~K}$, $\mathrm{mt}<322 \mathrm{~K}$, wr 1.00 to $14.00 \mu \mathrm{m} ; \Delta-\mathrm{h}$ at $1273 \mathrm{~K}, \mathrm{mt}<322 \mathrm{~K}$, wr 0.50 to $15.00 \mu \mathrm{m}$. ${ }^{22}$ 


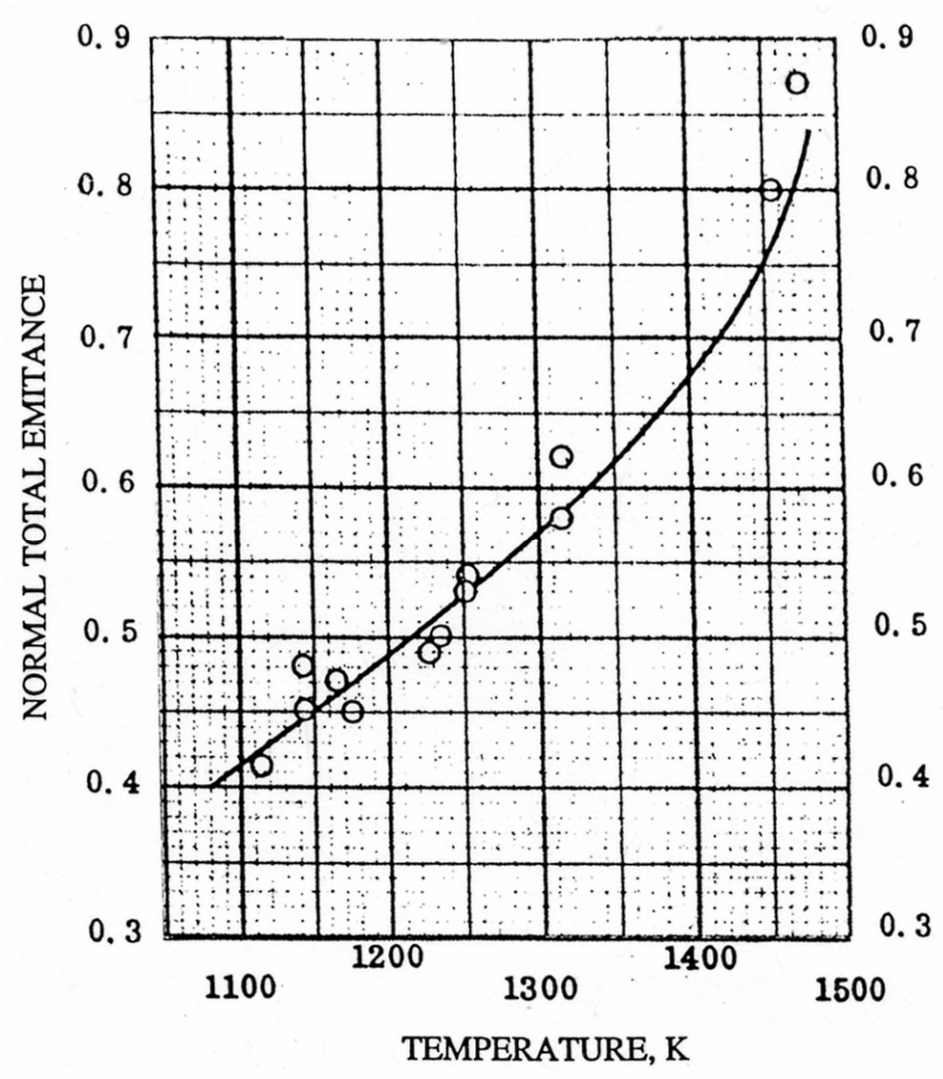

Fig. II-5-8 Normal total emittance of beryllium in air as a function of temperature. ${ }^{22}$

The normal total emittance of beryllium in air as a function of temperature is shown in Fig. II-5-8. ${ }^{22}$ The composition and history of the metal were not given. Figure. II-5-9 shows the normal spectral transmittance of beryllium as a function of wavelength at $298 \mathrm{~K} .{ }^{33}$ Measurements were made on aluminum-backed beryllium film (875 $\pm 100 \AA$ thick) with both aluminum and beryllium being deposited by evaporation on a glass side. The data was corrected for transmittance of aluminum and glass. About $10 \%$ error was indicated for $\lambda>0.035 \mu$ and $25 \%$ for $\lambda<0.035 \mu$. Geometries of $\theta$ and were approximately zero. Figure II-5-10 shows the normal total emittance as a function of temperature during heating (1116 to $1473 \mathrm{~K}$ ) and cooling (1473 to $1255 \mathrm{~K})$. The geometry was given as $\theta^{1}$ being approximately zero. $^{22}$ 


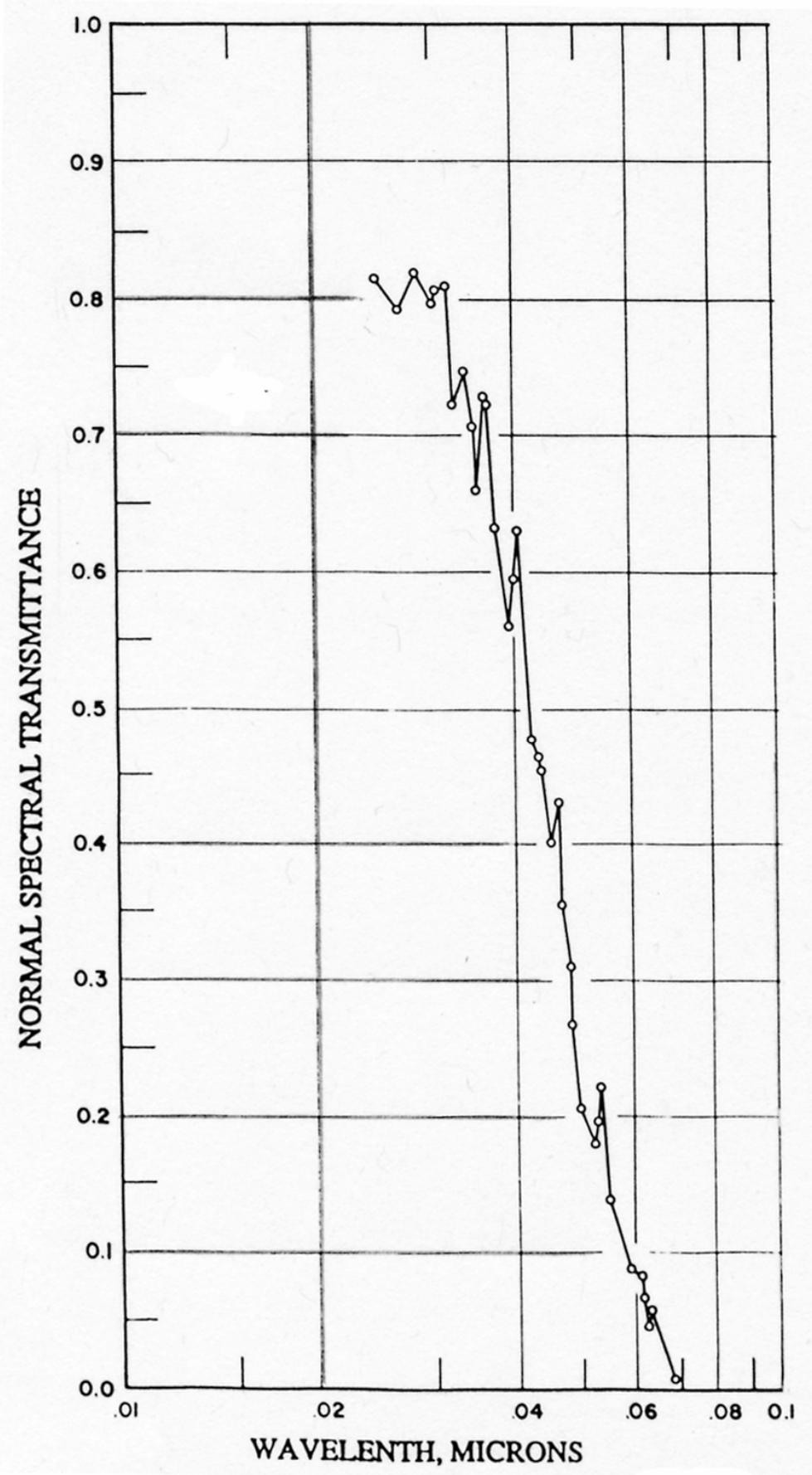

Fig. II-5-9 Normal Spectral Transmittance of beryllium as a function of wave length at $298 \mathrm{~K}$ measured on an aluminum-backed beryllium film ( $875 \pm 100 \AA$ thick).

Aluminum and beryllium, evaporated at $2 \times 10^{-5}$ torr on a glass slide. Data corrected for transmittance of Aluminum and glass. About $10 \%$ error for $\lambda>0.035 \mu \mathrm{m}$ and $<25 \%$ for $\lambda<0.035 \mu \mathrm{m}$. Geometry, $\theta$ and $\theta^{1} \sim 0 .{ }^{34}$ 


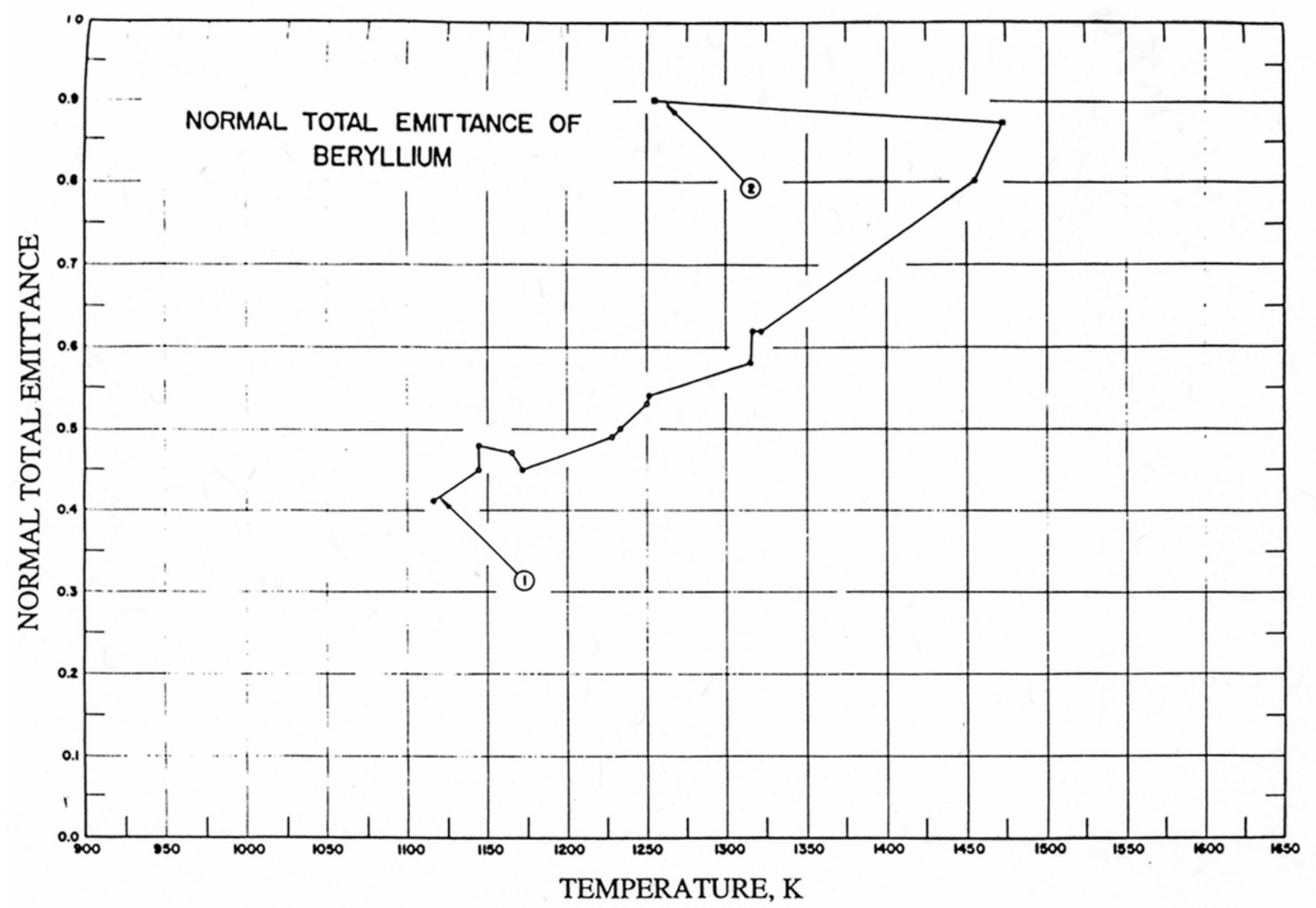

Fig. II-5-10 Normal total emittance of beryllium as a function of temperature: 1 -heating (1116 to $1473 \mathrm{~K}$ ); 2 -cooling (1473 to $1255 \mathrm{~K}$ ); geometry, $\theta^{1} \sim 0 .{ }^{22}$ 


\section{$\underline{\text { References }}$}

1. Handbook of Chemistry and Physics, $84^{\text {th }}$ Edition, CRC Publication, 2003-2004

2. A. J. Stonehouse etal., Physical Properties, in Beryllium: Its Metallurgy and Properties, Editor, Henry H. Hauser, Publ. University of California Press, Berkeley, California, pp.191-205,1965

3. Beryllium and Beryllium Alloys, in Kirk-Othmer Encyclopedia of Chemical Technology, Publ. John Wiley and Sons, Inc., 2002

4. Metals Handbook, Ninth Edition, vol. 2, Properties and Selection: Nonferrous Alloys and Pure Metals. Publ., American Society of Metals, Metals Park, Ohio, 1979. Also Tenth Edition, vol. 2, Nonferrous Alloys and Special Purpose Materials, 1990

5. A. J. Stonehouse, Physics and Chemistry of Beryllium, J. Vac. Sci. Technol, vol. A4 (3), pp. 1163-1170, 1986

6. F. Scaffidi-Argentina et al., Beryllium R\&D for Fusion Applications, Fusion Eng. and Design, vol 51-52, pp. 23-41, 2000

7. D. W. Lillie, The Physical and Mechanical Properties of Beryllium, in The Metal Beryllium, Eds., D. W. White, Jr., and J. E. Burke, Publ. American Society for Metals, Cleveland, Ohio, pp. 304-327, 1965

8. D. H. Killpatrick, Elastic Properties of Beryllium, Internal Report, Logicon, (now Northrup Gruman), Albquerque, NM

9. M. F. Smith et al., Thermomechanical Testing of Beryllium for Limiters in ISX-B and JET, Fusion Technology, vol. 8, pp 174-1183, July, 1985

10. W. J. Haws, Characterization of Beryllium Structural GradeS-200F, TM-778 Report, Brush Wellman, May 27, 1985

11. M. C. Billone, Status of Beryllium Development for Fusion Applications, Fusion Engineering and Design, vol. 27, pp. 179-190, 1995

12. D. R. Christman and F. J. Feistmann, Dynamic Properties of S-200-E Beryllium, DNA 2785FMSL 71-23 Report, Materials and Structures Laboratory, General Motors Technical Center, Warren, MI 48090, February, 1972

13. N. P. Pinto, Properties, in Beryllium Science and Technology, vol. 2, Eds. D. R. Floyd and J. N. Lowe, Plenum Publishing Corp., pp. 319-350,1979

14. W. Meyerhoff and J. F. Smith, Anisotropic Thermal Expansion of Single Crystals of Thalium, Yttrium, Beryllium, and Zinc at Low Temperatures, Journal of Applied Physics, vol. 33 (1), pp. 219-224, 1961

15. Chemical Properties Handbook, Ed., C. L. Yaws, Publ., McGraw-Hill, 1999

16. C. A. Swenson, Thermal Expansivity from 4 to $300 \mathrm{~K}$ and Heat Capacity from 1 to $108 \mathrm{~K}, \mathrm{~J}$. Appl. Phys., vol. 70, pp. 3046-3051, 1991

17. W. J. Haws, Thermal Expansion of S-200F Beryllium from 100 to $450 \mathrm{~K}$, Brush Wellman Report, TM-894, May, 1988 
18 Thermophysical Properties of Matter, vol. 12, Thermal Expansion, Metallic Elements and Alloys, Eds. Y. S. Touloukian and R. K. Kirby, R. E. Taylor, and P. D. Desai, Publ., IFI/Plenum, New York, 1975

19. Henry H .Hauser, Nuclear Properties, in Beryllium: Its Metallurgy and Properties, Editor, Henry H. Hauser, Publ., University of California Press, Berkeley, California, pp. 234-239, 1965

20. C. G. Jennings et al., Dimensional Stability and Thermal Expansion Characteristics of Beryllium, in Beryllium Technology, vol. 1, Proceedings of the Second International Conference on Beryllium Technology, 1964 Conf. Co-Chairmen, L. McD. Schetky and H. A. Johnson, Gordon and Breach, Science Publishers, Inc, New York, 1966, pp. 467-478

21. R. W. Armstrong and N. R. Borch, Thermal Microstresses in Beryllium and other HCP Metals, UCRL-72915 Rev. 1 Preprint June 15, 1971. Also Met. Trans. vol 2, pp 3073-3077, 1971

22. Thermophysical Properties of High Temperature Solid Materials, vol. 1 Elements, Ed. Y. S. Touloukian, Publ., The Macmillian Company, New York, 197 ?

23. Thermophysical Properties of Matter, vol. 4, Specific Heat, Metallic Elements and Alloys, Eds. Y. S. Touloukian, and E. H. Buyco, Publ., IFI/Plenum, New York, 1970

24. Thermophysical Properties of Matter, vol. 10 Thermal Diffusivity, Eds. Y. S. Touloukian, R. W. Powell, C. Y. Ho, and M. C. Nicolaou, Publ., IFI/Plenum, New York, 1973

25. Thermophysical Properties of Matter, vol. 1, Thermal Conductivity, Metallic Elements and Alloys, Eds. Y. S. Touloukian, R. W. Powell, C. Y. Ho, and P. G. Klemenss, Publ., IFI/Plenum, New York, 1975

26. C. H. Lee, Self Diffusion in Beryllium Single Crystals, in Beryllium Technology, vol 1 , Proceedings of the Second International Conference on Beryllium Technology, 1964 Conf. CoChairmen, L. McD. Schetky and H. A. Johnson, Publ., Gordon and Breach, Science Publishers, Inc, New York,, 1966, pp. 307-317

27. J. M. Dupouy etal., Self Diffusion and Diffusion of Foreign Atoms in Beryllium, in Beryllium Technology, vol. 1, Proceedings of the Second International Conference on Beryllium Technology, 1964 Conf. Co-Chairmen, L. McD. Schetky and H. A. Johnson, Gordon and Breach, Science Publishers, Inc, New York,, 1966, pp. 319-333

28. Chart of the Nuclides with Physical Constants, Conversion Factors and Period Table, 13th Edition, Publ. General Electric Company San Jose Ca, 95125, 1984

29. A. Khomutov et al., Beryllium for Fusion Application-Recent Results, J. Nucl. Mater., vol. 307-311, pp. 630-637, 2002

30. G. Petzow, et al., Beryllium and Beryllium Compounds, Table 1, in Ullmann's Encyclopedia of Industrial Chemistry, Publ. Wiley-VCH Vertag GmbH, Weinheim, Germany, 2002

31. J. R. Stehn, The Nuclear Properties of Beryllium, in The Metal Beryllium, Eds., D. W. White, Jr., and J. E. Burke, Publ. American Society for Metals, Cleveland, Ohio, pp. 328-366, 1965

32. J. M. Logerot, Mechanical and Electrical Properties of Beryllium Wire, in Beryllium Technology, vol. 1, Proceedings of the Second International Conference on Beryllium Technology, 1964 Conf. Co-Chairmen, L. McD. Schetky and H. A. Johnson, Gordon and Breach, Science Publishers, Inc, New York, 1966, pp. 445-466 
33. R. Reichlin, Measuring the Electrical Resistance of Metals to $40 \mathrm{GPa}$ in the Diamond-Anvil Cell UCRL-88370 Preprint, Lawrence Livermore National Laboratory, Livermore, CA, June, 1983

34. Thermophysical Properties of Matter, vol. 7, Thermal Radiative Properties, Metallic Elements and Alloys, Eds. Y. S. Touloukian and D. P. DeWitt, IFI/Plenum, New y York, 1970 